\title{
Inhaled analgesia for pain management in labour (Review)
}

\author{
Klomp T, van Poppel M, Jones L, Lazet J, Di Nisio M, Lagro-Janssen ALM
}

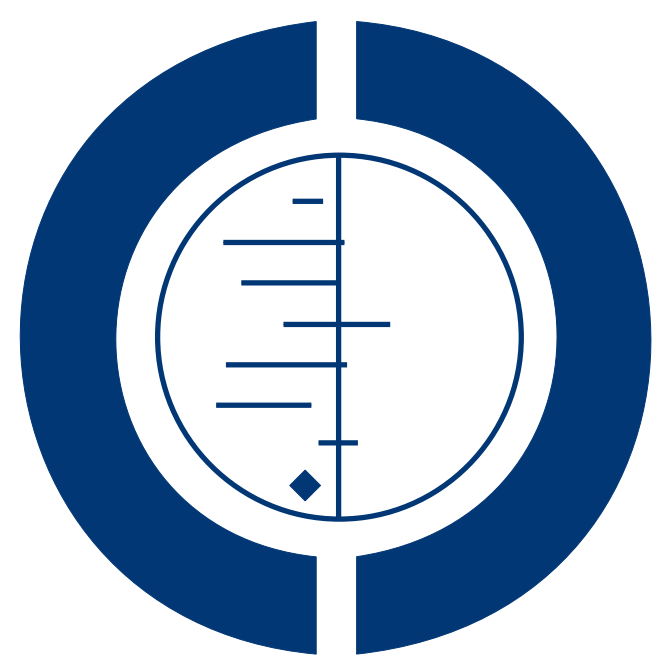

\section{THE COCHRANE COLLABORATION $^{\circledR}$}

This is a reprint of a Cochrane review, prepared and maintained by The Cochrane Collaboration and published in The Cochrane Library 2012, Issue 9

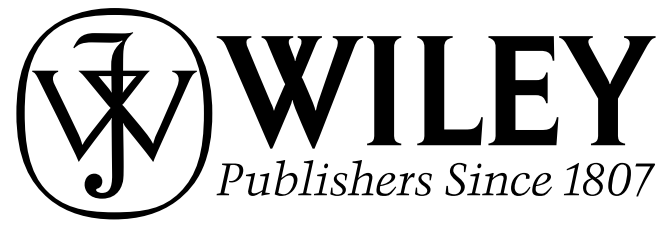

Inhaled analgesia for pain management in labour (Review)

Copyright $\odot 2012$ The Cochrane Collaboration. Published by John Wiley \& Sons, Ltd. 
TABLE OF CONTENTS

HEADER . . . . . . . . . . . . . . . . . . . . . . . . . . . . . . . . . . . . . . . 1

ABSTRACT . . . . . . . . . . . . . . . . . . . . . . . . . . . . . . . . . . . . . . . . . . . . . . . . 1

PLAIN LANGUAGE SUMMARY . . . . . . . . . . . . . . . . . . . . . . . . . . . . . . . . . . . . . 2

BACKGROUND . . . . . . . . . . . . . . . . . . . . . . . . . . . . . . . . . . . . . . . . . .

OBJECTIVES . . . . . . . . . . . . . . . . . . . . . . . . . . . . . . . . . . . . . . . . . . . . . . .

METHODS . . . . . . . . . . . . . . . . . . . . . . . . . . . . . . . . . . . . . . .

RESULTS . . . . . . . . . . . . . . . . . . . . . . . . . . . . . . . . . . . . . . . . . . . .

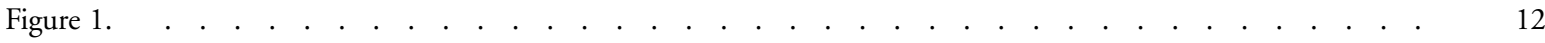

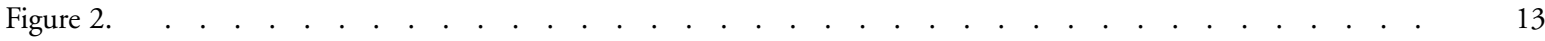

DISCUSSION . . . . . . . . . . . . . . . . . . . . . . . . . . . . . . . . . . . . . . . . 21

AUTHORS' CONCLUSIONS . . . . . . . . . . . . . . . . . . . . . . . . . . . . . . . . . . . .

ACKNOWLEDGEMENTS . . . . . . . . . . . . . . . . . . . . . . . . . . . . . . . . . . . . . .

REFERENCES . . . . . . . . . . . . . . . . . . . . . . . . . . . . . . . . . . . . . . . .

CHARACTERISTICS OF STUDIES . . . . . . . . . . . . . . . . . . . . . . . . . . . . . . . . . . . . . . . . . .

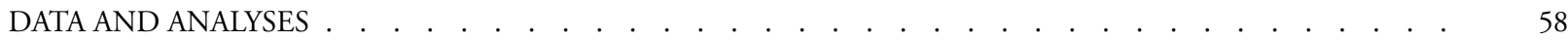

Analysis 1.1. Comparison 1 Nitrous oxide versus flurane derivatives, Outcome 1 Pain intensity (VAS 0-100 first stage). 60

Analysis 1.2. Comparison 1 Nitrous oxide versus flurane derivatives, Outcome 2 Pain relief (VAS 0-100 as 100 is the most

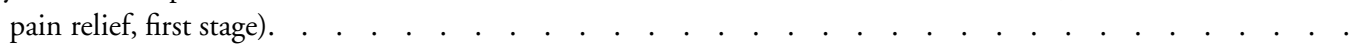

Analysis 1.3. Comparison 1 Nitrous oxide versus flurane derivatives, Outcome 3 Satisfaction with pain relief (first and second stage, considerable to complete). . . . . . . . . . . . . . . . . . . . . . . . . . . . . . . . .

Analysis 1.4. Comparison 1 Nitrous oxide versus flurane derivatives, Outcome 4 Satisfaction with pain relief (second stage, good to excellent).

Analysis 1.5. Comparison 1 Nitrous oxide versus flurane derivatives, Outcome 5 Assisted vaginal birth. . . . . . .

Analysis 1.6. Comparison 1 Nitrous oxide versus flurane derivatives, Outcome 6 Caesarean section. . . . . . . . .

Analysis 1.7. Comparison 1 Nitrous oxide versus flurane derivatives, Outcome 7 Amnesia. . . . . . . . . . . . . . 64

Analysis 1.8. Comparison 1 Nitrous oxide versus flurane derivatives, Outcome 8 Drowsiness (VAS 0-100 mm). $\quad . \quad 65$

Analysis 1.9. Comparison 1 Nitrous oxide versus flurane derivatives, Outcome 9 Nausea. . . . . . . . . . . . . 66

Analysis 1.10. Comparison 1 Nitrous oxide versus flurane derivatives, Outcome 10 Vomiting. . . . . . . . . . 66

Analysis 1.11. Comparison 1 Nitrous oxide versus flurane derivatives, Outcome 11 Blood loss in mL. . . . . . . . $\quad 67$

Analysis 1.12. Comparison 1 Nitrous oxide versus flurane derivatives, Outcome 12 Apgar score less than seven at five minutes.

Analysis 1.13. Comparison 1 Nitrous oxide versus flurane derivatives, Outcome 13 NACS $<35$ at 2 hours after delivery.

Analysis 2.1. Comparison 2 Inhaled analgesia of one strength versus inhaled analgesia of different strength, Outcome 1 Satisfaction with pain relief (first stage, good to complete).

Analysis 2.2. Comparison 2 Inhaled analgesia of one strength versus inhaled analgesia of different strength, Outcome 2 Satisfaction with pain relief (second stage, good to complete).

Analysis 2.3. Comparison 2 Inhaled analgesia of one strength versus inhaled analgesia of different strength, Outcome 3 Caesarean section.

Analysis 2.4. Comparison 2 Inhaled analgesia of one strength versus inhaled analgesia of different strength, Outcome 4 Assisted vaginal birth.

Analysis 2.5. Comparison 2 Inhaled analgesia of one strength versus inhaled analgesia of different strength, Outcome 5 Vomiting.

Analysis 2.6. Comparison 2 Inhaled analgesia of one strength versus inhaled analgesia of different strength, Outcome 6 Postpartum haemorrhage. . . . . . . . . . . . . . . . . . . . . . . . . . . . . . . . . . . . . . .

Analysis 2.7. Comparison 2 Inhaled analgesia of one strength versus inhaled analgesia of different strength, Outcome 7 Hypoxaemia mother.

Analysis 3.1. Comparison 3 Inhaled analgesia using one type of delivery system versus a different delivery system, Outcome 1 Satisfaction with pain relief (first stage, considerable to complete)..$\quad$. . . . . . . . . . . . . . . . .

Analysis 3.2. Comparison 3 Inhaled analgesia using one type of delivery system versus a different delivery system, Outcome 2 Caesarean section. 
Analysis 3.3. Comparison 3 Inhaled analgesia using one type of delivery system versus a different delivery system, Outcome 3 Vomiting ( $\mathrm{N} 2 \mathrm{O}+$ nasal).

Analysis 3.4. Comparison 3 Inhaled analgesia using one type of delivery system versus a different delivery system, Outcome 4 Vomiting dichotomous Penthr./Cypr..

Analysis 3.5. Comparison 3 Inhaled analgesia using one type of delivery system versus a different delivery system, Outcome 5 Postpartum haemorrhage.

Analysis 3.6. Comparison 3 Inhaled analgesia using one type of delivery system versus a different delivery system, Outcome 6 Mild pre-eclampsia.

Analysis 3.7. Comparison 3 Inhaled analgesia using one type of delivery system versus a different delivery system, Outcome

7 Apgar score (continuous, at $5 \mathrm{~min}$.Penthr/Cypr).

Analysis 3.8. Comparison 3 Inhaled analgesia using one type of delivery system versus a different delivery system, Outcome 8 Apgar score (continuous $\mathrm{N} 2 \mathrm{O} / \mathrm{N} 2 \mathrm{O}$ with nasal suppl.). . . . . . . . . . . . . . . . . . . . . . . . . . . . . 77

Analysis 4.1. Comparison 4 Inhaled analgesia versus placebo control/no treatment, Outcome 1 Pain intensity (first stage, clear/severe to intense/extreme).

Analysis 4.2. Comparison 4 Inhaled analgesia versus placebo control/no treatment, Outcome 2 Pain intensity (first stage, VAS 0-10 after 1 hour).

Analysis 4.3. Comparison 4 Inhaled analgesia versus placebo control/no treatment, Outcome 3 Assisted vaginal birth. Analysis 4.4. Comparison 4 Inhaled analgesia versus placebo control/no treatment, Outcome 4 Caesarean section. Analysis 4.5. Comparison 4 Inhaled analgesia versus placebo control/no treatment, Outcome 5 Vomiting. . . . . Analysis 4.6. Comparison 4 Inhaled analgesia versus placebo control/no treatment, Outcome 6 Nausea. . . . . . . Analysis 4.7. Comparison 4 Inhaled analgesia versus placebo control/no treatment, Outcome 7 Dizziness. . . . . . Analysis 4.8. Comparison 4 Inhaled analgesia versus placebo control/no treatment, Outcome 8 Drowsiness. . . .
Analysis 4.9. Comparison 4 Inhaled analgesia versus placebo control/no treatment, Outcome 9 Neonatal asphyxia. . Analysis 4.10. Comparison 4 Inhaled analgesia versus placebo control/no treatment, Outcome 10 Apgar score $5 \mathrm{~min}$. "def "def CD009351-CMP\{\}“edef 004-10\{\}"edef 10-\{\}"penalty -100“relax "edef CD009351-CMP\{8924\}"epsfysize $=10$ pt"global "def $0\{72\}$ "global "def $25\{72\}$ "global "def $70\{540\}$ "global "def $155\{720\}$ "def $\{[\}$ "def $10-\{[\}$ "let "openin "epsffilein = "relax "errhelp = "epsfnoopenhelp "errmessage \{Could not open file, ignoring it $\}\{$ “chardef =12"def "global "catcode ‘\# 121 \{“catcode ‘\#1=\}"global "catcode “" 12 "global "catcode " "par\}"closein "epsffilein "epsfrsize $=155$ "pspoints "advance "epsfrsize by-25"pspoints "epsftsize =70"pspoints "advance "epsftsize by-0"pspoints "epsfxsize ="epsfxsize "epsfxsize ="epsftsize "epsfysize ="epsfrsize "epsfrsize =0pt: BoundingBox:llx = 0 lly = 25 urx = 70 ury = 155

Analysis 4.11. Comparison 4 Inhaled analgesia versus placebo control/no treatment, Outcome 11 Apgar score 5 min.cont.

Analysis 5.1. Comparison 5 Inhaled analgesia versus TENS, Outcome 1 Satisfaction pain relief first period ordinal partial to complete.

Analysis 5.2. Comparison 5 Inhaled analgesia versus TENS, Outcome 2 Pain intensity first period ordinal moderate to severe.

HISTORY . . . . . . . . . . . . . . . . . . . . . . . . . . . . . . . . . . . . . . .

CONTRIBUTIONS OF AUTHORS . . . . . . . . . . . . . . . . . . . . . . . . . . . . . . . . .

DECLARATIONS OF INTEREST . . . . . . . . . . . . . . . . . . . . . . . . . . . . . . . . . . . . . . . . . .

SOURCES OF SUPPORT . . . . . . . . . . . . . . . . . . . . . . . . . . . . . . . . . . . .

DIFFERENCES BETWEEN PROTOCOL AND REVIEW _. . . . . . . . . . . . . . . . . . . . . . 8 88

INDEX TERMS . . . . . . . . . . . . . . . . . . . . . . . . . . . . . . . . . . . . . 88

Inhaled analgesia for pain management in labour (Review)

Copyright $\odot 2012$ The Cochrane Collaboration. Published by John Wiley \& Sons, Ltd. 


\title{
[Intervention Review]
}

\section{Inhaled analgesia for pain management in labour}

\author{
Trudy Klomp ${ }^{1}$, Mireille van Poppel ${ }^{2}$, Leanne Jones ${ }^{3}$, Janine Lazet ${ }^{4}$, Marcello Di Nisio ${ }^{5}$, Antoine LM Lagro-Janssen ${ }^{6}$ \\ ${ }^{1}$ Department of Midwifery Science, AVAG and the EMGO Institute for Health and Care Research, VU University Medical Center, \\ Amsterdam, Netherlands. ${ }^{2}$ Department of Public and Occupational Health, EMGO Institute for Health and Care Research, VU \\ University Medical Center, Amsterdam, Netherlands. ${ }^{3}$ Cochrane Pregnancy and Childbirth Group, Department of Women's and \\ Children's Health, The University of Liverpool, Liverpool, UK. ${ }^{4}$ Primary Care Midwifery Practice, Geboortes \& Zo, Utrecht, Nether- \\ lands. ${ }^{5}$ Department of Medicine and Aging; Centre for Aging Sciences (Ce.S.I.), Internal Medicine Unit, “University G. D’Annunzio” \\ Foundation, Chieti, Italy. ${ }^{6}$ Department of Primary and Community Care, Women's Studies Medicine, Radboud University Nijmegen \\ Medical Centre, Nijmegen, Netherlands \\ Contact address: Trudy Klomp, University of Profession, Medical Education, Midwifery Academie of Amsterdam, Louwesweg 6, \\ Amsterdam, NH, 1066EC, Netherlands. trudy.klomp@inholland.nl. trudyklomp@planet.nl.
}

Editorial group: Cochrane Pregnancy and Childbirth Group.

Publication status and date: New, published in Issue 9, 2012.

Review content assessed as up-to-date: 24 July 2012.

Citation: Klomp T, van Poppel M, Jones L, Lazet J, Di Nisio M, Lagro-Janssen ALM. Inhaled analgesia for pain management in labour. Cochrane Database of Systematic Reviews 2012, Issue 9. Art. No.: CD009351. DOI: 10.1002/14651858.CD009351.pub2.

Copyright (C) 2012 The Cochrane Collaboration. Published by John Wiley \& Sons, Ltd.

\begin{abstract}
A B S T R A C T

\section{Background}

Many women would like to have a choice in pain relief during labour and also would like to avoid invasive methods of pain management in labour. Inhaled analgesia during labour involves the self-administered inhalation of sub-anaesthetic concentrations of agents while the mother remains awake and her protective laryngeal reflexes remain intact. Most of the agents are easy to administer, can be started in less than a minute and become effective within a minute.
\end{abstract}

\section{Objectives}

To examine the effects of all modalities of inhaled analgesia on the mother and the newborn for mothers who planned to have a vaginal delivery.

\section{Search methods}

We searched the Cochrane Pregnancy and Childbirth Group's Trials Register (31 January 2012), ClinicalTrials.gov, and Current Controlled Trials (2 June 2012), handsearched conference proceedings from the American Society of Clinical Anesthesia (from 1990 to 2011), contacted content experts and trialists and searched reference lists of retrieved studies.

\section{Selection criteria}

Randomised controlled trials comparing inhaled analgesia with other inhaled analgesia or placebo or no treatment or other methods of non-pharmacological pain management in labour.

\section{Data collection and analysis}

Review authors independently assessed trials for eligibility, methodological quality and extracted all data. Data were double checked for accuracy.

Inhaled analgesia for pain management in labour (Review)

Copyright $\odot 2012$ The Cochrane Collaboration. Published by John Wiley \& Sons, Ltd. 


\section{Main results}

Twenty-six studies, randomising 2959 women, were included in this review.

\section{Inhaled analgesia versus a different type of inhaled analgesia}

Pain relief was measured using a Visual Analogue Scale (VAS) from 0 to $100 \mathrm{~mm}$ where 100 corresponds to the most relief. Pain intensity was measured using a VAS from 0 to $100 \mathrm{~mm}$, where 0 corresponds to no pain at all and 100 corresponds to the worst pain. The highest score for pain relief is the most positive in contrast to 'pain intensity' in which the higher score is more negative.

Flurane derivatives were found to offer better pain relief than nitrous oxide in first stage of labour as measured by a lower pain intensity score (average mean difference (MD) 14.39, 95\% confidence interval (CI) 4.41 to 24.37, three studies, 70 women), also a higher pain relief score for flurane derivatives compared with nitrous oxide (average MD -16.32, 95\% CI -26.85 to -5.79, two studies, 70 women). Substantial heterogeneity was found in the analyses of pain intensity $(\mathrm{P}=0.003)$ and in the analysis of pain relief $(\mathrm{P}=0.002)$. These findings should be considered with caution because of the questionable design of the included cross-over trials. More nausea was found in the nitrous oxide group compared with the flurane derivatives group (risk ratio (RR) $6.6095 \%$ CI 1.85 to 23.52 , two studies, 98 women).

\section{Inhaled analgesia versus placebo or no treatment}

Placebo or no treatment was found to offer less pain relief compared to nitrous oxide (average RR 0.06, 95\% CI 0.01 to 0.34 , two studies, 310 women; MD -3.50, 95\% CI -3.75 to -3.25 , one study, 509 women). However, nitrous oxide resulted in more side effects for women such as nausea (RR 43.10, 95\% CI 2.63 to 706.74, one study, 509 women), vomiting (RR 9.05, 95\% CI 1.18 to 69.32, two studies, 619 women), dizziness (RR 113.98, 95\% CI 7.09 to 1833.69, one study, 509 women) and drowsiness (RR 77.59, 95\% CI 4.80 to 1254.96 , one study, 509 women) when compared with placebo or no treatment.

There were no significant differences found for any of the outcomes in the studies comparing one strength versus a different strength of inhaled analgesia, in studies comparing different delivery systems or in the study comparing inhaled analgesia with TENS.

Due to lack of data, the following outcomes were not analysed within the review: sense of control; satisfaction with childbirth experience; effect on mother/baby interaction; breastfeeding; admission to special care baby unit; poor infant outcomes at long-term follow-up; or costs.

\section{Authors' conclusions}

Inhaled analgesia appears to be effective in reducing pain intensity and in giving pain relief in labour. However, substantial heterogeneity was detected for pain intensity. Furthermore, nitrous oxide appears to result in more side effects compared with flurane derivatives. Flurane derivatives result in more drowsiness when compared with nitrous oxide. When inhaled analgesia is compared with no treatment or placebo, nitrous oxide appears to result in even more side effects such as nausea, vomiting, dizziness and drowsiness. There is no evidence for differences for any of the outcomes comparing one strength verus a different strength of inhaled analgesia, comparing different delivery systems or comparing inhaled analgesia with TENS.

\section{PLAIN LANGUAGE SUMMARY}

\section{Inhaled analgesia for relieving pain during labour}

Labour pain and methods to relieve it are major concerns for pregnant women, healthcare workers and the general public. These concerns have implications for the course of labour, for the quality of maternal and infant outcomes as well as for the costs of obstetric health care.

Women in labour who need pain relief should not only have access to invasive methods such as an epidural, which may have considerable side effects, but other means of pain relief as well. Futhermore, even in hospitals with full-time obstetric anaesthesia coverage no one may be available to give an epidural, and in primary care, invasive methods for pain relief are not available at all.

All women in labour should have the opportunity to choose some non-invasive method of relatively effective and safe analgesia at short notice when they wish it during labour. Inhaled pain relief, such as nitrous oxide and some flurane derivatives, may be a very useful additional method for pain relief. It is relatively easy to administer, can be started in less than a minute, and become effective within a

Inhaled analgesia for pain management in labour (Review)

Copyright $\odot 2012$ The Cochrane Collaboration. Published by John Wiley \& Sons, Ltd. 
minute. Nitrous oxide is more widely known and used as inhaled pain relief during labour compared to flurane derivatives, probably due to the availability of safe equipment, no pungent smell and the ease of administration.

In this review of 26 randomised controlled trials of 2959 women, the effectiveness and safety of inhaled analgesia as pain relief for women in labour were studied. It was found that inhaled analgesia may help relieve pain during labour but women have to be informed about the side effects, such as nausea, vomiting, dizziness and drowsiness.

Inhaled analgesia may help relieve labour pain without adversely increasing operative delivery rates (forceps or vacuum extraction, caesarian section), or affecting neonatal well being. Flurane derivatives were found to be slightly more effective than nitrous oxide for the reduction of pain and for pain relief although nitrous oxide also helped to relieve pain when compared with no treatment.

Women who used nitrous oxide were more likely to experience nausea compared with flurane derivatives. When nitrous oxide was compared with no treatment or placebo, nitrous oxide resulted in side effects such as nausea, vomiting, dizziness and drowsiness.

There was no information for satisfaction with childbirth experience or sense of control in labour in these studies and further research on these two important outcomes would be helpful.

\section{B A C K G R O U N D}

\section{Description of the condition}

Labour pain and methods to relieve it are major concerns for women, healthcare workers and the general public (Caton 2002). These concerns have implications for the course of labour, for the quality of maternal and infant obstetric outcomes as well as for the costs of obstetric health care. In our modern society, pain has a negative connotation for the general public. Fear of labour pain is strongly associated with the fear of pain in general (Lowe 2002; Rosen 2002). Different views about the importance of pain during labour are reflected in great differences between countries worldwide with regard to the numbers of women who receive pain relief during labour, as well as the type of pharmacological analgesia that is used. Culture plays a significant role in attitudes towards childbirth pain, the definition of the meaning of childbirth pain, perceptions of pain and coping mechanisms used to manage pain in childbirth.

\section{Description of the intervention}

Inhaled analgesia during labour involves the inhalation of subanaesthetic concentrations of agents while the mother remains awake and her protective laryngeal reflexes remain intact. The use of inhaled analgesics for pain relief during labour dates back to 1847, when James Simpson used it for the first time for vaginal delivery (Rae 1997). Nitrous oxide was first used in 1881 by Stanislaw Klikovich, who studied the effects of pre-mixed nitrous oxide $80 \%$ in oxygen on women in labour (Richards 1976). In 1934, Minnitt introduced an apparatus for the self-administration of nitrous oxide (Minnitt 1934). Other possibilities for inhaled analgesia for pain relief in labour are isoflurane, sevoflurane, trichloroethylene in air, methoxyflurane and cyclopropane. Trichloroethylene cannot be administered through a $\mathrm{CO}_{2}$ absorber and is flammable, while cyclopropane is explosive even in sub-anaesthetic concentrations. Both drugs are no longer used in the developed world and therefore must be seen as of historical interest only. Sevoflurane is not recommended as analgesia because it has no analgesic activity at sub-anaesthetic concentrations. Sub-anaesthetic concentrations of nitrous oxide, enflurane, isoflurane and methoxyflurane do not significantly decrease uterine contractions and are preferable for this reason. However, only the use of nitrous oxide is widespread in modern obstetric practice. The reason why is not clear but probably due to ease of administration, lack of flammability, lack of pungent odour, lack of effect on uterine contractions, lack of relation with pathologic temperature, minimal toxicity and minimal depression of the cardio-vascular system (KNOV 2009; Rosen 2002). The evidence on the use of nitrous oxide for relief of labour pain has been summarised in a systematic review (Rosen 2002). Nitrous oxide mixed with oxygen as labour pain management in labour is self-administered by labouring women by inhalation through a mouthpiece or facemask. Entonox is a trade marked name for a mix of 50\% nitrous oxide and 50\% oxygen in liquid state in a single pressured container. Alternatively, Entonox can be used by blending a fixed concentration of $50 \%$ nitrous oxide and $50 \%$ oxide by two separate cylinders or hospital pipeline supply; the distribution of Entonox is carried out through a small regulator apparatus (Nitronox ${ }^{\mathrm{TM}}$ ). The Midogas device is another way to inhale Entonox which allows adjustment of the nitrous oxide concentration within a narrow range. The cylinders are connected to a facemask or mouthpiece. The demand valve 
opens only when the user applies a negative pressure by inspiring through the mouthpiece or well-sealed mask covering the parturient's mouth and nose. The demand valve eliminates flow when the parturient is not inhaling to minimise environmental contamination. Unlike the Entonox apparatus, the Nitronox apparatus allows exhaled gas to be scavenged. In countries such as Canada, Denmark, Finland, New Zealand, the United Kingdom and the United States of America, midwives are allowed to 1) set up the equipment for nitrous oxide, 2) instruct the woman how to use it and 3) monitor her use of it. The woman can self-administer it after initial supervision. Inhaled analgesia can be used by the woman either intermittently with discontinuation of use as the contraction pain eases or disappears, or continuously, by inhaling both during and between contractions. There is a rapid uptake/ washout rate for most of the inhaled analgesia, which means a low blood/gas solubility ratio. The blood/gas solubility ratio for nitrous oxide is 0.47 at 37 degrees C; for Isoflurane: 1.4; for Sevoflurane: 0.69; for Enflurane: 1.64 and for Methoxuyflurane: 13. For Methoxyflurane, the onset of analgesia is relatively slow but in spite of the low solubility it is far more potent than any of these agents and is therefore still used for inhalational analgesia in some settings. Maximal effect for nitrous oxide is observed in 30 to 60 seconds and wash-out effect can be obtained in three or four exhalations (Talebi 2009).

However, there is controversy about the use of nitrous oxide because of concerns about the safety of nitrous oxide for the sub fecundability (reduction in the ability to conceive) of female maternity care professionals and an increased incidence of spontaneous abortions of the pregnant maternity care professionals (Ahlborg 1996; Axelsson 1996; Bodin 1999; Boivin 1997; Rooks 2011; Zielhuis 1999). The underlying cause is thought to be inactivation of methionine synthase by nitrous oxide (Sanders 2008). Cellularlevel damage can begin during a maternity-care worker's shift in a poorly ventilated hospital where nitrous oxide is used without scavenging. The damage-producing process stops when the maternity-care worker leaves the hospital's contaminated environment. While she is away from the hospital, her body begins to repair any cellular-level damage. The healing of damage that has not caused actual pathology is referred to as restitution. If she returns to work in a nitrous oxide-polluted environment before restitution is complete, the damage-producing process resumes and restitution will be incomplete. Over time, the damage may accumulate enough to produce pathology (Rooks 2011).

Subfecundability in the form of maternal absorption of malformed conceptions has been found in animal studies of the reproductive effects of very prolonged exposures to very high doses of nitrous oxide (Sanders 2008). Nitrous oxide-induced fertility problems occur in rats at 1000 parts per million (ppm) but not at $500 \mathrm{ppm}$ or lower. Rats are known to be particularly sensitive to damage from nitrous oxide.

More months on average to conceive was found in a study of dental assistants working in settings that did not use scavenging of exhaled nitrous oxide (Rowland 1992). It was estimated that the ambient air in which they worked was contaminated by greater than 1000 ppm of nitrous oxide.

Current standards in the Netherlands and United States call for limiting occupational exposure to nitrous oxide to not more than an eight-hour time-weighted average (TWA) concentration of 25 ppm (KNOV 2009). The UK, Finland, Germany and Sweden have set 100 ppm as their upper limits. The United States' 25 ppm standard was set arbitrarily during the 1970 s without benefit of actual data. Nevertheless, the American Society of Anesthesiologists (ASA), the National Institute of Occupational Safety and Health $(\mathrm{NIOSH})$ and the US Occupational Safety and Health Administration (OSHA) all believe that this standard has been effective in protecting American health workers. Concerns about reproductive toxicity from occupational exposure to nitrous oxide at levels below the 25-ppm standard are not supported by the available data, which, however, do not include findings from prospective studies.

The risk of reproductive failure related to occupational exposure to nitrous oxide is essentially eliminated when nitrous oxide labour analgesia is used in well-ventilated modern hospitals and 'scavenging' is used. The Boivin 1997 meta-analysis reached the same conclusion as the Rosen 2002 review: scavenging solves the problem. Epidemiological studies based on data obtained in the pre-scavenging era indicated an increased risk of spontaneous abortion.

Other side effects are maternal drowsiness, nausea and vomiting when inhaled analgesia is used too long or extensively, especially if the rule of self-administration is violated. Renal and hepatic toxicity and uterine relaxation are usually not of concern at analgesic levels of inhaled analgesia but we will include them if possible.

\section{How the intervention might work}

The precise mechanism of action of pain relief by inhaled analgesia remains uncertain. Maze and Fuginaga hypothesised that nitrous oxide induces the release of endogenous opioid peptides in the periaqueductual grey area of the midbrain (Maze 2000). The release of this substance in the midbrain could modulate pain stimuli through the descending spinal cord nerve pathways.

\section{Why it is important to do this review}

It is important to do this review because all women should have access to some form of relatively effective and safe analgesia during labour and to provide this analgesia when women need some form of pharmacological pain relief during labour (Rooks 2007). Even in hospitals with full-time obstetric anaesthesia coverage, no one may be available to place an epidural, provide another highly effective method of labour analgesia, or provide a labour-intensive non-pharmacological method to help the woman in pain. 
More invasive options such as epidural analgesia are associated with significant side effects. Approximately $20 \%$ of women who had a vaginal delivery in the UK (DOH 2005; Khor 2000), 59\% to $61 \%$ of women in the USA (Declercq 2007; Osterman 2011) and $10 \%$ of women in the Netherlands (PRN 2008) used an epidural injection as pain relief in labour. The use of an epidural injection in labour has steadily increased until the last decade in modern highly developed countries (Anim-Somuah 2005). In some countries these figures are expected to rise even more in the coming years, for example, in the Netherlands. The use of epidural analgesia, especially within primary obstetric care, determines a higher rate of deliveries in secondary or tertiary obstetric care hospitals, which increases medicalisation as well as healthcare costs. In conclusion, it is important to have other options for pain relief during labour in view of the side effects of the invasive options.

Inhaled pain relief during labour, especially by nitrous oxide, is relatively easy to administer, can be started in less than a minute and becomes effective within a minute. Since it does not affect the physiology of labour, it can be started whenever it is needed. However, the effectiveness and efficacy of nitrous oxide use for management of labour pain is hard to ascertain because of the few available data. The available data are out of date (Rosen 2002); thus a systematic assessment of the evidence regarding the safety and efficacy of inhaled analgesia for pain relief in labour is urgently needed as well as for anaesthesiologists, obstetricians, hospital administrators, midwives, nurses, women as for the general public. This review is one in a series of Cochrane reviews examining pain management in labour. These reviews contribute to an overview of systematic reviews of pain management for women in labour (Jones 2012), and share a generic protocol (Jones 2011).

\section{O B JECT IVES}

The main objective was to explore the efficacy and safety of inhaled analgesia as pain relief for women in labour planning a vaginal delivery. Although important to look at, the effects of occupational exposure and toxic effects on reproduction for maternity healthcare workers can only be found in large-scale epidemiological studies. Since we only included intervention studies (see Types of studies), we did not include these outcomes in this review.

\section{METHODS}

\section{Criteria for considering studies for this review}

\section{Types of studies}

Randomised controlled trials (RCTs) and studies with a cross-over design were included. We did not include quasi-RCTs.

\section{Types of participants}

Women in labour including women in high-risk groups, e.g. preterm labour or following induction of labour.

\section{Types of interventions}

This review is one in a series of Cochrane reviews examining pain management in labour. These reviews contribute to an overview of systematic reviews of interventions for pain management in labour (Jones 2012), and share a generic protocol (Jones 2011). To avoid duplication, the different methods of pain management have been listed in a specific order, from one to 15 . Individual reviews focusing on particular interventions include comparisons with only the interventions above it in the list. Methods of pain management identified in the future will be added to the end of the list. The current list is as follows.

1. Placebo/no treatment

2. Hypnosis (Madden 2011)

3. Biofeedback (Barragán 2011)

4. Intracutaneous or subcutaneous sterile water injection

(Derry 2012)

5. Immersion in water (Cluett 2009)

6. Aromatherapy (Smith 2011a)

7. Relaxation techniques (yoga, music, audio)* (Smith 2011c)

8. Acupuncture or acupressure (Smith 2011b)

9. Manual healing methods including massage and reflexology* (Smith 2011d)

10. TENS (transcutaneous electrical nerve stimulation)

(Dowswell 2009)

11. Inhaled analgesia (this review)

12. Opioids (Ullman 2010)

13. Non-opioid drugs (Othman 2011)

14. Local anaesthetic nerve blocks (Novikova 2011)

15. Epidural (including combined spinal epidural)

(Anim-Somuah 2011; Simmons 2007)

Accordingly, this review only includes comparisons of inhaled analgesia with other inhaled analgesia or with: 1 . placebo/no treatment; 2. hypnosis; 3. biofeedback; 4. sterile water injection; 5 . immersion in water; 6. aromatherapy; 7. relaxation techniques (yoga, music, audio); 8. acupuncture or acupressure; 9. manual methods (massage, reflexology); or 10. TENS.

Interventions were any inhaled analgesia during labour such as isoflurane, enflurane methoxyflurane and nitrous oxide. We included any frequency or duration of administration, any dosage/ intensity, any combinations of inhaled analgesia and any timing of labour (first, second or third stage). 
Types of outcome measures

Primary outcomes

\section{Effects of interventions}

- Pain intensity (as defined by trialists) (Likert 1932)

- Satisfaction with pain relief (as defined by trialists) collected within 48 hours after birth

- Sense of control in labour (as defined by trialists)

- Satisfaction with childbirth experience (as defined by trialists)

\section{Safety of interventions}

- Effect on mother/baby interaction (skin-to-skin contact of mother and baby within the first hour of birth)

- Breastfeeding (at specified time points; within the first hour of birth, at discharge of the hospital)

- Assisted vaginal birth

- Caesarean section

- Side effects (nausea, vomiting, drowsiness, renal and hepatic toxicity, uterine relaxation)

- Admission to special care baby unit/neonatal intensive care unit (as defined by trialists)

- Apgar score less than seven at five minutes

- Need for rescue analgesia (mother or baby)

- Poor infant outcomes at long-term follow-up (as defined by trialists)

\section{Other outcomes}

- Cost (as defined by trialists)

\section{Secondary outcomes}

For the baby

- Differences in the one, two, five or 10 minute Apgar scores

- Neurological integrity scale of the newborn

For the professional

- Occupational exposure

- Toxic effects on reproduction

\section{Search methods for identification of studies}

\section{Electronic searches}

The Trials Search Co-ordinator was contacted to search the Cochrane Pregnancy and Childbirth Group's Trials Register (31 January 2012).
The Cochrane Pregnancy and Childbirth Group's Trials Register is maintained by the Trials Search Co-ordinator and contains trials identified from:

1. monthly searches of the Cochrane Central Register of Controlled Trials (CENTRAL);

2. weekly searches of MEDLINE;

3. weekly searches of EMBASE;

4. handsearches of 30 journals and the proceedings of major conferences;

5. weekly current awareness alerts for a further 44 journals plus monthly BioMed Central email alerts.

Details of the search strategies for CENTRAL, MEDLINE and EMBASE, the list of handsearched journals and conference proceedings, and the list of journals reviewed via the current awareness service can be found in the 'Specialized Register' section within the editorial information about the Cochrane Pregnancy and Childbirth Group.

Trials identified through the searching activities described above are each assigned to a review topic (or topics). The Trials Search Co-ordinator searches the register for each review using the topic list rather than keywords.

In addition, we searched ClinicalTrials.gov, and Current Controlled Trials to identify ongoing trials (2 June 2012) using the search terms detailed in Appendix 1 and Appendix 2.

\section{Searching other resources}

We searched reference lists of identified studies and handsearched the conference proceedings from the American Society of Clinical Anesthesia (from 1990 to 2011). We also contacted content experts and trialists.

We did not apply any language restrictions.

\section{Data collection and analysis}

\section{Selection of studies}

Two review authors independently assessed for inclusion all the potential studies identified through the search strategy. Any disagreement was resolved through discussion and, if there could not be achieved consensus, a third author was consulted.

\section{Data extraction and management}

A form was designed to extract data. For eligible studies, two review authors extracted the data using the agreed form. Discrepancies were resolved through discussion or, if required, by consulting a third author. Data were entered into Review Manager software (RevMan 2011) and checked for accuracy.

When information regarding any of the above was unclear, we contacted the authors of the original reports to provide further details. 


\section{Assessment of risk of bias in included studies}

Two review authors independently assessed risk of bias for each study using the criteria outlined in the Cochrane Handbook for Systematic Reviews of Interventions (Higgins 2011). Any disagreement was resolved by discussion or by involving a third assessor. To assess the risk of bias, the following items were evaluated:

\section{(I) Random sequence generation (checking for possible selection bias)}

The methods used to generate the allocation sequence were described for each included study in sufficient detail to allow an assessment of whether it should produce comparable groups.

The method were assessed as:

- low risk of bias (any truly random process, e.g. random number table; computer random number generator);

- high risk of bias (any non-random process, e.g. odd or even date of birth; hospital or clinic record number);

- unclear risk of bias.

\section{(2) Allocation concealment (checking for possible selection} bias)

The methods used to conceal the allocation sequence were described for each included study and determined whether intervention allocation could have been foreseen in advance of, or during recruitment, or changed after assignment.

The methods were assessed as:

- low risk of bias (e.g. telephone or central randomisation; consecutively numbered sealed opaque envelopes);

- high risk of bias (open random allocation; unsealed or nonopaque envelopes, alternation; date of birth);

- unclear risk of bias.

\section{(3) Blinding (checking for possible performance bias)}

The methods used, if any, to blind study participants and personnel from knowledge of which intervention a participant received were described for each included study. Studies were considered at low risk of bias if they were blinded, or if was judged that the lack of blinding could not have affected the results. Blinding was assessed separately for different outcomes or classes of outcomes.

The methods were assessed as:

- low, high or unclear risk of bias for participants;

- low, high or unclear risk of bias for personnel;

- low, high or unclear risk of bias for outcome assessors.

Partial blinding was used as an option because many of the administered inhaled analgesia cannot be completely blinded because of their odour. Partial blinding was also used for self-reported efficacy outcomes and when these outcomes are recorded by blinded personnel.
(4) Incomplete outcome data (checking for possible attrition bias through withdrawals, dropouts, protocol deviations)

The completeness of data including attrition and exclusions from the analysis were described for each included study and for each outcome or class of outcomes. Where attrition and exclusions were stated it was reported, the numbers included in the analysis at each stage (compared with the total randomised participants), reasons for attrition or exclusion where reported, and whether missing data were balanced across groups or were related to outcomes. Where sufficient information was reported, or could be supplied by the trial authors, we planned to re-include the missing data in the analyses which we undertook. Methods were assessed as:

- low risk of bias ( $20 \%$ or less missing data);

- high risk of bias;

- unclear risk of bias.

\section{(5) Selective reporting bias}

How the possibility of selective outcome reporting bias was investigated and what was found was described for each included study (Sterne 2001).

The methods were assessed as:

- low risk of bias (where it is clear that all of the study's prespecified outcomes and all expected outcomes of interest to the review have been reported);

- high risk of bias (where not all the study's pre-specified outcomes have been reported; one or more reported primary outcomes were not pre-specified; outcomes of interest are reported incompletely and so cannot be used; study fails to include results of a key outcome that would have been expected to have been reported);

- unclear risk of bias.

\section{(6) Other sources of bias}

Concurrent or prior use of analgesia was identified in the selected studies because the concurrent or prior use of analgesia can give some bias of the effects of the studied analgesia. Furthermore, any other important concerns about other possible sources of bias was described for each included study.

Each study was assessed whether the study was free of other problems that could put it at risk of bias:

- low risk of bias;

- high risk of bias;

- unclear risk of bias.

\section{(7) Overall risk of bias}

Explicit judgements were made about whether studies were at high risk of bias, according to the criteria given in the Handbook (Higgins 2011). The likely magnitude and direction of the bias was assessed with reference to (1) to (6) above and whether it 
was considered as likely to impact on the findings. We planned to explore the impact of the level of bias through undertaking sensitivity analyses - see Sensitivity analysis.

The following questions were considered for assessing risk of bias for cross-over trials.

- Was use of a cross-over design appropriate (Elbourne 2002)?

- Is it clear that the order of receiving treatments was randomised?

- Can it be assumed that the trial was not biased from carryover effects? Inhaled analgesia has a relatively rapid uptake/ washout effect. We take four exhalations as the safe cut-off point for no residual effect.

- Are unbiased data available (period effects)? Pain of uterine contractions are not consistent over time. The pain becomes more intense as the labour progresses until the start of delivery. Pain of the contractions change during the delivery of the baby. We looked for any control for labour progress at the start of the inhaled analgesia. If the start of the analgesia was not in the same stage of labour (in the active first stage after $3 \mathrm{~cm}$ dilatation) and second stage after $10 \mathrm{~cm}$ dilation until birth of the baby), we reported this risk of bias.

\section{Measures of treatment effect}

\section{Dichotomous data}

For dichotomous date, we presented results as summary risk ratio with $95 \%$ confidence intervals and, where relevant, as risk difference and number needed to treat either to benefit or to harm.

\section{Ordinal data}

Results of ordinal data were transformed to dichotomous data for analysis and described in the section on data analysis.

\section{Continuous data}

For continuous data, we used mean difference if outcomes were measured in the same way between trials. The standardised mean difference was used to combine trials that measured the same outcome, but used different methods. Where appropriate, we used standard inverse-variance random-effects meta-analysis to combine the trials (DerSimonian 2007). The method of Hozo 2005 was used to estimate the mean and variance from the median, range, and the size of the sample when the published reports of the included trials only reported the median, range and the size of trial.

\section{Unit of analysis issues}

\section{Cross-over trials}

\section{Other unit of analysis issues}

The appropriate analysis for continuous data from a two-period, two-intervention cross-over trial, a paired T-test was planned if neither carry-over, (a minimum of four exhalations with room air), nor period effects were thought to be a problem. This evaluates the value of 'measurement on experimental intervention (E)' minus 'measurement on control intervention (C)' separately for each participant. The mean and standard error of these different measures are the building blocks of an effect estimate and a statistical test. The effect estimate may be included in a meta-analysis using the generic inverse-variance method in RevMan 2011.

The simple formula of Hozo 2005 was used for small sample sizes below 25 participants to estimate the mean using the values of the median, low and high end of the range. The best estimator for sample sizes which exceeds 25 is the median itself. The known estimator Range/4 was used to estimate the standard variation for small sample sizes between 15 and 70 participants.

\section{Dealing with missing data}

Levels of attrition were noted for included studies. We planned to explore the impact of including studies with high levels of missing data in the overall assessment of treatment effect by using sensitivity analysis.

Analyses were carried out for all outcomes, as far as possible, on an intention-to-treat basis, i.e. we attempted to include all participants randomised to each group in the analyses, and all participants were analysed in the group to which they were allocated, regardless of whether or not they received the allocated intervention. The denominator for each outcome in each trial was the number randomised minus any participants whose outcomes were known to be missing.

\section{Assessment of heterogeneity}

Heterogeneity of treatment effects was measured between trials using the $\mathrm{Chi}^{2}$ test and the $\mathrm{I}^{2}$ statistic (Deeks 2001; Higgins 2011), which describe the percentage of total variation across trials that is attributable to heterogeneity rather than to chance.

We assessed statistical heterogeneity in each meta-analysis using the $\mathrm{T}^{2}, \mathrm{I}^{2}$ and $\mathrm{Chi}^{2}$ statistics. We regarded heterogeneity as substantial if $\mathrm{T}^{2}$ was greater than zero and either $\mathrm{I}^{2}$ was greater than $30 \%$ or there was a low $\mathrm{P}$ value (less than 0.10 ) in the $\mathrm{Chi}^{2}$ test for heterogeneity.

Inhaled analgesia for pain management in labour (Review)

Copyright $\odot 2012$ The Cochrane Collaboration. Published by John Wiley \& Sons, Ltd. 


\section{Assessment of reporting biases}

If 10 or more studies had contributed data to meta-analysis for any particular outcome, we planned to investigate reporting biases (such as publication bias) using funnel plots. We would have assessed possible asymmetry visually, and used formal tests for funnel plot asymmetry. For continuous outcomes, we would have used the test proposed by Egger 1997, and for dichotomous outcomes, we would have used the test proposed by Harbord 2006. If asymmetry was detected in any of these tests or was suggested by a visual assessment, we planned to perform exploratory analyses to investigate it.

\section{Data synthesis}

Statistical analysis were carried out using the Review Manager software (RevMan 2011). Fixed-effect meta-analysis was used for combining data where it was reasonable to assume that studies were estimating the same underlying treatment effect: i.e. where trials were examining the same intervention, and the trials' populations and methods were judged sufficiently similar. If there was clinical heterogeneity sufficient to expect that the underlying treatment effects differed between trials, or if substantial statistical heterogeneity was detected, random-effects meta-analysis was used to produce an overall summary if an average treatment effect across trials was considered clinically meaningful. Results were presented as the average treatment effect with its $95 \%$ confidence interval, and the estimates of $\mathrm{T}^{2}$ and $\mathrm{I}^{2}$ where random-effects analysis was used.

\section{Subgroup analysis and investigation of heterogeneity}

If substantial heterogeneity was identified, for the primary outcomes, where data were available, we planned to carry out the following subgroup analyses.

1. Spontaneous labour versus induced labour.

2. Primiparous versus multiparous.

3. Term versus preterm birth.

4. Continuous support in labour versus no continuous support.

5. Mode of delivery: spontaneous vaginal, operative vaginal, mode of delivery mixed or unclear.

6. Different methods and doses of inhaled pain relief (inhalation agent regimen and doses).

7. Obese versus non obese women.

We also planned to look separately at results of studies in which a $50 \% / 50 \%$ blend of $\mathrm{N}_{2} \mathrm{O}$ and $\mathrm{O}_{2}$ was self-administered by labouring women and distinguish the results of those studies from the results of studies in which:

a. the ratio of $\mathrm{N}_{2} \mathrm{O}$ to $\mathrm{O}_{2}$ was higher than $50 \%$,

b. the ratio of $\mathrm{N}_{2} \mathrm{O}$ to $\mathrm{O}_{2}$ was lower than $50 \%$,

c. the ratio of the gases could be changed by a professional,

d. the ratio could be changed by the labouring woman, e. the ratio was $50 \% / 50 \%$ but someone other than the woman who was inhaling it administered it to her.

We planned to assess differences between subgroups by interaction tests as described in the Handbook (Higgins 2011).

\section{Sensitivity analysis}

We planned to carry out sensitivity analyses to explore the effect of trial quality assessed by concealment of allocation, and for the cross-over trials as assessed by 'correct analyses for cross-over design used', with poor quality studies with high risk of bias being excluded from the analyses in order to assess whether this made any difference to the overall results. We planned to carry out sensitivity analyse for primary outcomes only.

\section{RE S U L T S}

\section{Description of studies}

See: Characteristics of included studies; Characteristics of excluded studies; Characteristics of studies awaiting classification.

\section{Results of the search}

A total of 54 reports of studies were identified from the search strategy. A total of 26 studies reporting data on 2959 women (31 reports) were included in this review (see Characteristics of included studies) and 21 studies (23 reports) were excluded (see Characteristics of excluded studies).

\section{Included studies}

\section{Study design}

Eighteen of the studies were parallel design (Abboud 1981; Abboud 1995; Arthurs 1979; Belfrage 1974; Cheng 2001; Einarsson 1996; Enrile 1973; Ji 2002; Jones 1969; Jones 1969a; MRC 1970; Rezaeipour 2008; Shao 2000; Stefani 1982; Swart 1991; Talebi 2009; Wang 1994; Zhang 2001) and eight crossover design (Arora 1992; Bergsjo 1971; Carstoniu 1994; Chia 1990; McGuinness 1984; McLeod 1985; Wee 1993; Yeo 2007). One study had two parts (Chia 1990); the second part was a randomised cross-over study. For this study, we used only the data from the cross-over study (part II), and data were only available for the first period (before first cross-over). Two studies had three arms (Cheng 2001; Stefani 1982) and all the remaining studies had two comparison arms. We did not include the third arm of these two studies which were the control arms (no treatment). The main comparison groups included: 
1. studies comparing one type of inhaled analgesia with another type of inhaled analgesia (Abboud 1981; Abboud 1995; Arora 1992; Belfrage 1974; Bergsjo 1971; Cheng 2001; Jones 1969; Jones 1969a; McGuinness 1984; McLeod 1985; Stefani 1982; Swart 1991; Wee 1993; Yeo 2007);

2. studies comparing the same types of inhaled analgesia of different strengths (Einarsson 1996; MRC 1970);

3. studies comparing the same types of inhaled analgesia using different delivery systems (Arthurs 1979; Enrile 1973);

4. studies comparing inhaled analgesia with placebo control/ no treatment (Carstoniu 1994; Cheng 2001; Ji 2002; Rezaeipour 2008; Shao 2000; Stefani 1982; Talebi 2009; Wang 1994; Zhang 2001);

5. and one study comparing inhaled analgesia with TENS (Chia 1990).

\section{Sample sizes}

Sample size in the included studies ranged from 18 (Wee 1993) to 509 patients (Talebi 2009).

\section{Study location}

The studies were conducted in the following locations: five studies were undertaken in the USA (Abboud 1981; Abboud 1995; Enrile 1973; Stefani 1982; Swart 1991); nine studies in the UK (Arora 1992; Arthurs 1979; Jones 1969; Jones 1969a; McGuinness 1984; McLeod 1985; MRC 1970; Wee 1993; Yeo 2007; two studies in Sweden (Belfrage 1974; Einarsson 1996); one study in Norway (Bergsjo 1971); one study in Canada (Carstoniu 1994); five studies in China (Cheng 2001; Ji 2002; Shao 2000; Wang 1994; Zhang 2001); one study in Singapore (Chia 1990); and two studies in Iran (Rezaeipour 2008; Talebi 2009).

\section{Participants}

One study recruited only women scheduled for induced labour (Talebi 2009) and one study only women in spontaneous labour (Arora 1992). Three studies recruited women in both spontaneous and induced labour (Chia 1990; Enrile 1973; Yeo 2007) and reporting on the onset of labour was unclear in the remaining studies. Fifteen studies recruited both primiparous and multiparous women (Abboud 1981; Abboud 1995; Arora 1992; Arthurs 1979; Belfrage 1974; Bergsjo 1971; Carstoniu 1994; Chia 1990; Einarsson 1996; Enrile 1973; Jones 1969; Jones 1969a; MRC 1970; Talebi 2009; Wee 1993); four studies recruited only primiparous women (Cheng 2001; Ji 2002; Rezaeipour 2008; Shao 2000); and in the remaining studies parity was not reported (McGuinness 1984; McLeod 1985; Stefani 1982; Swart 1991; Wang 1994; Yeo 2007; Zhang 2001). The interventions were administered at term in five studies (Cheng 2001; Ji 2002; Shao 2000; Talebi 2009; Yeo 2007) and term of birth was unclear in the remaining studies. The interventions were administered during the first stage of labour (until complete dilatation and before the urge of pushing started) for 16 studies (Arora 1992; Arthurs 1979; Bergsjo 1971; Carstoniu 1994; Cheng 2001; Chia 1990; Einarsson 1996; Ji 2002; McGuinness 1984; McLeod 1985; Rezaeipour 2008; Shao 2000; Talebi 2009; Wee 1993; Yeo 2007; Zhang 2001); in the second stage of labour (from the start of pushing until the baby is born) for six studies (Abboud 1981; Abboud 1995; Belfrage 1974; Enrile 1973; Stefani 1982; Swart 1991); in the first and second stages of labour in three studies (Jones 1969; Jones 1969a; MRC 1970); and stage of labour was unknown in one study (Wang 1994). Continuous support and obesity were not reported upon in any of the studies.

\section{Types of intervention}

Thirteen studies compared nitrous oxide $30 \%$ to $60 \%$ with a different form of inhaled analgesia (flurane derivatives): enflurane $0.25 \%$ to $1.25 \%$ (Abboud 1981; McGuinness 1984; Stefani 1982); desflurane $1.4 \%$ to $5 \%$ (Abboud 1995; Swart 1991); methoxyflurane $0.3 \%$ to $0.8 \%$ (Bergsjo 1971; Belfrage 1974; Jones 1969; Jones 1969a); sevoflurane 0.7\% (Yeo 2007); isoflurane $0.2 \%$ to $0.75 \%$ (McLeod 1985; Cheng 2001); isoflurane $0.2 \%$ to $0.25 \%$ and nitrous oxide $50 \%$ (Arora 1992 ; Wee 1993). One study Belfrage 1974 , studied nitrous oxide $70 \%$ with methoxyflurane $0.3 \%$ to $0.8 \%$. Of these studies, in five the interventions were administered on a continuous basis (Abboud 1981; Abboud 1995; Jones 1969; Stefani 1982; Yeo 2007) and in seven on an intermittent basis (Arora 1992; Bergsjo 1971; Cheng 2001; Jones 1969a; McGuinness 1984; McLeod 1985; Wee 1993). In one study the method of administration was not reported (Swart 1991) and in one study it reported that the drugs were self-administered (Belfrage 1974).

In two studies nitrous oxide $50 \%$ was compared with nitrous oxide $70 \%$ ( (Einarsson 1996; MRC 1970). In one of these studies the intervention was administered on a intermittent basis (Einarsson 1996) and in one study the administration was not reported (MRC 1970). In one study intermittent nitrous oxide 50\% alone was compared with intermittent nitrous oxide $50 \%$ plus continuous nasal supplementation of nitrous oxide 50\% (Arthurs 1979). In one study nitrous oxide $50 \%$ delivered via a Penthrane® Analgizer was compared with nitrous oxide 50\% delivered via a Cyprane ${ }^{\circledR}$ inhaler (Enrile 1973).

Nine studies compared inhaled analgesia with placebo control/ no treatment (Carstoniu 1994; Cheng 2001; Ji 2002; Rezaeipour 2008; Shao 2000; Stefani 1982; Talebi 2009; Wang 1994; Zhang 2001). In five studies nitrous oxide $30 \%$ to $50 \%$ was compared with oxygen or compressed air (Carstoniu 1994; Cheng 2001; Rezaeipour 2008; Talebi 2009; Zhang 2001) and in four studies nitrous oxide $30 \%$ to $50 \%$ was compared with no treatment (Ji 2002; Shao 2000; Stefani 1982; Wang 1994). 
One study compared nitrous oxide 50\% with TENS (Chia 1990). See Characteristics of included studies.

\section{Outcome measures}

The following primary outcomes on effects of interventions were reported upon in the studies: pain intensity (linear analogue pain score - mean standard deviation (SD), LAS mean SD, mean pain intensity, visual analogue scale (VAS), WHO pain scale, Mulleetr's pain in labour scale) (Arora 1992; Arthurs 1979; Carstoniu 1994; Cheng 2001; Chia 1990; Ji 2002; McGuinness 1984; McLeod 1985; MRC 1970; Rezaeipour 2008; Shao 2000; Talebi 2009; Wang 1994; Wee 1993; Yeo 2007; Zhang 2001); satisfaction with pain relief (within 48 hours birth, after delivery) (Abboud 1981; Abboud 1995; Arthurs 1979; Belfrage 1974; Bergsjo 1971; Chia 1990; Jones 1969; Jones 1969a; MRC 1970; Rezaeipour 2008; Stefani 1982; Swart 1991). No study reported upon satisfaction with childbirth experience and no study reported upon sense of control in labour.

The following primary outcomes on safety of interventions were reported upon in the studies: assisted vaginal birth (Abboud 1995; Arora 1992; Belfrage 1974; Bergsjo 1971; Ji 2002; Jones 1969; McGuinness 1984; MRC 1970; Rezaeipour 2008; Stefani 1982; Yeo 2007); caesarean section (Arora 1992; Belfrage 1974; Bergsjo 1971; Enrile 1973; Ji 2002; McGuinness 1984; MRC 1970; Rezaeipour 2008; Yeo 2007; Zhang 2001); side effects (vomiting, amnesia, dizziness, nausea, hypoxaemia, post-partum haemorrhage, anoxia newborn, neonatal asphyxia) (Abboud 1981; Abboud 1995; Arora 1992; Arthurs 1979; Bergsjo 1971; Einarsson 1996; Enrile 1973; Ji 2002; Jones 1969; Jones 1969a; McGuinness 1984; McLeod 1985; MRC 1970; Shao 2000; Swart 1991; Talebi 2009; Wang 1994; Wee 1993; Yeo 2007; Zhang 2001); admission to special care baby unit/neonatal intensive care (Chia 1990);
Apgar score (Abboud 1981; Arthurs 1979; Belfrage 1974; Cheng 2001; Chia 1990; Enrile 1973; Jones 1969; Rezaeipour 2008; Stefani 1982; Talebi 2009; Wang 1994; Wee 1993; Ji 2002). No studies reported upon the need of rescue analgesia or upon effect on mother/baby interaction, breastfeeding or poor infant outcomes at long-term follow-up.

The only secondary outcome reported upon in the studies was neurological integrity scale of the newborn (Abboud 1995; Cheng 2001; Stefani 1982; Swart 1991). No study reported upon outcomes of the professionals attending the birth.

\section{Excluded studies}

We excluded 21 studies: see Characteristics of excluded studies. Six studies were not randomised controlled trials (Arozenius 1980; Chessor 2005; Cosmi 1969; Davies 1975; McAneny 1963; Roberts 1957) and five studies used quasi methods of randomisation (Arthurs 1981; Davies 1974; Major 1967; Rosen 1969; Rosen 1972). In two studies the studies were investigating the effect of general anaesthesia in women undergoing caesarean section and not during childbirth (Crawford 1975; Krantz 1974) and in three studies the comparison interventions are no longer used in practice (trichloroethylene; cyclopropane) (Major 1966; Phillips 1971; Shnider 1963). In five studies the comparison interventions were opioids, epidural or other multidrug interventions and therefore did not meet the inclusion criteria of this review according to the pain management hierarchy (Clark 1979; Creasser 1974; Howell 2001; Robinson 1980; Volmanen 2005).

\section{Risk of bias in included studies}

See Figure 1; Figure 2, for further details regarding 'Risk of bias' assessment. 
Figure I. 'Risk of bias' graph: review authors' judgements about each risk of bias item presented as percentages across all included studies.

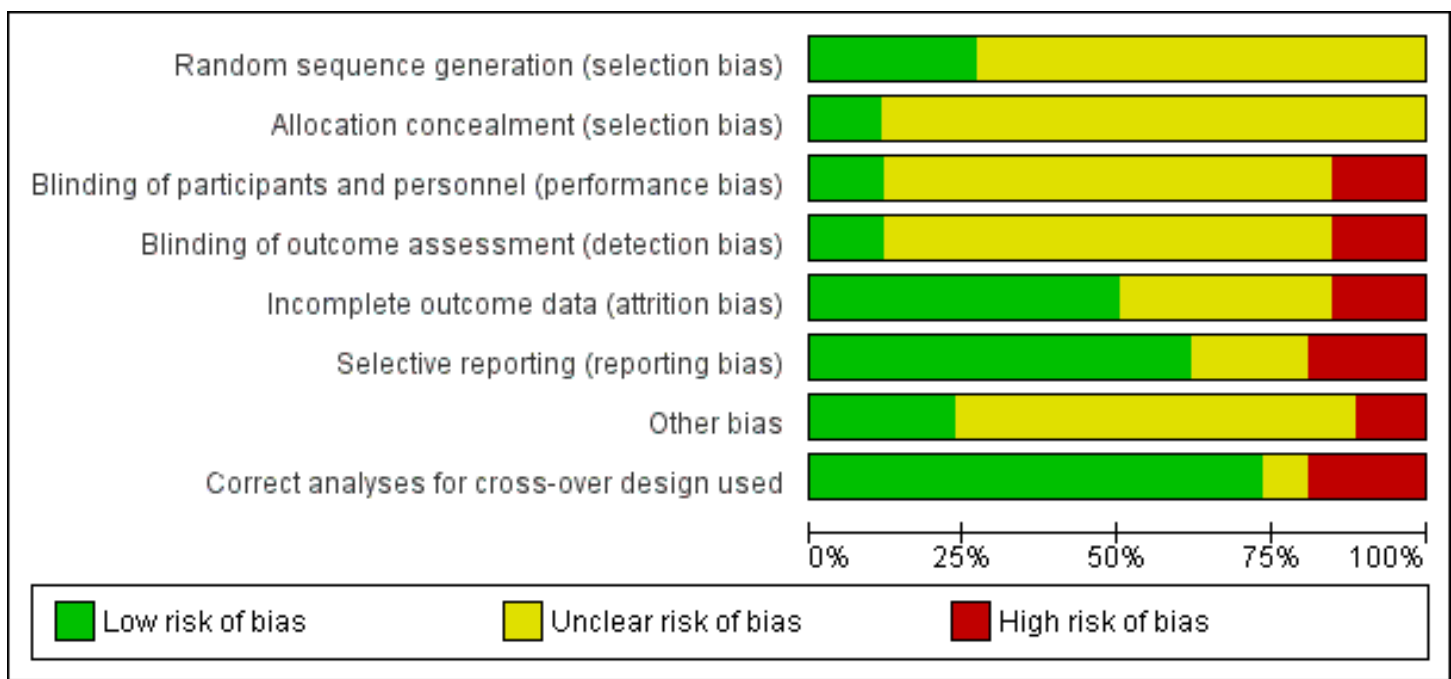


Figure 2. 'Risk of bias' summary: review authors' judgements about each risk of bias item for each included study.

\begin{tabular}{|c|c|c|c|c|c|c|c|c|}
\hline & 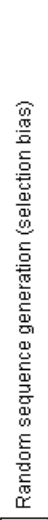 & 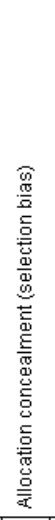 & 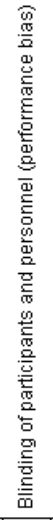 & 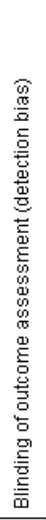 & 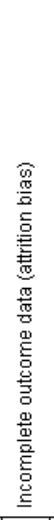 & 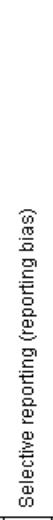 & 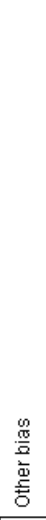 & 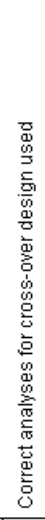 \\
\hline Abboud 1981 & $?$ & $?$ & $\oplus$ & $?$ & $\bullet$ & + & $?$ & 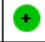 \\
\hline Abboud 1995 & + & ? & 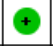 & ? & $\odot$ & + & $?$ & $\odot$ \\
\hline Arora 1992 & 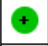 & $?$ & $?$ & $?$ & $\bullet$ & $\odot$ & $?$ & $\odot$ \\
\hline Arthurs 1979 & $?$ & $?$ & $?$ & $?$ & $?$ & $\odot$ & $?$ & $\odot$ \\
\hline Belfrage 1974 & $?$ & $?$ & - & - & $?$ & $?$ & $?$ & 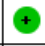 \\
\hline Bergsjo 1971 & + & 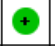 & $\odot$ & - & $\odot$ & + & $?$ & $?$ \\
\hline Carstoniu 1994 & 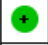 & $\oplus$ & $?$ & $?$ & - & $\oplus$ & 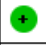 & $?$ \\
\hline Cheng 2001 & $?$ & $?$ & $?$ & $?$ & $?$ & $\odot$ & $?$ & 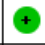 \\
\hline Chia 1990 & $?$ & $\oplus$ & $?$ & ? & ? & + & + & 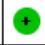 \\
\hline Einarsson 1996 & $?$ & $?$ & $?$ & $?$ & $\oplus$ & 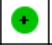 & $?$ & $\oplus$ \\
\hline Enrile 1973 & $\odot$ & $?$ & - & - & $?$ & & $\Rightarrow$ & $\bullet$ \\
\hline Ji 2002 & $?$ & $?$ & $?$ & $?$ & $?$ & + & - & 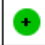 \\
\hline Jones 1969 & $?$ & $?$ & $?$ & $?$ & - & $\odot$ & $?$ & $\bullet$ \\
\hline Jones $1969 a$ & $?$ & $?$ & $?$ & $?$ & + & + & + & + \\
\hline McGuinness 1984 & $?$ & $?$ & $?$ & $?$ & $\bullet$ & $\odot$ & $?$ & $\odot$ \\
\hline McLeod 1985 & $?$ & $?$ & $?$ & $?$ & + & + & + & - \\
\hline MRC 1970 & $?$ & $?$ & $?$ & $?$ & $\odot$ & $\odot$ & $?$ & $\oplus$ \\
\hline Rezaeipour 2008 & $?$ & $?$ & $?$ & + & + & $?$ & $?$ & $\oplus$ \\
\hline Shao 2000 & $\odot$ & $?$ & $?$ & $?$ & $?$ & $?$ & $?$ & $\odot$ \\
\hline Stefani 1982 & $?$ & $?$ & $?$ & + & 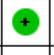 & + & + & $\odot$ \\
\hline Swart 1991 & $?$ & $?$ & + & $?$ & $?$ & $?$ & $?$ & + \\
\hline Talebi 2009 & + & $?$ & $?$ & + & + & + & - & $\odot$ \\
\hline Wang 1994 & $?$ & $?$ & $?$ & $?$ & $?$ & $?$ & $?$ & 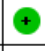 \\
\hline Wee 1993 & $?$ & $?$ & $?$ & $?$ & + & + & $?$ & $\odot$ \\
\hline Yeo 2007 & $?$ & $?$ & - & 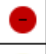 & - & + & 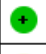 & G \\
\hline Zhang 2001 & $?$ & $?$ & $?$ & $?$ & $\bullet$ & $\Theta$ & $?$ & $\bullet$ \\
\hline
\end{tabular}




\section{Random sequence generation}

Seven of the trials (27\%) were rated as low risk of bias for sequence generation (Abboud 1995; Arora 1992; Bergsjo 1971; Carstoniu 1994; Enrile 1973; Shao 2000; Talebi 2009) and in the remaining trials the method of sequence generation was unclear (Abboud 1981; Arthurs 1979; Belfrage 1974; Cheng 2001; Chia 1990; Einarsson 1996; Ji 2002; Jones 1969; Jones 1969a; McGuinness 1984; McLeod 1985; MRC 1970; Rezaeipour 2008; Stefani 1982; Swart 1991; Wang 1994; Wee 1993; Yeo 2007; Zhang 2001).

\section{Allocation concealment}

In only three studies $(11 \%)$ was allocation concealment rated as low risk of bias (Bergsjo 1971; Carstoniu 1994; Chia 1990) and unclear in the remaining trials (Abboud 1981; Abboud 1995; Arora 1992; Arthurs 1979; Belfrage 1974; Cheng 2001; Einarsson 1996; Enrile 1973; Ji 2002; Jones 1969; Jones 1969a; McGuinness 1984; McLeod 1985; MRC 1970; Rezaeipour 2008; Shao 2000; Stefani 1982; Swart 1991; Talebi 2009; Wang 1994; Wee 1993; Yeo 2007; Zhang 2001).

\section{Blinding}

Blinding of participants and personnel was at low risk of bias three studies (11\%) (Abboud 1981; Abboud 1995; Swart 1991), high risk in four studies (Belfrage 1974; Bergsjo 1971; Enrile 1973; Yeo 2007) and unclear in the remaining studies (Arora 1992; Arthurs 1979; Carstoniu 1994; Cheng 2001; Chia 1990; Einarsson 1996; Ji 2002; Jones 1969; Jones 1969a; McGuinness 1984; McLeod 1985; MRC 1970; Rezaeipour 2008; Shao 2000; Stefani 1982; Swart 1991; Talebi 2009; Wang 1994; Wee 1993; Zhang 2001). Blinding of outcome assessment was at low risk of bias in three studies (Stefani 1982; Rezaeipour 2008; Talebi 2009) (9\%), high risk in four studies (Belfrage 1974; Bergsjo 1971; Enrile 1973; Yeo 2007) and unclear in the remaining studies (Abboud 1981; Abboud 1995; Arora 1992; Arthurs 1979; Carstoniu 1994; Cheng 2001; Chia 1990; Einarsson 1996; Ji 2002; Jones 1969; Jones 1969a; McGuinness 1984; McLeod 1985; MRC 1970; Shao 2000; Swart 1991; Wang 1994; Wee 1993; Zhang 2001).

\section{Incomplete outcome data}

Thirteen $(50 \%)$ of the trials were rated as low risk of bias for incomplete outcome data (Abboud 1981; Abboud 1995; Arora 1992; Bergsjo 1971; Einarsson 1996; Jones 1969a; McLeod 1985 McGuinness 1984; Rezaeipour 2008; Stefani 1982; Talebi 2009; Wee 1993; Zhang 2001) and at high risk of bias in four (Carstoniu 1994; Jones 1969; MRC 1970; Yeo 2007). In the remaining studies risk of bias for incomplete outcome data was unclear (Arthurs
1979; Belfrage 1974; Cheng 2001; Chia 1990; Enrile 1973; Ji 2002; Shao 2000; Swart 1991; Wang 1994).

\section{Selective outcome reporting}

Sixteen $(62 \%)$ of the trials were rated as low risk of bias for selective outcome reporting (Abboud 1981; Abboud 1995; Bergsjo 1971; Carstoniu 1994; Chia 1990; Einarsson 1996; Ji 2002; Jones 1969; Jones 1969a; McGuinness 1984; McLeod 1985; MRC 1970; Stefani 1982; Talebi 2009; Wee 1993; Yeo 2007) and at high risk of bias in five (Arora 1992; Arthurs 1979; Cheng 2001; Enrile 1973; Zhang 2001). In the remaining studies risk of bias for was unclear (Belfrage 1974; Rezaeipour 2008; Shao 2000; Swart 1991; Wang 1994).

\section{Other bias}

Six $(23 \%)$ of the trials were rated as being at low risk of bias for 'other bias' (Carstoniu 1994; Chia 1990; Jones 1969a; McLeod 1985; Stefani 1982; Yeo 2007) and at high risk of bias in three studies (baseline imbalance including no information of prior or concurrent use of other analgesia; delivery systems for interventions not comparable) (Enrile 1973; Ji 2002; Talebi 2009). In the remaining 17 studies (65\%), risk of bias for was unclear (Abboud 1981; Abboud 1995; Arora 1992; Arthurs 1979; Belfrage 1974; Bergsjo 1971; Cheng 2001; Einarsson 1996; Jones 1969; McGuinness 1984; MRC 1970; Rezaeipour 2008; Shao 2000; Swart 1991; Wang 1994; Wee 1993; Zhang 2001).

\section{Cross-over trials}

All eight cross-over trials randomised the order of interventions. Three studies (Arora 1992; Bergsjo 1971; Carstoniu 1994) were at low risk of bias for method of randomisation due to well described randomisation and five studies (Chia 1990; McGuinness 1984; McLeod 1985; Wee 1993; Yeo 2007) are with unclear risk of bias due to unclear description of randomisation.

In one study (Chia 1990), the study was divided into two parts: the first part was not randomised and the second part was a randomised cross-over trial. The data from the first period of the cross-over trial were used and analysed as a parallel trial. One study (McLeod 1985) had an adequate wash-out period of two contractions. Two studies (Arora 1992; Bergsjo 1971) used one contraction with air breathing between the two different agents, long enough to ensure an adequate four wash-out exhalation period. Three cross-over trials (Carstoniu 1994; McGuinness 1984; Wee 1993) reported no information on a wash-out period, but the inhaled analgesia were self-administered during contractions. This means that an adequate wash-out period of a minimum of four exhalations was met in the pause between two contractions. In the study by Yeo 2007, the wash-out period is unclear, due to 
the fact that participants were given the option, if they wished, to omit the wash-out period of breathing room air over one contraction between the different agents. No information was given on how many participants took this option. However, the minimum wash-out period of four exhalations was probably met, due to the method of self-administering the inhaled analgesia in this study. It is very likely that the women will have rested for a moment between the contractions, probably without inhaling the agent. The double cross-over design of Yeo 2007 and Wee 1993 included compensation for the progressive nature of labour and therefore are evaluated as a good and appropriate design. The five cross-over studies of Arora 1992; Bergsjo 1971; Carstoniu 1994; McGuinness 1984 and McLeod 1985 were all single cross-over studies but are believed to have an appropriate design due to the short duration of the intervention and comparison period (from three to five contractions in active part of labour). In these single cross-over studies progression of labour is not thought to be of influence.

All the eight cross-over studies (Arora 1992; Bergsjo 1971; Carstoniu 1994; Chia 1990; McGuinness 1984; McLeod 1985; Wee 1993; Yeo 2007) were carried out during the first stage in active (established) labour until $10 \mathrm{~cm}$ dilation or when women felt the urge to push (end of the first stage and start second stage). We were only able to obtain individual patient data from one study (Wee 1993) which appeared to be incomplete. We decided to use only the data of the first part of this study as a parallel group trial. The appropriate data necessary to include from a paired analysis were only available for the incidence of side effects from one study (Yeo 2007). However, because of concern over carry-over effects, outcome data for side effects for cross-over studies were not included in any analyses.

In two studies (McGuinness 1984; McLeod 1985), the Wilcoxon paired T-sample test was performed for the effect estimate of pain relief and pain intensity. No data were available on individual patients for the meta-analysis. It was not possible to extract the paired data from these two studies (McGuinness 1984; McLeod 1985). In five cross-over studies, continuous data on pain intensity or pain relief were reported (Arora 1992; McGuinness 1984; McLeod 1985; Wee 1993; Yeo 2007), and data were represented as mean/SD (Arora 1992) or median/range (McGuinness 1984, Yeo 2007) or mean/range (McLeod 1985) or individual VAS after one hour (Wee 1993) before the first cross-over. These data were available only for the whole experimental and comparison group periods separately and analysed as if the trials were a parallel group trial of experimental verus comparison. This statistical method is of high risk due to the conservative way that studies are under weighted, rather than over weighted (Elbourne 2002).

Correct analysis for cross-over design used

Five of the cross-over studies (63\%) were rated as high risk of bias for 'correct analysis for cross-over design used' (Arora 1992; McGuinness 1984; McLeod 1985; Wee 1993; Yeo 2007).

\section{Effects of interventions}

We included data from 23 trials (2599 women) using different modalities of inhaled analgesia for pain management in labour for our meta-analyses. In three studies (Carstoniu 1994; Shao 2000; Wang 1994), data could not be included in the meta-analyses. In the Carstoniu 1994 study, data were not reported in a form that could be included in the meta-analyses (only in figures). In Shao 2000 and Wang 1994, the data are limited in the translation of the papers, which were not published in English. We included only the data of the first period before the first cross over for the Wee 1993 cross-over trial, because the data from the second and third periods were incomplete. Wee 1993 was analysed as if the trial was a parallel group study design. We used the data from the whole of each intervention period for the following four crossover studies Arora 1992, McGuinness 1984, McLeod 1985 and Yeo 2007 and analysed the data as if it were from a parallel study. We did not combine results from parallel and cross-over studies in the analyses, but analysed these separately.

\section{I) Inhaled analgesia nitrous oxide versus a different type of inhaled analgesia (flurane derivatives)}

\section{Primary outcomes}

\section{Effects of interventions}

\section{1) Pain intensity}

Pain intensity was measured using a VAS from 0 to $100 \mathrm{~mm}$, where 0 corresponds to no pain at all and 100 corresponds to the worst pain. Measurements were taken during the first stage of labour (until pushing occurred) and the data were reported as continuous data. Three studies with 123 measurements of 70 women (Analysis 1.1) reported on this outcome. The three studies were all cross-over trials with an adequate wash-out period of minimum of four exhalations. No period effect was present, because the trials started in active labour with regular contractions to $4 \mathrm{~cm}$ dilatation, during a period of three to five consecutive contractions (McGuinness 1984; McLeod 1985) to one hour (Wee 1993). We could not analyse the outcomes for the first period, before the first cross-over took place, because only the Wee 1993 study gave the individual patient data after correspondence with the trialist. The other two studies (McGuinness 1984; McLeod 1985) did not report on this first period and we did not succeed in contacting the trialist for the original data. The data for a paired analysis were not available. We decided to analyse the studies conservatively, as if the trials had a parallel group design, thereby under-estimating rather than over-estimating any differences between interventions. 
There was substantial heterogeneity indicated by the $\mathrm{I}^{2}$ statistics $\left(\mathrm{Tau}^{2}=32.85, \mathrm{I}^{2}=42 \%\right)$ and therefore we applied a random-effects model. The flurane derivatives group reported a lower intensity of pain compared with the nitrous oxide group (average mean difference (MD) 14.39, 95\% confidence interval (CI) 4.41 to 24.37), Analysis 1.1.

\section{2) Pain relief}

Pain relief was measured using a VAS from 0 to $100 \mathrm{~mm}$ in the first stage of labour where 100 means the most relief. The highest score is the most positive contrary to 'pain intensity' in which the higher scores is more negative. Continuous data on pain relief of women in the first stage of labour were reported from two cross-over trials with 158 measurements of 70 women (Analysis 1.2). The two studies were both cross-over trials with no data available to use for paired analysis. We also decided to analyse these studies in the conservative way. There was substantial heterogeneity indicated by the $\mathrm{I}^{2}$ statistics $\left(\mathrm{Tau}^{2}=24.42, \mathrm{I}^{2}=40 \%\right)$ and therefore, we applied a random-effects model. The Flurane derivatives group reported better pain relief compared with the nitrous oxide group (average MD -16.32, 95\% CI -26.85 to -5.79).

\section{3) Satisfaction with pain relief}

Satisfaction with pain relief scores assesses to what extent women are satisfied with the form of pain relief, rather than scoring the extent of pain itself. Satisfaction of pain relief was measured during the first and second stages of labour as considerable to complete and reported as dichotomous data. A considerable to complete score means the women were satisfied with the amount of pain relief. It was reported in two studies with 98 women (Analysis 1.3). There was no difference in satisfaction with pain relief for women receiving methoxyflurane (continuous (mean $0.22 \%$ ) or intermittent $(0.35 \%)$ ) compared with women receiving nitrous oxide (continuous (41.2\%) or intermittent $(50 \%)$ ) (risk ratio (RR) $0.97,95 \%$ CI 0.80 to 1.18$)$.

\section{4) Satisfaction with pain relief}

This was measured during the second stage of labour as good to excellent and was reported in four studies with 323 women (Analysis 1.4). A good to excellent score means the women were satisfied with the amount of pain relief.There was no difference in satisfaction with pain relief for women receiving nitrous oxide (selfadministered, intermittent or continuous) compared with women receiving an agent from the flurane derivatives group (self-administered or continuous) (RR $0.89,95 \%$ CI 0.78 to 1.01 ).

No trials reported on the following outcomes: sense of control in labour and satisfaction with childbirth experience.

\section{Safety of interventions}

\section{5) Assisted vaginal birth (vacuum extraction or forceps)}

Numbers of assisted vaginal births are given in five studies (Abboud 1981; Abboud 1995; Belfrage 1974; Jones 1969; Stefani 1982) with 371 women (Analysis 1.5). There was substantial heterogeneity indicated by the $\mathrm{I}^{2}$ statistics $\left(\mathrm{I}^{2}=34 \%\right.$, Tau $\left.{ }^{2}=0.10\right)$ and therefore, we applied a random-effects model. There were no differences in assisted vaginal births between women receiving nitrous oxide and those receiving a flurane derivative (average RR 0.71 , $95 \%$ CI 0.44 to 1.15 ). All the trials were conducted in the second stage of labour.

\section{6) Caesarean section}

Caesarean section was reported in one trial (Belfrage 1974) with 98 women (Analysis 1.6). There were no caesarean sections in either group.

\section{7) Amnesia}

Amnesia in women, which was scored as a dichotomous outcome, was reported in three studies with 245 women (Analysis 1.7). There was significant heterogeneity indicated by the $\mathrm{I}^{2}$ statistics $\left(\mathrm{I}^{2}=74 \%, \mathrm{Tau}^{2}=2.76\right)$ and therefore we applied a random-effects model. There was no difference in amnesia between groups with these three trials (average RR $0.26,95 \%$ CI 0.03 to 2.38). We repeated the analysis excluding Abboud 1981 due to using a different flurane derivative, (enflurane instead of desflurane). In the remaining studies of Abboud 1995; Swart 1991, both using desflurane 0.1 to $4.5 \%, \mathrm{I}^{2}=0 \%$, we applied a fixed-effects model. There was less amnesia in nitrous oxide group compared to desflurane group (RR 0.09, 95\% CI 0.02 to 0.48 ).

\section{8) Drowsiness}

Drowsiness in women, which was scored with VAS, 0 to $100 \mathrm{~mm}$, was reported in one study with 18 women (Analysis 1.8). There was no difference in drowsiness between the nitrous oxide group and the Isoflurane group (MD -11.64, 95\% CI -16.04 to 39.32).

\section{9) Nausea}

Nausea in women, which was scored as a dichotomous outcome, was reported in two trials with 98 women (Analysis 1.9). The nitrous oxide group reported more nausea compared with the flurane derivatives group (RR 6.60, 95\% CI 1.85 to 23.52). 


\subsection{0) Vomiting}

Vomiting in women, which was scored as a dichotomous outcome, was reported in three trials with 203 women (Analysis 1.10). There was no difference in vomiting between nitrous oxide group compared with the flurane derivatives group (RR 2.02, 95\% CI 0.75 to 5.46 ).

\subsection{1) Blood loss}

Blood loss in the third stage of labour, which was scored as a continuous outcome in $\mathrm{ml}$, was reported in two studies with 185 women (Analysis 1.11). Data from Abboud 1995 were not reported in a form that could be included in the meta-analysis (mean without standard error). There was no difference in blood loss between groups (MD $6.0 \mathrm{ml}, 95 \% \mathrm{CI}-32.91$ to 44.91, one trial, 105 women).

\subsection{2) Apgar score less than seven at five minutes}

Apgar scores of less than or equal to seven or less than seven at five minutes were reported in five trials with 373 women with single births (Analysis 1.12). There were no differences between groups, although each study used slightly different parameters. Abboud 1981; Belfrage 1974; Cheng 2001 and Stefani 1982 reported the percentages of babies in each group with Apgar scores less than eight at five minutes and Abboud 1995 reported the percentage of babies with Apgar scores less than seven at five minutes. Two babies were reported with an Apgar score of less than eight at five minutes postpartum in the Flurane derivatives group in one study (RR 0.22 , 95\% CI 0.01 to 4.47 ) and none in the nitrous oxide group. There were no low Apgar scores in the other five trials. No trials reported on effect on mother/baby interaction or skin to skin contact of mother and baby within the first hour of birth; breastfeeding at specified time points, i.e. within the first hour of birth and at discharge of the hospital; admission to special care baby unit or neonatal intensive care unit; need for rescue analgesia for mother or baby; poor infant outcomes at long-term follow-up.

\section{Other outcomes}

No trials reported on any cost outcome.

\section{Secondary outcomes}

For the infant

1.13) Neurologic Adaptive Capacity Scores (NACS) lower than 35 at two hours after delivery
NACS were reported in three studies with 170 babies (Analysis 1.13). There were no differences in NACS between groups (RR $1.45,95 \%$ CI 0.91 to 2.33 ).

No trials reported on differences in the one, two, five or 10 minute Apgar scores of the baby.

\section{For the professional}

No trials reported on differences in occupational exposure and toxic effects on reproduction for the professional.

\section{2) Inhaled analgesia (same type) of one strength versus a different strength}

\section{Primary outcomes}

\section{Effects of interventions}

\section{1) Satisfaction with pain relief}

Satisfaction with pain relief during the first stage of labour was scored on an ordinal scale as good to complete and reported in one study with 501 women comparing nitrous oxide $50 \%$ with nitrous oxide $70 \%$ (Analysis 2.1). There was no difference in satisfaction with pain relief as good to complete between groups (RR 1.05, $95 \%$ CI 0.94 to 1.17 ).

\section{2) Satisfaction with pain relief}

Satisfaction with pain relief in the second stage of labour was scored on an ordinal scale as good to complete in one study with 501 women (Analysis 2.2). This study compared nitrous oxide $50 \%$ with nitrous oxide $70 \%$. There was no difference in satisfaction with pain relief as good to complete between groups (RR 0.97, 95\% CI 0.87 to 1.08 ).

No trials reported on effect on mother/baby interaction or skinto-skin contact of mother and baby within the first hour of birth; breastfeeding at specified time points, i.e. within the first hour of birth and at discharge of the hospital; admission to special care baby unit or neonatal intensive care unit; need for rescue analgesia for mother or baby; poor infant outcomes at long-term follow-up; sense of control in labour; satisfaction with childbirth experience.

\section{Other outcomes}

No trials reported on any cost outcome. 
Safety of interventions

\section{3) Caesarean section}

Caesarean section was reported in one study with 501 women comparing nitrous oxide $50 \%$ with nitrous oxide $70 \%$ (Analysis 2.3). There was no difference in caesarean section rate between groups (RR $0.31,95 \%$ CI 0.06 to 1.53 ).

\section{4) Assisted vaginal birth}

Assisted vaginal birth was reported in one study with 501 women comparing nitrous oxide 50\% with nitrous oxide 70\% (Analysis 2.4). There was no difference in assisted vaginal birth rate between groups (RR 0.83, 95\% CI 0.61 to 1.14 ).

\section{5) Vomiting}

Vomiting, scored as a dichotomous outcome, was reported in one study with 501 women comparing nitrous oxide $50 \%$ with nitrous oxide $70 \%$ (Analysis 2.5). There was no difference in vomiting between groups (RR 1.29, 95\% CI 0.86 to 1.94 ).

\section{6) Postpartum haemorrhage}

Postpartum haemorrhage, which was scored as a dichotomous outcome and not defined (probably more than $500 \mathrm{~mL}$ blood loss due to being an English report and international standards), was reported in one study with 501 women comparing nitrous oxide $50 \%$ with nitrous oxide $70 \%$ (Analysis 2.6). There was no difference in postpartum haemorrhage between groups (RR 0.80, 95\% CI 0.38 to 1.70$)$.

\section{7) Hypoxaemia in mother}

Hypoxia of the mother, which was scored as a dichotomous outcome, was reported in one study of 24 women comparing nitrous oxide $50 \%$ with nitrous oxide $70 \%$ (Analysis 2.7). There was no difference in hypoxia of the mother between groups (RR 1.00, $95 \%$ CI 0.07 to 14.21 ).

\section{Secondary outcomes}

No trials reported on the following outcomes: differences in the one, two, five or 10 minute Apgar scores, neurological integrity scale of the newborn, occupational exposure and toxic effects on reproduction for the professional.

\section{3) Inhaled analgesia using one type of delivery system versus a different system}

Primary outcomes

\section{Effects of interventions}

\section{1) Satisfaction with pain relief}

Satisfaction with pain relief during the first stage of labour was scored on an ordinal scale as considerable to complete in one study with 42 women. The study compared nitrous oxide 50\% with nasal supplement of nitrous oxide $50 \%$ versus nitrous oxide $50 \%$ and no supplement (Analysis 3.1). There was no difference in satisfaction with the pain relief between groups (RR 1.18, 95\% CI 0.94 to 1.48$)$.

\section{Other outcomes}

No trials reported on any cost outcome.

\section{Safety of interventions}

\section{2) Caesarean section}

Caesarean section was reported in one study with 26 women ( Analysis 3.2). The study compared methoxyflurane delivered from a Penthrane ${ }^{\circledR}$ analgizer versus methoxyflurane delivered from a Cyprane ${ }^{\circledR}$ inhaler.There was no difference in caesarean section rate between groups (RR 2.60, 95\% CI 0.12 to 58.48).

\section{3) Vomiting (N2O/N2O with nasal supplement)}

Vomiting, which was scored as a dichotomous outcome, was reported in one study with 49 woman (Analysis 3.3). The study compared nitrous oxide $50 \%$ with continuous nasal supplementation of nitrous oxide $50 \%$ versus nitrous oxide $50 \%$ with no inhalation. There was no difference in vomiting between groups (RR $1.76,95 \%$ CI 0.77 to 4.00 ).

\section{4) Vomiting (Penthrane ${ }^{\circledR}$ versus Cyprane ${ }^{\circledR}$ )}

Vomiting, which was scored as a dichotomous outcome, was reported in one study with 26 women (Analysis 3.4). The study compared methoxyflurane delivered from a Penthrane ${ }^{\circledR}$ analgizer versus methoxyflurane delivered from a Cyprane ${ }^{\circledR}$ inhaler. There 
was no difference in vomiting between groups (RR not estimable). There was no vomiting in either group.

\section{5) Postpartum haemorrhage}

Postpartum haemorrhage, which was scored as a dichotomous outcome probably scored above $500 \mathrm{~mL}$ blood loss due to the United States report and international standards, was reported in one study with 26 women (Analysis 3.5). The study compared methoxyflurane delivered from a Penthrane ${ }^{\circledR}$ analgizer versus methoxyflurane delivered from a Cyprane ${ }^{\circledR}$ inhaler. There was no difference in postpartum haemorrhage between groups (RR $0.29,95 \%$ CI 0.01 to 6.50$)$.

\section{6) Mild pre-eclampsia}

Mild pre-eclampsia was reported in one study with 26 women ( Analysis 3.6). The study compared methoxyflurane delivered from a Penthrane ${ }^{\circledR}$ analgizer versus methoxyflurane delivered from a Cyprane ${ }^{\circledR}$ inhaler. There was no difference in mild pre-eclampsia between groups (RR 0.86, 95\% CI 0.06 to 12.28 ).

\section{7) Apgar score less than seven at five minutes (continuous data)}

Apgar score at five minutes was reported in one study with 26 women with 14 observations in Analgizer group and 10 observations in Cyprane group. There were two missing observations in this Cyprane group (Analysis 3.7). The missing data could not be obtained from the original investigators. The study compared methoxyflurane delivered from a Penthrane ${ }^{\circledR}$ analgizer versus methoxyflurane delivered from a Cyprane ${ }^{\circledR}$ inhaler. There was no difference in Apgar scores between groups (MD 0.00, 95\% CI -0.37 to 0.37 ). The two missing data of AS are assumed to be 'not missing at random'. At first we imputed these two missing data and assumed them to be poor outcomes with Apgars scores of six at five minutes. There was still no difference apparent (MD 0.50, $95 \%$ CI -0.30 to 1.30 ). Secondly we imputed these data as means of both nine for the missing data in the Cyprane group (MD 0.00 95\% CI -0.35 to 0.35 ), and still no difference in Apgar Scores was found between groups.

\section{8) Apgar score less than seven at five minutes (continuous data) $\mathrm{N2O/N2O}$ with nasal supplementation}

Apgar score at five minutes was reported in one study with 49 women (Analysis 3.8). The study compared nitrous oxide 50\% versus nitrous oxide $50 \%$ with nasal supplementation of nitrous oxide $50 \%$. There was no difference of Apgar score between groups (MD - $0.30,95 \%$ CI -0.81 to 0.21 ).

\section{Secondary outcomes}

No trials reported on the following outcomes: differences in the one, two, five or 10 minute Apgar scores, neurological integrity scale of the newborn, occupational exposure and toxic effects on reproduction for the professional.

\section{4) Inhaled analgesia versus placebo control/no treatment}

\section{Primary outcomes}

\section{Effects of interventions}

\section{1) Pain intensity (dichotomous)}

Pain intensity during the first stage of labour reported as clear or severe to intense or extreme was reported in two studies with 310 women (Analysis 4.1). There was substantial heterogeneity indicated by the $\mathrm{I}^{2}$ statistics $\left(\mathrm{I}^{2}=51 \%\right.$, Tau $\left.{ }^{2}=1.08\right)$ and therefore we applied a random-effects model. The inhaled analgesia group of nitrous oxide $30 \%$ to $50 \%$ reported less pain compared with the control (O2 100\%) or no treatment group (average RR 0.06, $95 \%$ CI 0.01 to 0.34 ).

\section{2) Pain intensity (continuous)}

Pain intensity in the first stage of labour reported with the VAS (VAS, 0-10) after one hour was reported in one study with 509 women (Analysis 4.2). The study compared nitrous oxide 50\% versus oxide $50 \%$. The nitrous oxide group reported less pain compared with the oxide group (MD -3.50, 95\% CI -3.75 to $3.25)$.

\section{Other outcomes}

No trial reported on cost outcomes.

\section{Safety of interventions}

\section{3) Assisted vaginal birth}

Assisted vaginal birth was reported in one study with 200 women (Analysis 4.3). The study compared nitrous oxide 50\% versus 
no analgesic. There was no difference in assisted vaginal births between groups (RR 1.50, 95\% CI 0.44 to 5.15 ).

\section{4) Caesarean section}

Caesarean section was reported in three studies with 465 women (Analysis 4.4). The studies compared nitrous oxide 30\% to 50\% versus no analgesia or oxygen $100 \%$. There was no difference in caesarean section rate between groups (RR 1.20, 95\% CI 0.75 to 1.91).

\section{5) Vomiting}

Vomiting, which was scored as a dichotomous outcome, was reported in two studies with 619 women (Analysis 4.5). The studies compared nitrous oxide $30 \%$ to $50 \%$ versus oxide $50 \%$ to $100 \%$. The nitrous oxide group reported more vomiting compared with the oxide group (RR 9.05, 95\% CI 1.18 to 69.32).

\section{6 - 4.7 - 4.8) Nausea, dizziness and drowsiness}

Dichotomous data on nausea, dizziness and drowsiness were reported in one study with 509 women (Analysis 4.6, Analysis 4.7, Analysis 4.8). The study compared nitrous oxide $50 \%$ versus oxygen $50 \%$. The nitrous oxide group reported significantly more nausea (RR 43.10, 95\% CI 2.63 to 706.74), dizziness (RR 113.98, 95\% CI 7.09 to 1833.69 ) and drowsiness (RR 77.59, 95\% CI 4.80 to 1254.96 ) compared with the oxygen group.

\section{9) Neonatal asphyxia}

Neonatal asphyxia, which was scored as a dichotomous outcome without definition, was reported in one study with 110 women (Analysis 4.9). The study compared nitrous oxide $30 \%$ to $50 \%$ versus oxygen $100 \%$. There was no difference between groups (RR $1.11,95 \%$ CI 0.26 to 4.73 ).

\subsection{0) Apgar score the same or less than seven at five minutes}

Apgar scores lower than eight at five minutes postpartum were reported in one study with 200 women (Analysis 4.10). The study compared nitrous oxide $50 \%$ versus no analgesic use. There were 4/100 low Apgar scores in the nitrous oxide group and none in the control group, with no difference between groups (RR 9.00, $95 \%$ CI 0.49 to 165.00$)$.

\subsection{1) Apgar score (continuous data at five minutes)}

Apgar scores (continuous data) were reported in one study with 509 women (Analysis 4.11). The study compared nitrous oxide $50 \%$ versus oxygen $50 \%$. There was no difference between groups (MD $0.00,95 \%$ CI -0.13 to 0.13 ).

\section{Secondary outcomes}

No trials reported on the following outcomes: differences in the one, two, five or 10 minute Apgar scores, neurological integrity scale of the newborn, occupational exposure and toxic effects on reproduction for the professional.

\section{5) Inhaled analgesia versus TENS}

\section{Primary outcomes}

\section{Effects of interventions}

\section{1) Satisfaction with pain relief}

Satisfaction with pain relief in the first stage of labour was scored on an ordinal scale as partial to complete and was reported in one study with 20 women (Analysis 5.1). The study compared nitrous oxide $50 \%$ versus TENS. There was no difference between groups (RR $0.56,95 \%$ CI 0.29 to 1.07 ).

\section{2) Pain intensity first stage of labour, ordinal moderate to severe}

Pain intensity in the first stage of labour was scored on an ordinal scale as moderate to severe was reported in one study with 19 women (Analysis 5.2). The study compared nitrous oxide 50\% versus TENS. There was no difference between groups (RR 1.10, $95 \%$ CI 0.84 to 1.45$)$.

\section{Other outcomes}

No trial reported on cost outcomes.

\section{Secondary outcomes}

No trials reported on the following outcomes: differences in the one, two, five or 10 minute Apgar scores, neurological integrity scale of the newborn, occupational exposure and toxic effects on reproduction for the professional. 


\section{Assessment of reporting biases}

Due to the fact that there were not 10 or more studies (as we described in our protocol) in any meta-analysis, assessment of reporting biases (such as publication bias) was not appropriate.

\section{Subgroup analysis and investigation of heterogeneity}

Planned subgroup analyses were not carried out because a complete breakdown of the separate subgroup categories was not provided in the published articles.

\section{Sensitivity analysis}

Planned sensitivity analysis for studies of poor quality, as assessed by 'high risk of concealment of allocation' were not conducted because all studies were assessed as either low or unclear risk of bias for this item.

We could not conduct planned sensitivity analysis for the crossover trials of poor quality, as assessed by high risk of bias of 'correct analysis for cross-over design used' because all studies were assessed as high risk of bias for this item.

\section{ISCUSSION}

\section{Summary of main results}

This review demonstrated that women in labour using flurane derivatives as inhaled analgesia during the first stage of labour reported better pain relief and less intense pain than nitrous oxide, and reported less nausea. However, these findings should be considered with caution because of the way we analysed the data from the cross-over studies. The cross-over studies did not provide data in the form of a correct paired analysis. We were therefore only able to include data in meta-analyses from the whole of each intervention period for four of the studies (Arora 1992; McGuinness 1984; McLeod 1985; Yeo 2007) and from the first period before cross-over for one study (Wee 1993). We therefore analysed the data from the cross-over studies as if they were parallel group trials. The results for flurane derivatives are based on data from 13 studies. However, there was a high level of heterogeneity for the analyses of pain relief and for intensity of pain, and so these results should also be examined with caution. Although we reported on drowsiness with regards to safety of the intervention, we also know that drowsiness is often seen as a beneficial side effect.

This review also demonstrated that women reported less pain intensity for intermittent (self-administered) nitrous oxide 50\% when compared to no analgesia, during the first stage of labour and less intense pain intensity for intermittent (self-administered) nitrous oxide $50 \%$ when compared to oxygen $50 \%$ in the first stage of labour. More vomiting was observed with intermittent (self-administered) nitrous oxide $30 \%$ to $50 \%$ when compared to oxygen $50 \%$ to $100 \%$, and more nausea, dizziness and drowsiness was observed with intermittent (self-administered) nitrous oxide $50 \%$ when compared to oxygen $50 \%$. These results are based on data from three studies. There was a high level of heterogeneity for the analysis of pain intensity for nitrous oxide $50 \%$ versus no analgesia. Therefore, this result should also be examined with caution.

There were no significant differences found for any of the outcomes in the studies comparing one strength versus a different strength of inhaled analgesia, in studies comparing different delivery systems or in the study comparing inhaled analgesia with TENS.

All these conclusions need to be considered in the context of small sample sizes (range 27 to 320); only three trials achieved a sample size of more than 200; blinding to the intervention was hardly possible in many studies, due to the smell of the agent; and many outcomes were only considered in one or two trials in specific groups of comparison. These factors limit the interpretation of the results.

A sensitivity analysis was planned in order to explore the impact of excluding the cross-over trials, assessed as being at a high risk of bias for the item 'correct analysis for cross-over design used', to see if this would make a difference to the overall results. We could not perform this analysis for 'pain intensity' or 'pain relief' because these analyses only included cross-over trials and all of these were at high risk of bias for 'correct analysis for cross-over design used.' The majority of cross-over trials were analysed as if they were parallel group trials, using the data from the overall outcome of the intervention versus the overall outcome of the comparison agent. This statistical method is at high risk of bias due to the conservative way, that studies are under weighted rather than over weighted (Elbourne 2002).

\section{Overall completeness and applicability of evidence}

The completeness and applicability of the evidence is limited from the 26 included trials, with no trial at a low risk of bias on all domains. A weakness of a number of the trials is the inclusion of relatively few outcomes and for all trials omission of clinical safety outcomes for the professional. Although almost all participants across the included trials were considered at low risk of complications because of the following exclusion criteria within the individual trials: major uterine abnormalities, multiple gestation, cardiovascular or respiratory instability and acute or chronic obstetric pathologies such as pre-eclampsia and mostly participants in spontaneous labour, one trial (Chia 1990) explicitly included nulliparous with induced labour in the second part of the study, which was randomised. This trial (Chia 1990) is the only trial in the comparison group 'Inhaled analgesia versus TENS' and therefore, 
it was not possible to assess for subgroup differences. There were also no significant differences found between inhaled analgesia of nitrous oxide $50 \%$ and TENS for the two outcomes analysed. In $19 \%$ of the trials prior or additional use of other analgesia was an exclusion criteria (Carstoniu 1994; Chia 1990; McLeod 1985; Rezaeipour 2008; Talebi 2009). In 50\% of the trials additional or prior use of other analgesia was unclear (Abboud 1981; Abboud 1995; Arora 1992; Cheng 2001; Einarsson 1996; Ji 2002; MRC 1970; Shao 2000; Swart 1991; Wang 1994; Wee 1993; Yeo 2007; Zhang 2001). In $31 \%$ of the trials prior or additional use of other analgesia was available and used by the participants but not controlled for in the analysis of the effect estimate. Due to the fact that use of other analgesia can influence women's perception of the use of inhaled analgesia, results must be taken with caution. The findings of this review may not be applicable to current practice due to the differences in obstetric care in different countries worldwide, especially for low-risk women. Nitrous oxide is relatively inexpensive, has no pungent smell and is easy to administer by the women themselves with the right equipment and circumstances. It can also be used in primary care which means labouring women under supervision of primary care midwives or general practitioners. These births can take place either in a hospital, in a birthing centre or at home.

Inhaled analgesia from the flurane derivatives are also relatively inexpensive depending on which agent is used. They may be more expensive if the agent still has a patent. However, administration of these agents needs to be controlled by a well trained anaesthesia professional in order to ensure the right concentration of the agent and thus prevent unconsciousness or other administration problems. This is probably the main reason why use of flurane derivatives is not widespread and also why little research is done on this form of inhaled analgesia for the management of labour pain.

\section{Quality of the evidence}

The 'Risk of bias' tables (Figure 1; Figure 2) demonstrate that inhaled analgesia has not been consistently subjected to consistent rigorous study. The quality of reporting was poor in over $50 \%$ of trials. The risk of bias was low in respect of randomisation $(27 \%$ and $11 \%)$. In all the other trials randomisation was unclear. Not one trial was rated at a low risk of bias on all domains. For many studies, blinding of participants and personnel was not possible because of the different smells of different agents and the use of different apparatus. In many studies there was no information on blinding, and reporting indicated that the influence on the outcomes was unclear, with only $11 \%$ of the trials being at low risk of this bias. In $50 \%$ of the trials, the rates of follow-up were high, with only a small number of trials reporting a relatively substantial loss of participants. The small numbers of trials within comparisons and lack of high-quality trials suggests there remains insufficient evidence of a consistent treatment effect from inhaled analgesia. We contacted some authors of trials in order to request additional methodological and statistical information. However, only one author responded (Wee 1993).

The quality of evidence was affected by unexplained heterogeneity in some comparisons arising from both the heterogeneity of the clinical interventions, outcome assessments, and study designs. The small numbers of trials within comparisons, and lack of highquality trials prevented further exploration of heterogeneity to assess its impact on treatment effects.

It is questionable whether the findings of the old study of Enrile 1973 can still be generalised to the current situation. Any paper from 1973 that looks at caesarean section rate and postpartum haemorrhage from a generation ago has to now be interpreted in the context of a period when the caesarean section rate was less than $10 \%$, as well as many other changes to clinical practice.

\section{Potential biases in the review process}

We attempted to minimise publication bias. The search was comprehensive and there were no language restrictions. However, some of the articles were in Chinese and Iranian, and although these were translated, it is not possible to rule out the possibility of missed data. The variation in the duration, concentration, administration and concurrent or prior use of other analgesia suggest that inhaled analgesia may not have been therapeutically effective and in some cases may not represent best clinical practice.

\section{Agreements and disagreements with other studies or reviews}

There is no other systematic review with meta-analysis of inhaled analgesia. Nevertheless, there is one other systematic review without meta-analysis of nitrous oxide as inhaled analgesia for relief of labour pain (Rosen 2002). Rosen 2002 included studies that were excluded from this review because we were unable to ascertain the randomisation details or because the trial did not meet our eligibility criteria. Nevertheless, our findings and conclusions concerning the role of inhaled analgesia for the comparisons of nitrous oxide for pain relief in labour are similar (Rosen 2002). Rosen 2002 suggests that inhaled analgesia offers safe, reasonably effective pain relief for many women. However, our review also highlights some of the adverse effects (such as nausea and drowsiness) associated with some types of inhaled analgesia such as nitrous oxide with our meta-analysis.

\section{A U T OR S' CONCLUSIONS}




\section{Implications for practice}

Despite limitations in the 'Risk of bias' assessment of the randomised clinical trials with regards to trial design and representation of the results in the papers, the statistically significant results for reduction in pain intensity and increase in pain relief indicates that inhaled analgesia may be a useful form of pain management for some women in labour. Inhaled analgesia may be beneficial for those women in labour who want to have some form of pharmacological pain relief, without invasive methods. It was not possible to draw any conclusions in relation to poorer outcomes for the newborns or the mothers due to a paucity of evidence.

\section{Implications for research}

Further randomised controlled trials should be adequately powered and include relevant clinical outcomes as described in this review especially for three primary outcomes: 1) sense of control in labour and 2) satisfaction with childbirth and 3) breastfeeding experience of women. Particularly studies without the confounding factor of co-administration of other analgesia, would be very helpful. Moreover, there is a need for improving the quality and relevant, uniform reporting of future cross-over trials to make these trials useful to incorporate in a systematic review. It is highly desirable that authors report the results from each treatment in each period separately (Elbourne 2002). Cost-benefit analysis should be incorporated, whenever possible, into the design of future studies.

\section{ACK NOW LEDGEMENTS}

Special thanks to Judith Rooks (USA midwife and Epidemiologist) and Scott Simmons (Head of Anaesthesia at Mercy Hospital for Women, Melbourne) for their comments on the protocol, and to Winnie Schats (Medical Librarian at the library of the Slotervaart Hospital, Amsterdam) for her help with the comprehensive search of articles in PubMed and EMBASE for background papers.

Also special thanks to Mohammed Othman (Research Associate of the Cochrane Pregnancy and Childbirth Group) for his help assessing risk of bias.

We also thank the following people for their help with translations: Helay Zadran (Rezaeipour 2008); Gillan Lim (Ji 2002); Jing Zhang (Shao 2000); Lily Leung and Josh Annells (Wang 1994).

Thanks to Hans Bor (Statistician at the Department of Primary and Community Care, Radboud University Nijmegen Medical Center) and Roy Elbers (Statistician at the Dutch Cochrane Centre of the AMC, University of Amsterdam), for their statistical advice.

Finally, thanks also to Dr HJ Knape, Anaesthesiologist and Professor at the UMC, University of Utrecht for his advice on the differences and comparisons between the different agents of inhaled analgesia.

As part of the pre-publication editorial process, this review has been commented on by three peers (an editor and two referees who are external to the editorial team) and the Group's Statistical Adviser.

\section{R E F E R E N C E S}

\section{References to studies included in this review}

Abboud 1981 \{published data only\}

Abboud TK, Shnider SM, Wright RG, Rolbin SH, Craft

$\mathrm{JB}$, Henriksen EH, et al.Enflurane analgesia in obstetrics. Anesthesia and Analgesia 1981;60:133-7.

Abboud 1995 \{published data only\}

Abboud TK, Swart F, Zhu J, Donovan MM, Peres Da Silva E, Yakal K. Desflurane analgesia for vaginal delivery. Acta Anaesthesiologica Scandinavica 1995;39:259-61.

Arora 1992 \{published data only\}

Arora S, Tunstall M, Ross J. Self-administered mixture of Entonox and isoflurane in labour. International Journal of Obstetric Anesthesia 1992;1(4):199-202.

Arthurs 1979 \{published data only\}

Arthurs GJ, Rosen M. Self administered intermittent nitrous oxide analgesia for labour: enhancement of effect with continuous nasal inhalation of $50 \%$ nitrous oxide (Entonox). Anaesthesia 1979;34:301-9.

Belfrage 1974 \{published data only\}

Belfrage P, Carls H, Raabe N. Methoxyflurane (Penthrane) or nitrous oxide as agents of analgesia in childbirth?
[Metoxifluran (Penthrane) eller lustgas som analgesimedel vid forlossningar?]. Lakartidningen 1974;71(1):73-4.

\section{Bergsjo 1971 \{published data only\}}

Bergsjo P, Lindbaek E. Comparison between nitrous oxide and methoxyflurane for obstetrical analgesia. Acta Obstetricia et Gynecologica Scandinavica 1971;50:285-90.

Carstoniu 1994 \{published data only\}

* Carstoniu J, Levytam S, Norman P, Daley D, Katz J, Sandler AN. Nitrous oxide in early labor: safety and analgesic efficacy assessed by a double-blind, placebocontrolled study. Anesthesiology 1994;80:30-5.

Carstoniu J, Norman P, Daley D, Katz J, Levytan S, Sandler AN. Nitrous oxide in labour: safety and efficacy assessed by a double blind placebo controlled study. Anesthesiology 1992;77:Abstract no: A987.

Carstoniu J, Norman P, Sandler AN, Katz J. Nitrous oxide in labour: Safety and efficacy assessed by a double-blind, placebo controlled study. Canadian Journal of Anaesthesia 1992;39:A50

Cheng 2001 \{published data only\} Cheng G, Zhang X, Zhai Z, Jiang L. Neonatal 
neurobehavioral effects of inhalating isoflurane for analgesia in vaginal delivery. Journal of Henan Medical University 2001;36(1):13-6.

Chia 1990 \{published data only\}

Chia YT, Arulkumaran S, Chua S, Ratnam SS. Effectiveness of transcutaneous electric nerve stimulator for pain relief in labour. Asia-Oceania Journal of Obstetrics and Gynaecology 1990;16:145-51.

Einarsson 1996 \{published data only\}

* Einarsson S, Bengtsson A, Stenqvist O, Noren H, Bengtson JP. N20 analgesia and risk of diffusion hypoxia during first stage of labour. Acta Anaesthesiologica Scandinavica 1995; 39:167.

Einarsson S, Stenqvist O, Bengtsson A, Noren H, Bengtson JP. Gas kinetics during nitrous oxide analgesia for labour. Anaesthesia 1996;51(5):449-52.

Enrile 1973 \{published data only\} Enrile LL, Roux JF, Wilson R, Leherz TB. Methoxyflurane (penthrane) inhalation in labor. Obstetrics \& Gynecology 1973;41:860-4.

Ji 2002 \{published data only\}

Ji X, Qi H, Liu A. Clinical study on labor pain relief using the combined spinal-epidural analgesia and inhaling nitrous oxide. Chung-Hua Fu Chan Ko Tsa Chih [Chinese Journal of Obstetrics and Gynecology] 2002;37(7):398-401.

Jones 1969 \{published data only\}

Jones PL, Rosen M, Mushin WW, Jones EV. Methoxyflurane and nitrous oxide as obstetric analgesics. I. A comparison by continuous administration. British Medical Journal 1969;3: $255-9$.

Jones 1969a \{published data only\}

Jones PL, Rosen M, Mushin WW, Jones EV. Methoxyflurane and nitrous oxide as obstetric analgesics. II. A comparison by self-administered intermittent inhalation. British Medical Journal 1969;3:259-62.

McGuinness 1984 \{published data only\}

McGuinness C, Rosen M. Enflurane as an analgesic in labour. Anaesthesia 1984;39:24-6.

McLeod 1985 \{published data only\} McLeod DD, Ramayya GP, Tunstall ME. Self-administered isoflurane in labour. A comparative study with Entonox. Anaesthesia 1985;40:424-6.

MRC 1970 \{published data only\}

Medical RC. Clinical trials of different concentrations of oxygen and nitrous oxide for obstetric analgesia. British Medical Journal 1970;1:709-13.

Rezaeipour 2008 \{published data only\}

Rezaeipour A, Idenloo F, Khakbazan Z, Kazemnejad A. The effects of entonox on implication of painless labor and delivery satisfaction rate among pregnant women. Hayat: Faculty of Nursing \& Midwifery Quarterly 2008;13(4): $45-58$.

Shao 2000 \{published data only\} Shao HJ, Lu XR, Cheng WJ, Zhang B, Zheng HX. Clinical study on analgesic labor with inhaling laughing gas. Chinese
Journal of Practical Gynecology and Obstetrics 2000;16(2):

$83-5$.

Stefani 1982 \{published data only\}

Stefani SJ, Hughes SC, Shnider SM, Abboud TK, Henriksen $\mathrm{EH}$, Williams $\mathrm{V}$, et al.Neonatal neurobehavioral effects of inhalation analgesia for delivery. Anesthesiology 1980;53:

S314.

* Stefani SJ, Hughes SC, Shnider SM, Levinson G, Abboud TK, Henriksen EH, et al.Neonatal neurobehavioral effects of inhalation analgesia for vaginal delivery. Anesthesiology 1982;56:351-5.

Swart 1991 \{published data only\}

Swart F, Abboud TK, Zhu J, Donovan M, Peres da Silva E, Justice A, et al.Desflurane analgesia in obstetrics: maternal and neonatal effects. Anesthesiology 1991;75:A844.

Talebi 2009 \{published data only\}

Talebi H, Nourozi A, Jamilian M, Baharfar N, EghtesadiAraghi P. Entonox for labor pain: a randomized placebo controlled trial. Pakistan Journal of Biological Sciences 2009; 12(17):1217-21.

Wang 1994 \{published data only\}

Wang B, Zhang X, Wei L. Application of nitrous oxide in labor analgesia. Chinese Journal of Obstetrics \& Gynecology 1994;29:330-1.

Wee 1993 \{published data only\}

Wee MYK, Hasan MA, Thomas TA. Isoflurane in labour. Anaesthesia 1993;48:369-72.

Yeo 2007 \{published data only\}

Yeo S, Good M, Brennan C, Yentis SM, Holdcroft A. Sevoflurane vs Entonox during labour contractions. International Journal of Obstetric Anesthesia 2004;13(3):S9. * Yeo ST, Holdcroft A, Yentis SM, Stewart A, Bassett P. Analgesia with sevoflurane during labour: II. sevoflurane compared with entonox for labour analgesia. British Journal of Anaesthesia 2007;98(1):110-5.

Zhang 2001 \{published data only\} Zhang X, Wang B, Cheng GM, Wei L, Wang Z. Inhalation of nitrous oxide for labor analgesia and its effects on mothers and infants. Journal of Henan Medical University 2001;36 (1):7-9.

\section{References to studies excluded from this review}

Arozenius 1980 \{published data only\} Arozenius S, Dahlgren BE, Lindwall L, Akerlind I. A comparison of the analgesic effects of methoxyfluranenitrous oxide and nitrous oxide alone during labour related to the eysenck personality inventory test. Acta Obstetricia et Gynecologica Scandinavica 1980;59(3):203-7.

Arthurs 1981 \{published data only\} Arthurs GJ, Rosen M. Acceptability of continuous nasal nitrous oxide during labour - a field trial in six maternity hospitals. Anaesthesia 1981;36:384-8.

Chessor 2005 \{published data only\} Chessor E, Verhoeven M, Hon CY, Teschke K. Evaluation of a modified scavenging system to reduce occupational 
exposure to nitrous oxide in labor and delivery rooms. Journal of Occupational and Environmental Hygiene 2005;2 (6):314-22. [PUBMED: 16020092]

Clark 1979 \{published data only\}

Clark RB, Beard AG, Thompson DS. Renal function in newborns and mothers exposed to methoxyflurane analgesia for labor and delivery. Anesthesiology 1979;51:464-7.

Cosmi 1969 \{published data only\} Cosmi EV, Marx GF. The effect of anesthesia on the acidbase status of the fetus. Anesthesiology 1969;30:238-42.

Crawford 1975 \{published data only\}

Crawford JS, Davies P. A return to trichloroethylene for obstetric anaesthesia. British Journal of Anaesthesia 1975;47: 482-90.

Creasser 1974 \{published data only\}

Creasser CW, Stoelting RK, Krishna G, Peterson C. Methoxyflurane metabolism and renal function after methoxyflurane analgesia during labor and delivery. Anesthesiology 1974;41:62-6.

Davies 1974 \{published data only\}

Davies JM, Hogg MIJ, Rosen M. Upper limits of resistance of apparatus for inhalation analgesia during labour. British Journal of Anaesthesia 1974;46:136-44.

Davies 1975 \{published data only\} Davies JM, Hogg M, Rosen M. Maternal arterial oxygen tension during intermittent inhalation analgesia. British Journal of Anaesthesia 1975;47:370-8.

Howell 2001 \{published data only\}

Howell CJ, Kidd C, Roberts W, Upton P, Lucking L, Jones PW, et al.A randomised controlled trial of epidural compared with non-epidural analgesia in labour. BJOG: an international journal of obstetrics and gynaecology 2001;108 (1):27-33. [PUBMED: 11213000]

Krantz 1974 \{published data only\}

Krantz ML. Ketamine in obstetrics: comparison with methoxyflurane. Anesthesia and Analgesia 1974;53:890-3.

Major 1966 \{published data only\}

Major V, Rosen M, Mushin WW. Methoxyflurane as an obstetric analgesic: a comparison with trichloroethylene. British Medical Journal 1966;2:1554-61.

Major 1967 \{published data only\}

Major V, Rosen M, Mushin WW. Concentration of methoxyflurane for obstetric analgesia by self-administered intermittent inhalation. British Medical Journal 1967;4: $767-70$.

McAneny 1963 \{published data only\}

McAneny TM, Doughty AG. Self-administered nitrousoxide/oxygen analgesia in obstetrics With particular reference to the 'Lucy Baldwin' machine. Anaesthesia 1963; 18(4):488-97.

Phillips 1971 \{published data only\}

Phillips TJ, Macdonald RR. Comparative effect of pethidine, trichloroethylene, and entonox on fetal and neonatal acid-base and po2. British Medical Journal 1971;3 (774):558-60.
Roberts 1957 \{published data only\}

Roberts H, Kane KM, Percival N, Snow P, Please NW. Effects of some analgesic drugs used in childbirth with special reference to variation in respiratory minute volume of the newborn. Lancet 1957;1:128-32.

Robinson 1980 \{published data only\} Robinson JO, Rosen M, Evans JM, Revill SI, David H, Rees GAD. Maternal opinion about analgesia for labour. A controlled trial between epidural block and intramuscular pethidine combined with inhalation. Anaesthesia 1980;35: 1173-81.

Rosen 1969 \{published data only\}

* Rosen M, Mushin WW, Jones PL, Jones EV. Field trial of methoxyflurane, nitrous oxide, and trichloroethylene as obstetric analgesics. British Medical Journal 1969;3:263-7. Rosen M, Mushin WW, Jones PL, Jones EV. Methoxyflurane for obstetric analgesia. British Medical Journal 1969;4: 432-3.

\section{Rosen 1972 \{published data only\}}

Rosen M, Latto P, Asscher AW. Kidney function after methoxyflurane analgesia during labour. British Medical Journal 1972;1:81-3.

Shnider 1963 \{published data only\} Shnider SM, Moya F, Thorndike V, Bossers A, Morishima $\mathrm{H}$, James LS. Clinical and biochemical studies of cyclopropane analgesia in obstetrics. Anesthesiology 1963; 24:11-7.

Volmanen 2005 \{published data only\}

* Volmanen P, Akural E, Raudakoski T, Ohtonen P, Alahuhta S. Comparison of remifentanil and nitrous oxide in labour analgesia. Acta Anaesthesiologica Scandinavica 2005;49:453-8.

Volmanen P, Akural E, Raudaskoski, Alahuhta S. Comparison of maternal haemodynamic effects and respiratory indices during remifentanil and nitrous oxide labour analgesia. International Journal of Obstetric Anesthesia 2004;13(3):S19.

\section{References to studies awaiting assessment}

Su 2002 \{published data only\}

Su F, Wei X, Chen X, Hu Z, Xu H. Clinical study on efficacy and safety of labor analgesia with inhalation of nitrous oxide in oxygen. Zhonghua fu chan ke za zhi 2002; 37(10):584-7. [PUBMED: 12487929]

\section{Additional references}

\section{Ahlborg 1996}

Ahlborg G Jr, Axelsson G, Bodin L. Shift work, nitrous oxide exposure and subfertility among Swedish midwives. International Journal of Epidemiology 1996;25(4):783-90. [PUBMED: 8921457]

Anim-Somuah 2005

Anim-Somuah M, Smyth RMD, Howell CJ. Epidural versus non-epidural or no analgesia in labour. Cochrane Database of Systematic Reviews 2005, Issue 4. [DOI: 10.1002/14651858.CD000331.pub2] 


\section{Anim-Somuah 2011}

Anim-Somuah M, Smyth RMD, Jones L. Epidural versus non-epidural or no analgesia in labour. Cochrane Database of Systematic Reviews 2011, Issue 12. [DOI: 10.1002/ 14651858.CD000331.pub3]

\section{Axelsson 1996}

Axelsson G, Ahlborg G Jr, Bodin L. Shift work, nitrous oxide exposure, and spontaneous abortion among Swedish midwives. Occupational and Environmental Medicine 1996; 53(6):374-8. [PUBMED: 8758031]

\section{Barragán 2011}

Barragán LIM, Solà I, Juandó PC. Biofeedback for pain management during labour. Cochrane Database of Systematic Reviews 2011, Issue 6. [DOI: 10.1002/ 14651858.CD006168.pub2]

\section{Bodin 1999}

Bodin L, Axelsson G, Ahlborg G Jr. The association of shift work and nitrous oxide exposure in pregnancy with birth weight and gestational age. Epidemiology (Cambridge, Mass.) 1999;10(4):429-36. [PUBMED: 10401879]

\section{Boivin 1997}

Boivin JF. Risk of spontaneous abortion in women occupationally exposed to anaesthetic gases: a meta-analysis. Occupational and Environmental Medicine 1997;54(8): 541-8. [PUBMED: 9326157]

\section{Caton 2002}

Caton D, Corry MP, Frigoletto FD, Hopkins DP, Lieberman E, Mayberry L, et al.The nature and management of labor pain. American Journal of Obstetrics and Gynecology 2002; 186(5 Suppl Nature):S1-S15. [PUBMED: 12011869]

\section{Cluett 2009}

Cluett ER, Burns E. Immersion in water in labour and birth. Cochrane Database of Systematic Reviews 2009, Issue 2. [DOI: 10.1002/14651858.CD000111.pub3]

\section{Declercq 2007}

Declercq ER, Sakala C, Corry MP, Applebaum S. Listening to Mothers II: Report of the Second National U.S. Survey of Women's Childbearing Experiences: Conducted JanuaryFebruary 2006 for Childbirth Connection by Harris Interactive(R) in partnership with Lamaze International. Journal of Perinatal Education: an ASPO/Lamaze publication 2007;16(4):9-14. [PUBMED: 18769512]

\section{Deeks 2001}

Deeks JJ, Altman DG, Bradburn MJ. Statistical methods for examining heterogeneity and combining results from several studies in meta-analysis. In: Egger M, Davey Smith G, Altman DG editor(s). Systematic Reviews in Health Care: Meta-analysis in Context. London: BMJ Books, 2001.

\section{Derry 2012}

Derry S, Straube S, Moore RA, Hancock H, Collins SL. Intracutaneous or subcutaneous sterile water injection compared with blinded controls for pain management in labour. Cochrane Database of Systematic Reviews 2012, Issue 1. [DOI: 10.1002/14651858.CD009107.pub2]

\section{DerSimonian 2007}

DerSimonian R, Laird N. Random-effects model for metaanalysis of clinical trials: an update. Contemporary Clinical Trials 2007;28:105-14.

\section{DOH 2005}

Government Statistical Service for the Department of Health. Statistical Bulletin - NHS Maternity Statistics, England: 2003-2004. London, UK: Department of Health, 2004.

\section{Dowswell 2009}

Dowswell T, Bedwell C, Lavender T, Neilson JP. Transcutaneous electrical nerve stimulation (TENS) for pain management in labour. Cochrane Database of Systematic Reviews 2009, Issue 2. [DOI: 10.1002/ 14651858.CD007214.pub2]

\section{Egger 1997}

Egger M, Smith GD, Phillips AN. Meta-analysis: principles and procedures. BMJ 1997;315(7121):1533-7.

Elbourne 2002

Elbourne DR, Altman DG, Higgins JPT, Curtin F, Vaillancourt JM. Meta-analyses involving cross-over trials: methodological issues. International Journal of Epidemiology 2002;31:140-9.

\section{Harbord 2006}

Harbord RM, Egger M, Sterne JA. A modified test for small-study effects in meta-analyses of controlled trials with binary endpoints. Statistics in Medicine 2006;25:3443-57.

\section{Higgins 2011}

Higgins JPT, Green S, editors. Cochrane Handbook for Systematic Reviews of Interventions Version 5.1.0 [updated March 2011]. The Cochrane Collaboration, 2011. Available from www.cochrane-handbook.org.

\section{Hozo 2005}

Hozo SP, Djulbegovic B, Hozo I. Estimating the mean and variance from median, range, and the size of sample. $B M C$ Medical Research Methodology 2005;5:13.

Jones 2011

Jones L, Dou L, Dowswell T, Alfirevic Z, Neilson JP. Pain management for women in labour: generic protocol. Cochrane Database of Systematic Reviews 2011, Issue 6. [DOI: 10.1002/14651858.CD009167]

\section{Jones 2012}

Jones L, Othman M, Dowswell T, Alfirevic Z, Gates S, Newburn M, et al.Pain management for women in labour: an overview of systematic reviews. Cochrane Database of Systematic Reviews 2012, Issue 3. [DOI: 10.1002/ 14651858.CD009234.pub2]

\section{Khor 2000}

Khor LJ, Jeskins G, Cooper GM, Paterson-Brown S. National obstetric anaesthetic practice in the UK 1997/ 1998. Anaesthesia 2000;55(12):1168-72. [PUBMED: 11121925]

\section{KNOV 2009}

KNOV werkgroep Entonox. The use of Relivopan in primary care obstetrics [Adviesrapport: Het gebruik van 
Relivopan in de eerstelijns verloskunde]. Adviesrapport 2009; Vol. 3.

\section{Likert 1932}

Likert R. A technique for the measurement of attitudes. Archives of Psychology 1932;22:1-55.

Lowe 2002

Lowe NK. The nature of labor pain. American Journal of Obstetrics and Gynecology 2002;186(5 Suppl Nature): S16-24. [PUBMED: 12011870]

\section{Madden 2011}

Madden K, Middleton P, Cyna AM, Matthewson M. Hypnosis for pain management during labour and childbirth. Cochrane Database of Systematic Reviews 2011, Issue 10. [DOI: 10.1002/14651858.CD009356]

Maze 2000

Maze M, Fujinaga M. Recent advances in understanding the actions and toxicity of nitrous oxide. Anaesthesia 2000; Vol. 55, issue 4:311-4. [PUBMED: 10781114]

\section{Minnitt 1934}

Minnitt R. Self-administered anaesthesia in childbirth. British Medical Journal 1934;1:501-3.

\section{Novikova 2011}

Novikova N, Cluver C. Local anaesthetic nerve block for pain management in labour. Cochrane Database of Systematic Reviews 2011, Issue 7. [DOI: 10.1002/ 14651858.CD009200]

\section{Osterman 2011}

Osterman MJ, Martin JA. Epidural and spinal anesthesia use during labor: 27-state reporting area, 2008. National vital statistics reports: from the Centers for Disease Control and Prevention, National Center for Health Statistics, National Vital Statistics System 2011;59(5):1-13, 16. [PUBMED: 21553556]

\section{Othman 2011}

Othman M, Jones L, Neilson JP. Non-opioid drugs for pain management in labour. Cochrane Database of Systematic Reviews 2011, Issue 7. [DOI: 10.1002/ 14651858.CD009223]

\section{PRN 2008}

Perinatal Care in the Netherlands [Perinatale zorg in Nederland]. The Netherlands Perinatal Registration. http://www.perinatreg.nl/uploads/150/122/ Jaarboek 'Zorg ' in 'Nederland 2008.PDF (accessed August 2011) April 2009.

Rae 1997

Rae S, Wildsmith J. So just who was James "Young" Simpson?. British Journal of Anaesthesia 1997;79:271-3.

\section{RevMan 2011}

The Nordic Cochrane Centre, The Cochrane Collaboration. Review Manager (RevMan). 5.1. Copenhagen: The Nordic Cochrane Centre, The Cochrane Collaboration, 2011.

\section{Richards 1976}

Richards W, Parbrook GD, Wilson J. Stanislav Klikovich (1853-1910). Pioneer of nitrous oxide and oxygen analgesia. Anaesthesia 1976;31(7):933-40.
Rooks 2007

Rooks JP. Nitrous oxide for pain in labor--why not in the United States?. Birth (Berkeley, Calif.) 2007; Vol. 34, issue 1:3-5. [PUBMED: 17324171]

\section{Rooks 2011}

Rooks JP. Safety and risks of nitrous oxide labor analgesia: a review. Journal of Midwifery \& Women's Health 2011;56(6): 557-65. [PUBMED: 22060215]

\section{Rosen 2002}

Rosen MA. Nitrous oxide for relief of labor pain: a systematic review. American Journal of Obstetrics and Gynecology 2002;186(5 Suppl Nature):S110-S126. [PUBMED: 12011877]

\section{Rowland 1992}

Rowland AS, Baird DD, Weinberg CR, Shore DL, Shy CM, Wilcox AJ. Reduced fertility among women employed as dental assistants exposed to high levels of nitrous oxide. New England Journal of Medicine 1992;327(14):993-7. [PUBMED: 1298226]

\section{Sanders 2008}

Sanders RD, Weimann J, Maze M. Biologic effects of nitrous oxide: a mechanistic and toxicologic review. Anesthesiology 2008;109(4):707-22. [PUBMED: 18813051]

\section{Simmons 2007}

Simmons SW, Cyna AM, Dennis AT, Hughes D. Combined spinal-epidural versus epidural analgesia in labour. Cochrane Database of Systematic Reviews 2007, Issue 3. [DOI: 10.1002/14651858.CD003401.pub2]

Smith 2011a

Smith CA, Collins CT, Crowther CA. Aromatherapy for pain management in labour. Cochrane Database of Systematic Reviews 2011, Issue 7. [DOI: 10.1002/ 14651858.CD009215]

\section{Smith 2011b}

Smith CA, Collins CT, Crowther CA, Levett KM. Acupuncture or acupressure for pain management in labour Cochrane Database of Systematic Reviews 2011, Issue 7. [DOI: 10.1002/14651858.CD009232]

\section{Smith 2011c}

Smith CA, Levett KM, Collins CT, Crowther CA Relaxation techniques for pain management in labour. Cochrane Database of Systematic Reviews 2011, Issue 12. [DOI: 10.1002/14651858.CD009514]

\section{Smith 2011d}

Smith CA, Levett KM, Collins CT, Jones L. Massage, reflexology and other manual methods for pain management in labour. Cochrane Database of Systematic Reviews 2012, Issue 2. [DOI: 10.1002/14651858.CD009290.pub2]

\section{Sterne 2001}

Sterne JA, Egger M, Smith GD. Systematic reviews in health care: investigating and dealing with publication and other biases in meta-analysis. BMJ 2001;323(7304):101-5.

Ullman 2010

Ullman R, Smith LA, Burns E, Mori R, Dowswell T. Parenteral opioids for maternal pain management in labour. 
Cochrane Database of Systematic Reviews 2010, Issue 9.

[DOI: 10.1002/14651858.CD007396.pub2]

Zielhuis 1999

Zielhuis G, Peelen SJ, Florack EI, Roeleveld N. Hospital

work and fecundability. Scandinavian Journal of Work,

Environment \& Health 1999;25 Suppl 1:47-8. [PUBMED:

10235410]

* Indicates the major publication for the study 


\section{CHARACTERISTICS OF STUDIES}

\section{Characteristics of included studies [ordered by study ID]}

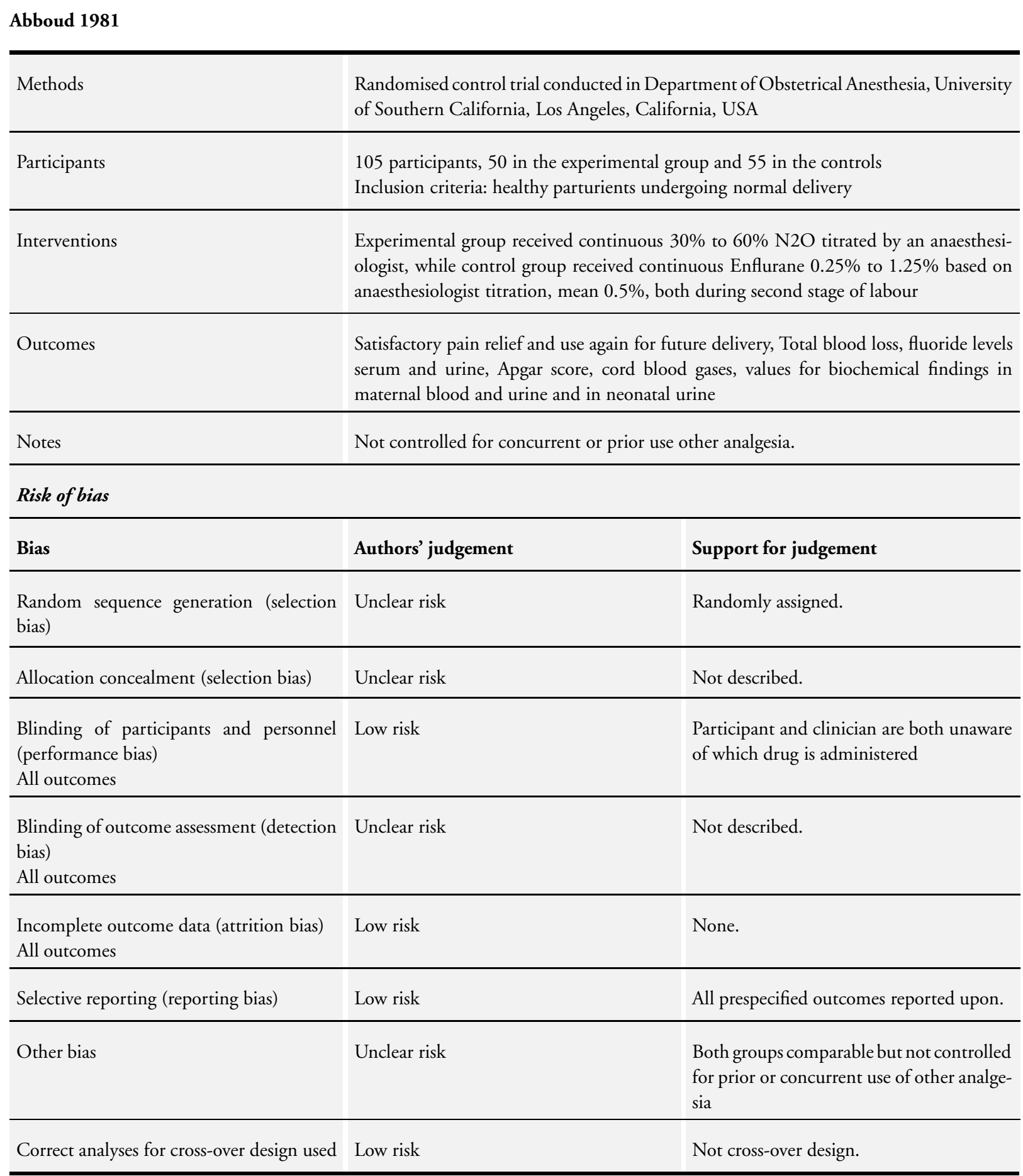

Inhaled analgesia for pain management in labour (Review) 
Abboud 1995

Methods $\begin{array}{ll}\text { Coun } & \\ \text { USA }\end{array}$

Randomised control trial conducted in Department of Anesthesiology, Los Angeles County and University of Southern California Medical Center, Los Angeles, California,

80 participants, 40 in each group.

Inclusion criteria: healthy parturients undergoing normal vaginal delivery

Exclusion criteria: any clinical significant history of gastrointestinal hepatic, renal, endocrine or respiratory disease, convulsive or neurological disorder, fetal distress, any history of chronic alcohol or drug use

Interventions

Experimental group received Desflurane $1 \%$ to $4.5 \%$ and oxygen during second stage of labour, while control group received nitrous oxide, $30 \%$ to $60 \%$ oxygen during second stage of labour

Outcomes

Patient, anaesthesiologist and obstetrician assessment of quality of pain relief. Patient willingness to receive again the same agent. Blood loss estimated the obstetrician, Apgar score at 1 and 5 minutes, cord acid base status and NASC at 2 and 24 hours of age of the baby, $\mathrm{Hb}, \mathrm{Ht}$, before use of analgesia and after 12 and 24 hours postpartum, osmolality and sodium ion concentrations of urine of the mother at the same time postpartum

Notes

No information regarding concurrent or prior use of analgesia

\section{Risk of bias}

\begin{tabular}{|c|c|c|}
\hline Bias & Authors' judgement & Support for judgement \\
\hline $\begin{array}{l}\text { Random sequence generation (selection } \\
\text { bias) }\end{array}$ & Low risk & $\begin{array}{l}\text { Randomly assigned using computer gener- } \\
\text { ated randomisation table }\end{array}$ \\
\hline Allocation concealment (selection bias) & Unclear risk & Not described. \\
\hline $\begin{array}{l}\text { Blinding of participants and personnel } \\
\text { (performance bias) } \\
\text { All outcomes }\end{array}$ & Low risk & $\begin{array}{l}\text { Patient, obstetrician and paediatrician un- } \\
\text { aware of drug. }\end{array}$ \\
\hline $\begin{array}{l}\text { Blinding of outcome assessment (detection } \\
\text { bias) } \\
\text { All outcomes }\end{array}$ & Unclear risk & Not described. \\
\hline $\begin{array}{l}\text { Incomplete outcome data (attrition bias) } \\
\text { All outcomes }\end{array}$ & Low risk & None. \\
\hline Selective reporting (reporting bias) & Low risk & All prespecified outcomes reported upon. \\
\hline Other bias & Unclear risk & $\begin{array}{l}\text { Both groups comparable but not controlled } \\
\text { for prior or concurrent use of other analge- } \\
\text { sia }\end{array}$ \\
\hline Correct analyses for cross-over design used & Low risk & Not cross-over design. \\
\hline
\end{tabular}

Inhaled analgesia for pain management in labour (Review) 
Arora 1992

Methods

Single cross-over study conducted in Department of Anaesthetics, Aberdeen Royal Infirmary, Foresterhill, Aberdeen, UK

Participants

39 participants, 20 in the experiment group and 19 in the controls

Inclusion criteria: patients in normal labour with regular painful uterine contractions who required inhalation analgesia.

Interventions

Experimental group received Entonox-isoflurane 0.25\%, while control group received Entonox (50\% nitrous oxide premixed in oxygen) in first stage of labour during 5 consecutive contractions

Outcomes

Pain relief, patient's responsiveness, patient's cooperation, reaction to odour and any adverse effects

Notes

$6^{\text {th }}$ contraction wash-out period with room air (supposed to be minimal 4 exhalation)

Afterwards trial there was use of other anaesthetics during labour

No information regarding concurrent or prior use of analgesia

\section{Risk of bias}

Bias

Authors' judgement

Support for judgement

Random sequence generation (selection Low risk

Random number sequence.

bias)

\begin{tabular}{|c|c|c|}
\hline Allocation concealment (selection bias) & Unclear risk & Not described. \\
\hline $\begin{array}{l}\text { Blinding of participants and personnel } \\
\text { (performance bias) } \\
\text { All outcomes }\end{array}$ & Unclear risk & $\begin{array}{l}\text { The Oxford Miniature Vaporizer (OMV) } \\
\text { was concealed in a box from the view of } \\
\text { both investigator and mother but } 1 \text { agent } \\
\text { has a particular smell (blinding not possi- } \\
\text { ble), unclear }\end{array}$ \\
\hline
\end{tabular}

Blinding of outcome assessment (detection Unclear risk

Not described.

bias)

All outcomes

Incomplete outcome data (attrition bias) Low risk All outcomes

2 women, unable to come to any decision on a linear analogue scale scores for pain relief

Selective reporting (reporting bias) High risk

Baby outcomes not clear.

Other bias

Unclear risk

None apparent but not controlled for prior or concurrent use of other analgesia

Correct analyses for cross-over design used High risk

Paired samples using Wilcoxon Rank Sum Test but mean/SD for experimental intervention alone and control (intervention)

Inhaled analgesia for pain management in labour (Review) 


\section{Arthurs 1979}

Methods

Participants

Interventions

Outcomes

Notes
This trial was conducted in Maelor General Hospital, Wrexham, UK. 3 studies were conducted in this trial:

Kinetic studies: observational study, the expired concentration of nitrous oxide was measured and recorded continuously with a mass spectrometer to measure the maximum concentrations and the end-tidal nitrous oxide concentration and its effects on mothers and babies

Within patient studies: observational study to measure patient preference.

Between patient studies: randomised trial, comparing self-administration of Entonox with a nasal supplement of Entonox with self-administration of Entonox with no nasal supplement for the evaluation of pain, mothers opinion, midwives opinion, acceptability of nasal catheter and maximum tolerable flow

49 participants 24 in the study group and 25 in the control group

Experiment group received self-administered Entonox and continuous nasal supplement of Entonox and controls received self-administered Entonox and no continuous nasal inhalation, probably during first and second stage of labour ("recording until delivery")

Pain on linear analogue after 2, 4, 6 contractions, pain rated immediately after delivery and between 24 and 48 hours later, how much inhalation helped, satisfaction with pain relief (memory of pain in labour), nausea and vomiting, caesarean section, Apgar score - mean at 1 and 5 minutes, pain relief as assessed by midwives

Only data from between patient studies used in this review.

Opiods also available.

\section{Risk of bias}

\section{Bias}

Random sequence generation (selection Unclear risk bias)

Allocation concealment (selection bias) Unclear risk

Blinding of participants and personnel Unclear risk (performance bias)

All outcomes

Blinding of outcome assessment (detection Unclear risk bias)

All outcomes

\section{Support for judgement}

Randomly allocated.

Not reported.

Not reported.

Not reported. 
Arthurs 1979 (Continued)

\begin{tabular}{|c|c|c|}
\hline $\begin{array}{l}\text { Incomplete outcome data (attrition bias) } \\
\text { All outcomes }\end{array}$ & Unclear risk & Not reported. \\
\hline Selective reporting (reporting bias) & High risk & $\begin{array}{l}\text { Pain data after } 6 \text { contractions and immedi- } \\
\text { ately after delivery not reported }\end{array}$ \\
\hline Other bias & Unclear risk & $\begin{array}{l}\text { Baseline characteristics seems comparable } \\
\text { but other opioids also available and no in- } \\
\text { formation of the use of these other analge- } \\
\text { sia }\end{array}$ \\
\hline Correct analyses for cross-over design used & Low risk & Not cross-over design. \\
\hline
\end{tabular}

\section{Belfrage 1974}

\begin{tabular}{ll}
\hline Methods & Randomised trial conducted in Karolinska Sjukhuset Hospital, Stockholm, Sweden \\
\hline Participants & 98 participants, 47 in the experiment group and 51 in the control group \\
\hline Interventions & $\begin{array}{l}\text { Experiment group received } 0.3 \% \text { to } 0.8 \% \text { of Methoxyflurane and controls received } \\
\text { nitrous oxide } 70 \% \text { with } 30 \% \text { oxygen in second stage of labour }\end{array}$ \\
\hline Outcomes & Pain scores, assisted vaginal birth, caesarean section. \\
\hline Notes & Concurrent or prior use of pethidine. \\
\hline
\end{tabular}

\section{Risk of bias}

\begin{tabular}{l|l|l}
\hline Bias & Authors' judgement & Support for judgement \\
\hline $\begin{array}{l}\text { Random sequence generation (selection } \\
\text { bias) }\end{array}$ & Unclear risk & $\begin{array}{l}\text { Women were randomly divided into } 2 \\
\text { groups. }\end{array}$ \\
\hline $\begin{array}{l}\text { Allocation concealment (selection bias) } \\
\text { Blinding of participants and personnel } \\
\text { (performance bias) } \\
\text { All outcomes }\end{array}$ & High risk & Women were randomly divided into 2 \\
\hline $\begin{array}{l}\text { Blinding of outcome assessment (detection } \\
\text { bias) } \\
\text { All outcomes }\end{array}$ & High risk & groups. blinded. \\
\hline $\begin{array}{l}\text { Incomplete outcome data (attrition bias) } \\
\text { All outcomes }\end{array}$ & Unclear risk & Not blinded. \\
\hline
\end{tabular}


Belfrage 1974 (Continued)

\begin{tabular}{lll}
\hline Selective reporting (reporting bias) & Unclear risk & Unclear from translation. \\
\hline Other bias & Unclear risk & $\begin{array}{l}\text { No baseline characteristics and concurrent } \\
\text { use of pethidine in both groups }\end{array}$ \\
\hline Correct analyses for cross-over design used & Low risk & Not cross-over design. \\
\hline
\end{tabular}

Bergsjo 1971

\begin{tabular}{l|l}
\hline Methods & Randomised single cross-over trial conducted in Aker Hospital Oslo, Norway \\
\hline Participants & $\begin{array}{l}63 \text { participants, } 26 \text { in the experiment group and } 37 \text { in the control group } \\
\text { Inclusion criteria: women in established labour with obvious pain and expected labour } \\
\text { to be normal } \\
\text { Exclusion criteria: history of liver and kidney disease. }\end{array}$ \\
\hline Interventions & $\begin{array}{l}\text { Experimental group received Nitrous oxide mixed with oxygen in } 50 \% \text { concentration } \\
\text { inhaled intermittent, followed by methoxyflurane, while control group received first } 0 .\end{array}$ \\
\hline $\begin{array}{l}5 \% \text { to } 0.8 \% \text { methoxyflurane, inhaled intermittent, followed by nitrous oxide/oxygen } \\
50 \% \text { in first stage of labour during } 3 \text { consecutive contractions }\end{array}$ \\
\hline Outcomes & $\begin{array}{l}\text { Drug of preference, degree of analgesic effect, unpleasant subjective side effects, other } \\
\text { side effects scored by observer, Apgar scores, total labour time and additional drugs } \\
\text { needed after the trial stopped }\end{array}$ \\
\hline Notes & $\begin{array}{l}\text { A wash-out period of } 1 \text { contraction with air breathing. } \\
\text { Concurrent or prior use of opioids or diazepam. }\end{array}$ \\
\hline
\end{tabular}

Risk of bias

\begin{tabular}{l|l|l}
\hline Bias & Authors' judgement & Support for judgement \\
\hline $\begin{array}{l}\text { Random sequence generation (selection } \\
\text { bias) }\end{array}$ & Low risk & A list of random numbers. \\
\hline $\begin{array}{l}\text { Allocation concealment (selection bias) } \\
\text { Blinding of participants and personnel }\end{array}$ & Low risk & High risk \\
$\begin{array}{l}\text { All outcomes } \\
\text { performance bias) }\end{array}$ & $\begin{array}{l}\text { List of random numbers to decide in which } \\
\text { order the drugs are given owned by office } \\
\text { personnel, not seen by the doctors }\end{array}$ \\
\hline
\end{tabular}




\section{Bergsjo 1971 (Continued)}

\begin{tabular}{|c|c|c|}
\hline $\begin{array}{l}\text { Blinding of outcome assessment (detection } \\
\text { bias) } \\
\text { All outcomes }\end{array}$ & High risk & $\begin{array}{l}\text { Entonox is inhaled through anaesthetic } \\
\text { face masks working by inhaled flow, and } \\
\text { methoxyflurane is inhaled by a specially } \\
\text { made Analgizer which is a cylindrical tube } \\
\text { with a mouthpiece }\end{array}$ \\
\hline $\begin{array}{l}\text { Incomplete outcome data (attrition bias) } \\
\text { All outcomes }\end{array}$ & Low risk & $\begin{array}{l}3 \text { participants did not scored their prefer- } \\
\text { ence. }\end{array}$ \\
\hline Selective reporting (reporting bias) & Low risk & All prespecified outcomes reported upon. \\
\hline Other bias & Unclear risk & $\begin{array}{l}1 \text { group older, but should have no impact } \\
\text { on results, prior or concurrent use of opi- } \\
\text { oids or diazepam }\end{array}$ \\
\hline Correct analyses for cross-over design used & Unclear risk & Single cross-over design. \\
\hline
\end{tabular}

\section{Carstoniu 1994}

Methods

Participants

Interventions

Notes

Outcomes
Single cross-over randomised trial conducted in Toronto Hospital, Toronto, Ontario, Canada

26 participants, 14 in the experimental group and 12 controls

Exclusion criteria: age $<18$ years, maternal cardiorespiratory disease, fetal distress, any condition affecting the accuracy of pulse oximetry or the use of opioids or regional anaesthesia

Experimental group received self-administered $50 \%$ nitrous oxide and oxygen for 5 consecutive contractions. For the next 5 contractions compressed air was self-administered. Control group received same gases in reverse order. Used in first stage of labour

VAS pain scores, the lowest Spo2 (maternal haemoglobin oxygen saturation) observed after a contraction, ability correctly to identify the order of the gases in the 2 groups, only reported in figures

No wash-out period (comparison with compressed air).

No concurrent or prior use of other analgesia.

\section{Risk of bias}

\begin{tabular}{l|ll}
\hline Bias & Authors' judgement & Support for judgement \\
\hline $\begin{array}{l}\text { Random sequence generation (selection } \\
\text { bias) }\end{array}$ & Low risk & Random number table. \\
\hline Allocation concealment (selection bias) & Low risk & Numbered sealed envelopes.
\end{tabular}




\section{Carstoniu 1994 (Continued)}

\begin{tabular}{|c|c|c|}
\hline $\begin{array}{l}\text { Blinding of participants and personnel } \\
\text { (performance bias) } \\
\text { All outcomes }\end{array}$ & Unclear risk & $\begin{array}{l}\text { Valves hidden from participants but nurses } \\
\text { are the ones hiding it and who open ran- } \\
\text { domisation envelope }\end{array}$ \\
\hline $\begin{array}{l}\text { Blinding of outcome assessment (detection } \\
\text { bias) } \\
\text { All outcomes }\end{array}$ & Unclear risk & Not reported. \\
\hline $\begin{array}{l}\text { Incomplete outcome data (attrition bias) } \\
\text { All outcomes }\end{array}$ & High risk & $\begin{array}{l}3 \text { participants excluded for not completing } \\
\text { the trial. }\end{array}$ \\
\hline Selective reporting (reporting bias) & Low risk & All outcomes reported. \\
\hline Other bias & Low risk & Both groups comparable. \\
\hline Correct analyses for cross-over design used & Unclear risk & $\begin{array}{l}\text { Data for paired groups only in figures, not } \\
\text { possible to extract paired data }\end{array}$ \\
\hline
\end{tabular}

\section{Cheng 2001}

Methods

Randomised controlled trial conducted in Third Affiliated Hospital, Henan Medical University, Zhengzhou, China

\begin{tabular}{ll}
\hline Participants & 75 participants, 25 in each group. \\
& Inclusion criteria: healthy full term 22-30 years old singleton vertex presentation prim- \\
ipara
\end{tabular}

$\begin{array}{ll}\text { Interventions } & \text { Group } 1 \text { received isoflurane } 0.2 \% \text { to } 0.75 \% \text { and oxygen. } \\ \text { Group } 2 \text { received nitrous oxide } 30 \% \text { to } 50 \% \text { and oxygen. } \\ \text { Group } 3 \text { - controls - received air. }\end{array}$

Outcomes

Pain intensity - effectiveness of inhalation analgesia, duration of each stage of labour, mode of delivery, postpartum haemorrhage, gas analysis of neonatal umbilical artery and vein, Apgar score and NACS

Notes Concurrent or prior use of other analgesia not known.

\section{Risk of bias}

\begin{tabular}{l|ll}
\hline Bias & Authors' judgement & Support for judgement \\
\hline $\begin{array}{l}\text { Random sequence generation (selection } \\
\text { bias) }\end{array}$ & Unclear risk & Randomly. \\
\hline Allocation concealment (selection bias) & Unclear risk & Not reported.
\end{tabular}




\section{Cheng 2001 (Continued)}

\begin{tabular}{|c|c|c|}
\hline $\begin{array}{l}\text { Blinding of participants and personnel } \\
\text { (performance bias) } \\
\text { All outcomes }\end{array}$ & Unclear risk & Semi-closed anaesthetic method. \\
\hline $\begin{array}{l}\text { Blinding of outcome assessment (detection } \\
\text { bias) } \\
\text { All outcomes }\end{array}$ & Unclear risk & Semi-closed anaesthetic method. \\
\hline $\begin{array}{l}\text { Incomplete outcome data (attrition bias) } \\
\text { All outcomes }\end{array}$ & Unclear risk & Not reported. \\
\hline Selective reporting (reporting bias) & High risk & $\begin{array}{l}\text { Data on pain intensity and mode of deliv- } \\
\text { ery reported upon in another article which } \\
\text { was not referenced }\end{array}$ \\
\hline Other bias & Unclear risk & $\begin{array}{l}\text { No baseline characteristics and prior or } \\
\text { concurrent use of other analgesia unknown }\end{array}$ \\
\hline Correct analyses for cross-over design used & Low risk & Not cross-over design. \\
\hline
\end{tabular}

\section{Chia 1990}

\begin{tabular}{l|l} 
Methods & $\begin{array}{l}\text { This study was conducted in National University Hospital, Singapore in } 2 \text { parts. Part I } \\
\text { is a quasi-randomised trial and part II is a cross-over trial, first period data available }\end{array}$ \\
\hline Participants & $\begin{array}{l}20 \text { participants, } 10 \text { in each group. Inclusion criteria were nulliparous who were to have } \\
\text { surgical induction of labour and exclusion criteria included desire for epidural analgesia, } \\
\text { in advanced labour or given any other form of analgesia }\end{array}$ \\
\hline Interventions & $\begin{array}{l}\text { Group C received TENS and group D received Entonox (a switch over of the modes of } \\
\text { pain relief was made when labour pain was no longer tolerable; patient using TENS was } \\
\text { commenced on Entonox and vice versa). Any use of wash-out time or time indication } \\
\text { of switch-over period not reported }\end{array}$
\end{tabular}

Outcomes

Pain intensity, satisfaction with pain relief (nil, partial, complete), birthweight admission to NICU and Apgar score

$\begin{array}{ll}\text { Notes } & \text { Only data from part II trial used in this review. Any information of wash-out period is } \\ \text { not reported } \\ \text { No prior or concurrent use of other analgesia (excluded). }\end{array}$

\section{Risk of bias}

\section{Bias}

Random sequence generation (selection Unclear risk bias)

\section{Support for judgement}

Randomised. 


\section{Chia 1990 (Continued)}

\begin{tabular}{|c|c|c|}
\hline Allocation concealment (selection bias) & Low risk & $\begin{array}{l}\text { "randomly allocated by use of sealed en- } \\
\text { velopes." }\end{array}$ \\
\hline $\begin{array}{l}\text { Blinding of participants and personnel } \\
\text { (performance bias) } \\
\text { All outcomes }\end{array}$ & Unclear risk & Not reported. \\
\hline $\begin{array}{l}\text { Blinding of outcome assessment (detection } \\
\text { bias) } \\
\text { All outcomes }\end{array}$ & Unclear risk & Not reported. \\
\hline $\begin{array}{l}\text { Incomplete outcome data (attrition bias) } \\
\text { All outcomes }\end{array}$ & Unclear risk & Not reported. \\
\hline Selective reporting (reporting bias) & Low risk & All outcomes reported. \\
\hline Other bias & Low risk & $\begin{array}{l}\text { Both groups are comparable, no use of } \\
\text { other analgesia. }\end{array}$ \\
\hline Correct analyses for cross-over design used & Low risk & $\begin{array}{l}\text { Only use of part II, this part is a randomised } \\
\text { controlled trial (parallel groups) }\end{array}$ \\
\hline
\end{tabular}

Einarsson 1996

\begin{tabular}{l|l}
\hline Methods & $\begin{array}{l}\text { Randomised controlled trial conducted in Dept Obstetrics and Gynaecology, Sahlgrenska } \\
\text { University Hospital, Sweden }\end{array}$ \\
\hline Participants & $\begin{array}{l}24 \text { participants, } 12 \text { in each group. } \\
\text { Inclusion criteria: women undergoing vaginal delivery. } \\
\text { Exclusion criteria: maternal cardiorespiratory disease, pre-eclampsia, any evidence of fetal } \\
\text { distress or used opioid or regional analgesia }\end{array}$ \\
\hline Interventions & $\begin{array}{l}\text { Experimental group received } 50 \% \text { nitrous oxide and control group received } 70 \% \text { nitrous } \\
\text { oxide }\end{array}$ \\
\hline Outcomes & $\begin{array}{l}\text { Inspiratory and end-tidal }(\mathrm{E}) \text { concentrations of carbon dioxide }\left(\mathrm{CO}_{2}\right), \text { oxygen and } \\
\text { nitrous oxide, pulse oximetry }\left(\mathrm{Spo}_{2}\right) \text { respiratory rate, tidal volume and expiratory minute } \\
\text { ventilation volume }\left(\mathrm{V}_{E}\right) .\end{array}$ \\
\hline Notes & $\begin{array}{l}\text { No information regarding use of prior or concurrent other analgesia, but presumably } \\
\text { not because intervention started when women first requested analgesia }\end{array}$ \\
\hline
\end{tabular}

\section{Risk of bias}

\section{Bias}

Random sequence generation (selection Unclear risk bias)

\section{Support for judgement}

Allocated randomly. 


\section{Einarsson 1996 (Continued)}

\begin{tabular}{l|ll}
\hline Allocation concealment (selection bias) & Unclear risk & Not reported. \\
\hline $\begin{array}{l}\text { Blinding of participants and personnel } \\
\text { (performance bias) } \\
\text { All outcomes }\end{array}$ & Unclear risk & Not reported. \\
\hline $\begin{array}{l}\text { Blinding of outcome assessment (detection } \\
\text { bias) } \\
\text { All outcomes }\end{array}$ & Unclear risk & Not reported. \\
\hline $\begin{array}{l}\text { Incomplete outcome data (attrition bias) } \\
\text { All outcomes }\end{array}$ & Low risk & No loss. \\
\hline Selective reporting (reporting bias) & Low risk & All outcomes reported. \\
\hline Other bias & Unclear risk & Both groups comparable but no informa- \\
\hline tion of use of other analgesia
\end{tabular}

\section{Enrile 1973}

\begin{tabular}{ll} 
Methods & $\begin{array}{l}\text { Randomised controlled trial conducted in Cleveland Metropolitan General Hospital, } \\
\text { Cleveland, Ohio, USA }\end{array}$ \\
\hline Participants & $\begin{array}{l}26 \text { participants, } 14 \text { in the experiment group and } 12 \text { in the controls } \\
\text { Inclusion criteria: American Society of Anaesthesiologists classification of physical status } \\
\text { (ASA) Class } 1 \text { or } 2\end{array}$
\end{tabular}

$\begin{array}{ll}\text { Interventions } & \begin{array}{l}\text { Both groups received Methoxyflurane but the experiment group used Analgizer while } \\ \text { controls used Cyprane Inhaler }\end{array}\end{array}$

\begin{tabular}{l|l}
\hline Outcomes & $\begin{array}{l}\text { Cord blood PH, Methoxyflurane concentration in maternal blood, Apgar score (2 miss- } \\
\text { ing in Cyprane group), orientation, motor co-ordination, level of analgesia, level of am- } \\
\text { nesia, caesarean section, satisfaction with analgesia, nausea and vomiting }\end{array}$ \\
\hline Notes & $\begin{array}{l}\text { Inhaler and pudendal block possible (7p in Cyprane, } 7 \mathrm{p} \text { in Penthrane), and spinal (3p } \\
\text { in Cyprane, } 5 \mathrm{p} \text { in Penthrane) }\end{array}$ \\
\hline
\end{tabular}

\section{Risk of bias}

\begin{tabular}{l|ll} 
Bias & Authors' judgement & Support for judgement \\
\hline $\begin{array}{l}\text { Random sequence generation (selection } \\
\text { bias) }\end{array}$ & Low risk & Computer-generated randomisation table. \\
\hline Allocation concealment (selection bias) & Unclear risk & Not reported. \\
\hline
\end{tabular}


Enrile 1973 (Continued)

\begin{tabular}{|c|c|c|}
\hline $\begin{array}{l}\text { Blinding of participants and personnel } \\
\text { (performance bias) } \\
\text { All outcomes }\end{array}$ & High risk & $\begin{array}{l}\text { Not reported but both delivery systems } \\
\text { completely different from each other }\end{array}$ \\
\hline
\end{tabular}

\begin{tabular}{|c|c|c|}
\hline $\begin{array}{l}\text { Blinding of outcome assessment (detection } \\
\text { bias) } \\
\text { All outcomes }\end{array}$ & High risk & $\begin{array}{l}\text { Not reported but both delivery systems } \\
\text { completely different from each other }\end{array}$ \\
\hline $\begin{array}{l}\text { Incomplete outcome data (attrition bias) } \\
\text { All outcomes }\end{array}$ & Unclear risk & $\begin{array}{l}\text { Not reported. } 2 \text { missing in Cyprane group } \\
\text { for Apgar score is less than } 20 \% \text { (low risk } \\
\text { of bias) }\end{array}$ \\
\hline Selective reporting (reporting bias) & High risk & $\begin{array}{l}\text { Some of outcomes incompletely reported } \\
\text { upon -results reported for only } 1 \text { of the } \\
\text { groups, e.g. evaluation of pain, satisfaction } \\
\text { pain relief, nausea and vomiting }\end{array}$ \\
\hline Other bias & High risk & $\begin{array}{l}\text { The patients utilising a mask attached to } \\
\text { the analgizer obtained better pain relief } \\
\text { than those using the analgizer without } \\
\text { a mask because the diluter hole in the } \\
\text { analgizer was left open during administra- } \\
\text { tion resulting in a lower concentration of } \\
\text { Methoxyflurane available for inhalation }\end{array}$ \\
\hline Correct analyses for cross-over design used & Low risk & Not cross-over trial. \\
\hline
\end{tabular}

\section{Ji 2002}

Methods

Randomised controlled trial conducted in Qingdao Municipal Hospital, Qingdao, China. From January 2001 to November 2001

Participants

300 participants, 100 in each arm.

Inclusion criteria: primiparous with single fetus, no significant cephalopelvic disproportion, with no contraindications to anaesthesia

Interventions

Group 1 received combined spinal epidural analgesia.

Group 2 received $50 \%$ nitrous oxide and 50\% oxygen, at a rate of $0-15 \mathrm{~L}$ every minute Controls received no treatment.

Outcomes

Analgesic effect, duration of labour, method of delivery, postpartum bleeding, rate of newborn anoxia, maternal radial artery blood for blood gas analysis and fetal umbilical blood for blood gas analysis

Notes

Only data from group 2 (nitrous oxide) versus control included in this review Control group did not receive any analgesia, no information regarding prior or concurrent use of other analgesia in nitrous oxide group 


\section{Risk of bias}

\begin{tabular}{|c|c|c|}
\hline Bias & Authors' judgement & Support for judgement \\
\hline $\begin{array}{l}\text { Random sequence generation (selection } \\
\text { bias) }\end{array}$ & Unclear risk & Not stated as per translation. \\
\hline Allocation concealment (selection bias) & Unclear risk & Not stated as per translation. \\
\hline $\begin{array}{l}\text { Blinding of participants and personnel } \\
\text { (performance bias) } \\
\text { All outcomes }\end{array}$ & Unclear risk & Not stated as per translation. \\
\hline $\begin{array}{l}\text { Blinding of outcome assessment (detection } \\
\text { bias) } \\
\text { All outcomes }\end{array}$ & Unclear risk & Not stated as per translation. \\
\hline $\begin{array}{l}\text { Incomplete outcome data (attrition bias) } \\
\text { All outcomes }\end{array}$ & Unclear risk & Not stated as per translation. \\
\hline Selective reporting (reporting bias) & Low risk & All prespecified outcomes reported upon. \\
\hline Other bias & High risk & $\begin{array}{l}\text { No baseline characteristics, no information } \\
\text { of use of other analgesia in nitrous oxide } \\
\text { group }\end{array}$ \\
\hline Correct analyses for cross-over design used & Low risk & Not cross-over trial. \\
\hline
\end{tabular}

\section{Jones 1969}

Methods

Randomised control trial conducted in Department of Anaesthetics, Royal Infirmary, Cardiff, UK

\begin{tabular}{l|l} 
Participants & $\begin{array}{l}48 \text { participants, } 24 \text { in each group. } \\
\text { Inclusion criteria: normal labour. } \\
\text { Exclusion criteria: received instruction in psychoprophylaxis or hypnosis }\end{array}$ \\
\hline Interventions & $\begin{array}{l}\text { Experimental group received methoxyflurane continuous, while control group received } \\
\text { nitrous oxide continuous }\end{array}$ \\
\hline Outcomes & $\begin{array}{l}\text { Efficacy assessment by } 4 \text {-point scale just after delivery, nausea during labour (intrapartum } \\
\text { or first } 24 \text { hours), vomiting, dreams and Apgar score } 1 \text { minute }\end{array}$ \\
\hline Notes & $\begin{array}{l}\text { Prior use of pethidine in the } 4 \text { hours preceding the beginning of inhalation (11p N2O- } \\
\text { group, } 14 p \text { meth.-group), }\end{array}$
\end{tabular}

\section{Risk of bias}


Jones 1969 (Continued)

\begin{tabular}{|c|c|c|}
\hline Bias & Authors' judgement & Support for judgement \\
\hline $\begin{array}{l}\text { Random sequence generation (selection } \\
\text { bias) }\end{array}$ & Unclear risk & Random basis. \\
\hline Allocation concealment (selection bias) & Unclear risk & Random basis. \\
\hline $\begin{array}{l}\text { Blinding of participants and personnel } \\
\text { (performance bias) } \\
\text { All outcomes }\end{array}$ & Unclear risk & Not described. \\
\hline $\begin{array}{l}\text { Blinding of outcome assessment (detection } \\
\text { bias) } \\
\text { All outcomes }\end{array}$ & Unclear risk & Not described. \\
\hline $\begin{array}{l}\text { Incomplete outcome data (attrition bias) } \\
\text { All outcomes }\end{array}$ & High risk & $\begin{array}{l}2 \text { mothers not questioned after birth be- } \\
\text { cause of stress (abnormal child and severe } \\
\text { nausea and vomiting). }\end{array}$ \\
\hline Selective reporting (reporting bias) & Low risk & All prespecified outcomes reported upon. \\
\hline Other bias & Unclear risk & $\begin{array}{l}\text { Both groups comparable but use of pethi- } \\
\text { dine as analgesia prior }\end{array}$ \\
\hline Correct analyses for cross-over design used & Low risk & Not cross-over trial. \\
\hline
\end{tabular}

Jones 1969a

Methods

Participants

Interventions

Outcomes

Notes
Randomised control trial conducted in Department of Anaesthetics, Royal Infirmary, Cardiff, UK

50 participants, 25 in each group.

Inclusion criteria: normal labour.

Exclusion criteria: received instruction in psychoprophylaxis or hypnosis

Experimental group received self-administered intermittent $\mathrm{N} 2 \mathrm{O} 50 \%$, while control group received self-administered intermittent methoxyflurane $0.35 \%$

Assessment of efficacy by 4-point scale just after delivery, nausea, vomiting, hazy memory, noted the smell of the gas, dreams, numbness or buzzing in the ears or 'pins and needles', Apgar score 1, 2, 5 and 10 minutes

Concurrent or prior use of pethidine (64\% meth. group, $68 \%$ N2O group)

\section{Risk of bias}

Bias

Authors' judgement

\section{Support for judgement}




\begin{tabular}{|c|c|c|}
\hline $\begin{array}{l}\text { Random sequence generation (selection } \\
\text { bias) }\end{array}$ & Unclear risk & Random basis. \\
\hline Allocation concealment (selection bias) & Unclear risk & Random basis. \\
\hline $\begin{array}{l}\text { Blinding of participants and personnel } \\
\text { (performance bias) } \\
\text { All outcomes }\end{array}$ & Unclear risk & Not described. \\
\hline $\begin{array}{l}\text { Blinding of outcome assessment (detection } \\
\text { bias) } \\
\text { All outcomes }\end{array}$ & Unclear risk & Not described. \\
\hline $\begin{array}{l}\text { Incomplete outcome data (attrition bias) } \\
\text { All outcomes }\end{array}$ & Low risk & None. \\
\hline Selective reporting (reporting bias) & Low risk & All prespecified outcomes reported upon. \\
\hline Other bias & Low risk & $\begin{array}{l}\text { Both groups comparable (also comparable } \\
\text { in prior use of pethidine) }\end{array}$ \\
\hline Correct analyses for cross-over design used & Low risk & Not cross-over trial. \\
\hline
\end{tabular}

McGuinness 1984

\begin{tabular}{ll} 
Methods & $\begin{array}{l}\text { Randomised cross-over trial conducted in Department of Anaesthetics, University Hos- } \\
\text { pital of Wales, Heath Park, Cardiff, UK }\end{array}$ \\
\hline Participants & $\begin{array}{l}20 \text { participants, } 20 \text { measurements for each intervention, total } 40 \text { measurements } \\
\text { Inclusion criteria: fit women who were in early normal labour }\end{array}$ \\
\hline Interventions & $\begin{array}{l}\text { Experimental group received enflurane during } 3 \text { consecutive contractions (no wash-out } \\
\text { time used), while control group received Entonox }(50 \% \text { N2O and } 50 \% \text { O2) during } 3 \\
\text { consecutive contractions }\end{array}$ \\
\hline Outcomes & $\begin{array}{l}\text { Pain assessment with linear analogue scale, drowsiness and nausea by linear analogue } \\
\text { scale }\end{array}$ \\
\hline Notes & $\begin{array}{l}\text { No wash-out time between agents. } \\
\text { Concurrent or prior use of opioids before or during use of N2O }\end{array}$ \\
\hline
\end{tabular}

Risk of bias

\begin{tabular}{|c|c|c|}
\hline Bias & Authors' judgement & Support for judgement \\
\hline $\begin{array}{l}\text { Random sequence generation (selection } \\
\text { bias) }\end{array}$ & Unclear risk & Not described. \\
\hline
\end{tabular}




\section{McGuinness 1984 (Continued)}

\begin{tabular}{|c|c|c|}
\hline Allocation concealment (selection bias) & Unclear risk & $\begin{array}{l}\text { Randomly given } 1 \text { of the analgesic agents. } \\
\text { Not described how. }\end{array}$ \\
\hline $\begin{array}{l}\text { Blinding of participants and personnel } \\
\text { (performance bias) } \\
\text { All outcomes }\end{array}$ & Unclear risk & $\begin{array}{l}\text { The orientation of the tap (agents delivered } \\
\text { via the same tubing and mouthpiece) was } \\
\text { concealed from the operator } \\
\text { Different odour of agents, not described. }\end{array}$ \\
\hline $\begin{array}{l}\text { Blinding of outcome assessment (detection } \\
\text { bias) } \\
\text { All outcomes }\end{array}$ & Unclear risk & Not described. \\
\hline $\begin{array}{l}\text { Incomplete outcome data (attrition bias) } \\
\text { All outcomes }\end{array}$ & Low risk & None. \\
\hline Selective reporting (reporting bias) & Low risk & All prespecified outcomes reported upon. \\
\hline Other bias & Unclear risk & $\begin{array}{l}\text { Both groups comparable, prior or concur- } \\
\text { rent use of pethidine in } 1 \text { group }\end{array}$ \\
\hline Correct analyses for cross-over design used & High risk & $\begin{array}{l}\text { Linear analogues scales were compared } \\
\text { with the Wilcoxon matched-pairs signed- } \\
\text { rank test, but no data of individual pa- } \\
\text { tients. Overall median/range of experimen- } \\
\text { tal group and comparison group separately, } \\
\text { not possible to extract paired data }\end{array}$ \\
\hline
\end{tabular}

McLeod 1985

Methods

Participants

Interventions

Outcomes
Randomised cross-over trial conducted in Department of Anaesthetics, Aberdeen Royal Infirmary, Foresterhill, Aberdeen, UK

32 participants with 31 measurements of entonox and 31 measurements of isoflurane Inclusion criteria: in ASA 1 group (completely healthy patient), in normal established labour, requiring analgesia

Exclusion criteria: receiving any other analgesic or sedative agent during labour

Experimental group received Isoflurane $0.75 \%$ during 5 consecutive contractions in first stage of labour (with a break of 2 contractions to allow of elimination of the first agent) , while control group received nitrous oxide during 5 consecutive contractions in first stage of labour

Linear analogue scores for pain measured before starting the trial ( 0 point) and after each contraction, drowsiness measured after the 5 contractions of each agent, comment of both analgesics and patients preference after delivery 
McLeod 1985 (Continued)

\begin{tabular}{|c|c|c|}
\hline Notes & \multicolumn{2}{|c|}{$\begin{array}{l}\text { Wash-out period of } 2 \text { contractions. } \\
\text { No concurrent or prior use of opioids (were excluded). Total } 31 \text { measurements of Entonox } \\
\text { and total } 31 \text { measurements of Isoflurane, in total } 62 \text { measurements, unknown why not } \\
64 \text { measurements, probably one women did not completed the study }\end{array}$} \\
\hline \multicolumn{3}{|l|}{ Risk of bias } \\
\hline Bias & Authors' judgement & Support for judgement \\
\hline $\begin{array}{l}\text { Random sequence generation (selection } \\
\text { bias) }\end{array}$ & Unclear risk & 'Randomized', not described. \\
\hline Allocation concealment (selection bias) & Unclear risk & Not described. \\
\hline $\begin{array}{l}\text { Blinding of participants and personnel } \\
\text { (performance bias) } \\
\text { All outcomes }\end{array}$ & Unclear risk & Not described. \\
\hline $\begin{array}{l}\text { Blinding of outcome assessment (detection } \\
\text { bias) } \\
\text { All outcomes }\end{array}$ & Unclear risk & Not described. \\
\hline $\begin{array}{l}\text { Incomplete outcome data (attrition bias) } \\
\text { All outcomes }\end{array}$ & Low risk & 1 because of smell of isoflurane. \\
\hline Selective reporting (reporting bias) & Low risk & All prespecified outcomes reported upon. \\
\hline Other bias & Low risk & Both groups comparable. \\
\hline Correct analyses for cross-over design used & High risk & $\begin{array}{l}\text { Pain scores were compared using the } \\
\text { Wilcoxon rank sum test for paired samples } \\
\text { but no data of individual patients. Overall } \\
\text { mean/range of experimental and compari- } \\
\text { son group separately, not possible to extract } \\
\text { paired data }\end{array}$ \\
\hline
\end{tabular}

MRC 1970

Methods

Randomised trial conducted in 7 hospitals: Aberdeen Maternity Hospital, Cardiff Royal Infirmary and Maternity Hospital, Simpson Memorial Maternity Pavilion (Edinburgh) , Hammersmith Hospital, Kingsbury Maternity Hospital, Kingston Hospital and Westminster Hospital

Participants

601 participants, 259 in the experiment group and 242 in the control group Exclusion criteria: multiple birth expected or if special delivery procedures were likely to be needed 
MRC 1970 (Continued)

\begin{tabular}{|c|c|c|}
\hline Interventions & \multicolumn{2}{|c|}{$\begin{array}{l}\text { Experimental group received intermittent } 50 \% \text { nitrous oxide, while control group re- } \\
\text { ceived intermittent } 70 \% \text { nitrous oxide }\end{array}$} \\
\hline Outcomes & \multicolumn{2}{|c|}{ Pain assessment, drowsiness and nausea, dreams, side effects } \\
\hline Notes & \multicolumn{2}{|c|}{ No information regarding concurrent or prior use of other analgesia } \\
\hline \multicolumn{3}{|l|}{ Risk of bias } \\
\hline Bias & Authors' judgement & Support for judgement \\
\hline $\begin{array}{l}\text { Random sequence generation (selection } \\
\text { bias) }\end{array}$ & Unclear risk & Not described. \\
\hline Allocation concealment (selection bias) & Unclear risk & Not described. \\
\hline $\begin{array}{l}\text { Blinding of participants and personnel } \\
\text { (performance bias) } \\
\text { All outcomes }\end{array}$ & Unclear risk & Not described. \\
\hline $\begin{array}{l}\text { Blinding of outcome assessment (detection } \\
\text { bias) } \\
\text { All outcomes }\end{array}$ & Unclear risk & Not described. \\
\hline $\begin{array}{l}\text { Incomplete outcome data (attrition bias) } \\
\text { All outcomes }\end{array}$ & High risk & $\begin{array}{l}21 \text { were excluded from the initial analysis, } \\
12 \text { because they had given birth to twins } \\
\text { and } 9 \text { because the information on the forms } \\
\text { was incomplete. Also } 277 \text { cases were ex- } \\
\text { cluded from the main analysis, some being } \\
\text { rejected for more than } 1 \text { reason }\end{array}$ \\
\hline Selective reporting (reporting bias) & Low risk & All prespecified outcomes reported upon. \\
\hline Other bias & Unclear risk & $\begin{array}{l}\text { Both groups comparable but no informa- } \\
\text { tion of prior or concurrent use of other } \\
\text { analgesia }\end{array}$ \\
\hline Correct analyses for cross-over design used & Low risk & Not cross-over trial. \\
\hline
\end{tabular}

\section{Rezaeipour 2008}

\begin{tabular}{ll} 
Methods & Randomised controlled trial conducted in Orumieh Hospital, Tehran, Iran \\
\hline Participants & $\begin{array}{l}155 \text { participants, } 78 \text { in the experiment group and } 77 \text { in the control group } \\
\text { Inclusion criteria: primipara, 18-35 years of age, not have used any anaesthesia, not for } \\
\text { inducing labour. With no restrictions in using Entonox (due to respiratory problems, } \\
\text { pneumothorax, and trauma to the head in the past) and have dilated } 4 \mathrm{~cm}\end{array}$
\end{tabular}


Exclusion criteria: any complications during labour and delivery and the need to induce labour

\begin{tabular}{ll}
\hline Interventions & Experiment group received Entonox while control group inhaled oxygen \\
\hline Outcomes & $\begin{array}{l}\text { Pain as measured by VAS, mothers vital signs, fetal heart rate, Apgar score at } 1 \text { and } 5 \\
\text { minutes, postpartum haemorrhage, mode of delivery, side effects for mother (drowsiness } \\
\text { and mouth stiffness) and satisfaction with delivery }\end{array}$ \\
\hline Notes & No use of prior or concurrent other analgesia. \\
\hline
\end{tabular}

\section{Risk of bias}

\begin{tabular}{|c|c|c|}
\hline Bias & Authors' judgement & Support for judgement \\
\hline $\begin{array}{l}\text { Random sequence generation (selection } \\
\text { bias) }\end{array}$ & Unclear risk & Not reported. \\
\hline Allocation concealment (selection bias) & Unclear risk & Not reported. \\
\hline $\begin{array}{l}\text { Blinding of participants and personnel } \\
\text { (performance bias) } \\
\text { All outcomes }\end{array}$ & Unclear risk & Single blinding. \\
\hline $\begin{array}{l}\text { Blinding of outcome assessment (detection } \\
\text { bias) } \\
\text { All outcomes }\end{array}$ & Low risk & Single blinding. \\
\hline $\begin{array}{l}\text { Incomplete outcome data (attrition bias) } \\
\text { All outcomes }\end{array}$ & Low risk & $\begin{array}{l}2 \text { women from the intervention (Entonox) } \\
\text { group and } 3 \text { from the control group had to } \\
\text { be excluded from the study due to the need } \\
\text { for emergency caesarean sections }\end{array}$ \\
\hline Selective reporting (reporting bias) & Unclear risk & Not clear from translation. \\
\hline Other bias & Unclear risk & No baseline characteristics. \\
\hline Correct analyses for cross-over design used & Low risk & Not cross-over trial. \\
\hline
\end{tabular}

Shao 2000

Methods

Participants

Interventions
Randomised parallel study conducted from 20th May to 9th December 1998 in Zhejiang Yuyao People's Hospital, Yuyao, China.

250 participants, 125 in each group.

Experiment group inhaled the laughing gas and control group no treatment 


\section{Shao 2000 (Continued)}

\begin{tabular}{|c|c|c|}
\hline Outcomes & \multicolumn{2}{|c|}{$\begin{array}{l}\text { Pain intensity (degree of labour pains), method of delivery, Apgar scores, intrapartum } \\
\text { haemorrhage, postpartum haemorrhage, other side effects (mild dizziness, fatigue and } \\
\text { sleepiness) }\end{array}$} \\
\hline Notes & \multicolumn{2}{|c|}{ No information regarding other used analgesia. } \\
\hline \multicolumn{3}{|l|}{ Risk of bias } \\
\hline Bias & Authors' judgement & Support for judgement \\
\hline $\begin{array}{l}\text { Random sequence generation (selection } \\
\text { bias) }\end{array}$ & Low risk & Computer generated. \\
\hline Allocation concealment (selection bias) & Unclear risk & No information as per translation. \\
\hline $\begin{array}{l}\text { Blinding of participants and personnel } \\
\text { (performance bias) } \\
\text { All outcomes }\end{array}$ & Unclear risk & No information as per translation. \\
\hline $\begin{array}{l}\text { Blinding of outcome assessment (detection } \\
\text { bias) } \\
\text { All outcomes }\end{array}$ & Unclear risk & No information as per translation. \\
\hline $\begin{array}{l}\text { Incomplete outcome data (attrition bias) } \\
\text { All outcomes }\end{array}$ & Unclear risk & No information as per translation. \\
\hline Selective reporting (reporting bias) & Unclear risk & $\begin{array}{l}\text { Can not tell completely from the transla- } \\
\text { tion. }\end{array}$ \\
\hline Other bias & Unclear risk & $\begin{array}{l}\text { No information as per translation, no in- } \\
\text { formation of use of other analgesia }\end{array}$ \\
\hline Correct analyses for cross-over design used & Low risk & Not cross-over trial. \\
\hline
\end{tabular}

\section{Stefani 1982}

\begin{tabular}{l|l} 
Methods & Randomised control trial conducted in University Hospital Southern California, USA \\
\hline Participants & $\begin{array}{l}61 \text { participants, } 22 \text { in the experiment group } 1,18 \text { in the experiment group } 2 \text { and } 21 \text { in } \\
\text { the controls } \\
\text { Inclusion criteria: healthy full-term parturients. }\end{array}$ \\
\hline
\end{tabular}

Interventions

Experimental group 1 received enflurane $0.3 \%$ to $0.8 \%$, experimental group 2 received nitrous oxide (30\% to $50 \%$ ), while control group received no treatment

Outcomes

NACS using the Early Neurobehavioral Scale, satisfactory pain relief 
Stefani 1982 (Continued)

\begin{tabular}{|c|c|c|}
\hline Notes & \multicolumn{2}{|c|}{$\begin{array}{l}\text { Concurrent or prior use of other analgesia: } 50 \% \text { to } 41 \% \text { received no narcotics, the other } \\
\text { group received small doses of opioids, } 66 \% \text { pudendal block }\end{array}$} \\
\hline \multicolumn{3}{|l|}{ Risk of bias } \\
\hline Bias & Authors' judgement & Support for judgement \\
\hline $\begin{array}{l}\text { Random sequence generation (selection } \\
\text { bias) }\end{array}$ & Unclear risk & Assigned randomly. \\
\hline Allocation concealment (selection bias) & Unclear risk & Assigned randomly. \\
\hline $\begin{array}{l}\text { Blinding of participants and personnel } \\
\text { (performance bias) } \\
\text { All outcomes }\end{array}$ & Unclear risk & Not described. \\
\hline $\begin{array}{l}\text { Blinding of outcome assessment (detection } \\
\text { bias) } \\
\text { All outcomes }\end{array}$ & Low risk & $\begin{array}{l}\text { "Two examiners, blind to both the nature } \\
\text { and duration of analgesia simultaneously } \\
\text { evaluated and scored the neuro behavioural } \\
\text { status of infants." }\end{array}$ \\
\hline $\begin{array}{l}\text { Incomplete outcome data (attrition bias) } \\
\text { All outcomes }\end{array}$ & Low risk & None. \\
\hline Selective reporting (reporting bias) & Low risk & All prespecified outcomes reported upon. \\
\hline Other bias & Low risk & $\begin{array}{l}\text { Both groups comparable and use of other } \\
\text { analgesia in both groups seems similar }\end{array}$ \\
\hline Correct analyses for cross-over design used & Low risk & Not cross-over trial. \\
\hline
\end{tabular}

\section{Swart 1991}

Methods

Randomised trial conducted in Department of Anesthesiology, Los Angeles County University of southern California Medical Centre, Los Angeles, California, USA

\begin{tabular}{ll}
\hline Participants & 60 participants, 30 in each group. \\
\hline Interventions & $\begin{array}{l}\text { Experimental group received desflurane } 1 \% \text { to } 4.5 \% \text { and oxygen while control group } \\
\text { received nitrous oxide } 30 \% \text { to } 60 \% \text { and oxygen }\end{array}$ \\
\hline Outcomes & Analgesia assessment, blood loss, Apgar score, blood acidity and NACS \\
\hline Notes & $\begin{array}{l}\text { Abstract (poster session) only - data limited. } \\
\text { No information regarding concurrent or prior use of other analgesia }\end{array}$ \\
\hline
\end{tabular}

\section{Risk of bias}




\section{Swart 1991 (Continued)}

\begin{tabular}{|c|c|c|}
\hline Bias & Authors' judgement & Support for judgement \\
\hline $\begin{array}{l}\text { Random sequence generation (selection } \\
\text { bias) }\end{array}$ & Unclear risk & Randomly assigned. \\
\hline Allocation concealment (selection bias) & Unclear risk & Not reported. \\
\hline $\begin{array}{l}\text { Blinding of participants and personnel } \\
\text { (performance bias) } \\
\text { All outcomes }\end{array}$ & Low risk & $\begin{array}{l}\text { Both patient and obstetrician did not know } \\
\text { the gas. }\end{array}$ \\
\hline $\begin{array}{l}\text { Blinding of outcome assessment (detection } \\
\text { bias) } \\
\text { All outcomes }\end{array}$ & Unclear risk & Not reported. \\
\hline $\begin{array}{l}\text { Incomplete outcome data (attrition bias) } \\
\text { All outcomes }\end{array}$ & Unclear risk & Not reported. \\
\hline Selective reporting (reporting bias) & Unclear risk & $\begin{array}{l}\text { There is insufficient information about the } \\
\text { numerical results in the abstract }\end{array}$ \\
\hline Other bias & Unclear risk & $\begin{array}{l}\text { Groups characteristics not reported in the } \\
\text { abstract. }\end{array}$ \\
\hline Correct analyses for cross-over design used & Low risk & Not cross-over trial. \\
\hline
\end{tabular}

Talebi 2009

Methods

Participants
Randomised control trial conducted from September 2004 to 2006 in Department of Anaesthesiology, Arak University Hospital, Arak, Iran

534 ASA I and II parturients, 260 in experimental group and 249 in control group Inclusion criteria: scheduled for elective labour, term (38-42 weeks) in active stage of labour (dilation more then $4 \mathrm{~cm}$ ).

Exclusion criteria: any evidence of fetal distress, or abnormal fetal heart pattern, maternal cardiorespiratory disease or any condition effecting the accuracy of pulse oximetry, history of taking opioids, administrations of sedation or regional analgesia (pudendal block, local infiltration), intolerance of Entonox, during trial when birth ended in caesarean section or forceps

Interventions

Experimental group received self-administration of pre-prepared mixture of $50 \%$ nitrous oxide and oxygen started as early as the onset of pain with each contraction (when patient first requested analgesia), while control group received self-administration of $50 \%$ oxygen as early as the onset of pain with each contraction

Outcomes

Pain scores of contractions by VAS (time at the start of inhaled analgesia and every hour from time 1 to 5), the lowest spO2 (by pulse oxymeter) and mean arterial blood pressure of the mother, Apgar scores of 1 and 5 minutes postpartum. Side effect as nausea, 
Talebi 2009 (Continued)

vomiting dizziness, dry mouth from gas, pins and needles or numbness and drowsiness measured at the end of the study

Notes No concurrent or prior use of other analgesia (excluded).

\section{Risk of bias}

\begin{tabular}{|c|c|c|}
\hline Bias & Authors' judgement & Support for judgement \\
\hline $\begin{array}{l}\text { Random sequence generation (selection } \\
\text { bias) }\end{array}$ & Low risk & Randomisation with a coin. \\
\hline Allocation concealment (selection bias) & Unclear risk & Randomisation with a coin. \\
\hline $\begin{array}{l}\text { Blinding of participants and personnel } \\
\text { (performance bias) } \\
\text { All outcomes }\end{array}$ & Unclear risk & Not described. \\
\hline $\begin{array}{l}\text { Blinding of outcome assessment (detection } \\
\text { bias) } \\
\text { All outcomes }\end{array}$ & Low risk & $\begin{array}{l}\text { Participants rating of pain was recorded by } \\
\text { someone blind to allocation, plus arterial } \\
\text { pressure and Apgar score }\end{array}$ \\
\hline $\begin{array}{l}\text { Incomplete outcome data (attrition bias) } \\
\text { All outcomes }\end{array}$ & Low risk & $\begin{array}{l}4 \text { of } 523 \text { loss to follow-up. No patient ex- } \\
\text { cluded after randomisation. Intention to } \\
\text { treat not known }\end{array}$ \\
\hline Selective reporting (reporting bias) & Low risk & All prespecified outcomes reported upon. \\
\hline Other bias & High risk & $\begin{array}{l}\text { More primipara in nitrous oxide group. } \\
\text { This would be in favour of control group } \\
\text { regarding pain. }\end{array}$ \\
\hline Correct analyses for cross-over design used & Low risk & Not cross-over trial. \\
\hline
\end{tabular}

\section{Wang 1994}

\begin{tabular}{l|l}
\hline Methods & $\begin{array}{l}\text { Randomised study conducted in The Third Affiliated Hospital of Henan Medical School, } \\
\text { China }\end{array}$ \\
\hline Participants & 84 participants, 34 in the experiment group and 50 controls. \\
\hline Interventions & Experiment group received nitrous oxide and control group received no treatment \\
\hline Outcomes & $\begin{array}{l}\text { Analgesic effects, respiratory and circulatory functions, uterine contractions, progress of } \\
\text { labour, Apgar score and postpartum bleeding }\end{array}$ \\
\hline Notes & No information of prior or concurrent use of other analgesia
\end{tabular}




\section{Risk of bias}

\begin{tabular}{|c|c|c|}
\hline Bias & Authors' judgement & Support for judgement \\
\hline $\begin{array}{l}\text { Random sequence generation (selection } \\
\text { bias) }\end{array}$ & Unclear risk & Not reported. \\
\hline Allocation concealment (selection bias) & Unclear risk & Not reported. \\
\hline $\begin{array}{l}\text { Blinding of participants and personnel } \\
\text { (performance bias) } \\
\text { All outcomes }\end{array}$ & Unclear risk & Not reported. \\
\hline $\begin{array}{l}\text { Blinding of outcome assessment (detection } \\
\text { bias) } \\
\text { All outcomes }\end{array}$ & Unclear risk & Not reported. \\
\hline $\begin{array}{l}\text { Incomplete outcome data (attrition bias) } \\
\text { All outcomes }\end{array}$ & Unclear risk & Not reported. \\
\hline Selective reporting (reporting bias) & Unclear risk & Only the abstract translated. \\
\hline Other bias & Unclear risk & Only the abstract translated. \\
\hline Correct analyses for cross-over design used & Low risk & Not cross-over trial. \\
\hline
\end{tabular}

\section{Wee 1993}

Methods

Participants
Randomised cross-over trial conducted in St Michael's Hospital, Bristol, UK

18 participants with 17 measurements of drowsiness and 18 measurements of pain intensity after 1 hour in first period before the first cross-over ended

Inclusion criteria: between 16 and 38 years old, in ASA grade 1, in normal labour and requesting inhalation analgesia (mothers were allowed to opt out if inhalational analgesia subsequently proved to be unsatisfactory)

Interventions

Experimental group received E-I-E sequence, mothers inhaled Entonox alone at the first hour, Entonox and $0.2 \%$ Isoflurane for the second and Entonox alone for the third hour, while control group received I-E-I sequence, mother inhaled Entonox and $0.2 \%$ isoflurane at the first hour, Entonox alone for the second and Entonox and $0.2 \%$ isoflurane for the third hour

Outcomes

Pain and drowsiness assessment measured with VAS, baseline score before any inhalation, subsequently scores recorded at 20 minutes intervals, obtained as soon as possible after each contraction during the hour of 1 agent (intervention and comparison group), baby Apgar score 1 and 5 minutes. The differences in median scores in both groups between baseline and the first hour, the first and the second hour, the second and the third hour were calculated 


Notes
No information on wash-out period between agents but inhalation agent was used for
1 complete hour and efficacy was scored after 20 minutes. Moreover the inhalation
gases were self-administered during contractions. This means that the minimal wash-
out period of 4 exhalations must have passed during the pauses between contractions
Probably no prior or concurrent use of other analgesia because women were allowed
to drop out if analgesia was not satisfactory. We used only data of the first period
(measurements after 1 hour) with 18 participants and 11 measurements of Entonox use
and 8 measurements of Isoflurane/Entonox use

\section{Risk of bias}

\begin{tabular}{|c|c|c|}
\hline Bias & Authors' judgement & Support for judgement \\
\hline $\begin{array}{l}\text { Random sequence generation (selection } \\
\text { bias) }\end{array}$ & Unclear risk & Not described. \\
\hline Allocation concealment (selection bias) & Unclear risk & Not described. \\
\hline $\begin{array}{l}\text { Blinding of participants and personnel } \\
\text { (performance bias) } \\
\text { All outcomes }\end{array}$ & Unclear risk & Not described. \\
\hline $\begin{array}{l}\text { Blinding of outcome assessment (detection } \\
\text { bias) } \\
\text { All outcomes }\end{array}$ & Unclear risk & Not described. \\
\hline $\begin{array}{l}\text { Incomplete outcome data (attrition bias) } \\
\text { All outcomes }\end{array}$ & Low risk & 1 woman did not complete the study. \\
\hline Selective reporting (reporting bias) & Low risk & All prespecified outcomes reported upon. \\
\hline Other bias & Unclear risk & $\begin{array}{l}\text { Baseline not reported for the } 2 \text { groups, no } \\
\text { information about other additional drugs }\end{array}$ \\
\hline Correct analyses for cross-over design used & High risk & $\begin{array}{l}\text { Probably paired t-test in this trial (no in- } \\
\text { formation). } \\
\text { Overall mean/SD for experimental and } \\
\text { comparison groups separately calculated by } \\
\text { individual data for first period after one } \\
\text { hour, analysed as parallel group data }\end{array}$ \\
\hline
\end{tabular}

Yeo 2007

Methods

Randomised, open label, double cross-over trial conducted in Anaesthetic Department, The County Hospital, Union Walk, Hereford, UK 


\begin{tabular}{ll}
\hline Participants & $\begin{array}{l}31 \text { participants, } 15 \text { in the experiment group and } 16 \text { in the controls with } 37 \text { measurements } \\
\text { of Entonox and } 43 \text { measurements of enflurane }\end{array}$ \\
$\begin{array}{l}\text { Inclusion criteria: active labour }(\geq 3 \mathrm{~cm} \text { cervical dilatation) with contractions occurring } \\
\text { at least } 1 \text { every } 3 \text { minutes, spontaneous or induced, } \geq 37 \text { weeks' gestation with prior } \\
\text { consent } \\
\text { Exclusion criteria: women who had no knowledge of the study before, major uterine ab- } \\
\text { normalities, multiple gestation, cardiovascular or respiratory instability, acute or chronic } \\
\text { obstetric pathology and women who received any analgesia before recruited }\end{array}$ \\
\hline $\begin{array}{l}\text { Experimental group received Entonox/Sevoflurane } 0.7 \% / \text { Entonox }(\text { ESE), each agent } \\
\text { during } 10 \text { contractions, while control group received Sevoflurane } 0.7 \% / E n t o n o x / S u- \\
\text { voflurane } 0.7 \% \text { (SES), each agent during } 10 \text { contractions. Between each agent a wash- } \\
\text { over period of breathing room air during } 1 \text { contraction, participant could omit this wash- } \\
\text { over period if they wished }\end{array}$ \\
\hline $\begin{array}{l}\text { VAS of overall pain relief with each contraction, pain intensity, sedation, mood and } \\
\text { Outcomes } \\
\text { pired gas concentration, maternal ventilator frequency, intermittent non invasive arterial } \\
\text { pressure, heart rate and maternal arterial oxygen saturation, fetal heart rate and maternal } \\
\text { contractions on cardiotocograph, type of analgesia used after trial, mode of delivery, and } \\
\text { preferred agent scored within } 48 \text { hours after delivery }\end{array}$ \\
\hline
\end{tabular}

Notes

Between agent a wash-out period during 1 contraction, participant could omit this wash-over period if they wished (no information on numbers) but the agents were selfadministered so probably there was a minimum of 4 exhalations between the 2 agents No prior use of other analgesia before treatment (excluded), no information on concurrent use. We extracted 43 measurements with Enflurane and 37 measurements with Entonox

Risk of bias

\begin{tabular}{l|l|l}
\hline Bias & Authors' judgement & Support for judgement \\
\hline $\begin{array}{l}\text { Random sequence generation (selection } \\
\text { bias) }\end{array}$ & Unclear risk & 'randomised.' \\
\hline $\begin{array}{l}\text { Allocation concealment (selection bias) } \\
\text { Blinding of participants and personnel } \\
\text { (performance bias) }\end{array}$ & High risk & 'randomised.' \\
\hline $\begin{array}{l}\text { All outcomes } \\
\text { Blinding of outcome assessment (detection } \\
\text { bias) } \\
\text { All outcomes }\end{array}$ & High risk & 'open label.' \\
\hline $\begin{array}{l}\text { Incomplete outcome data (attrition bias) } \\
\text { All outcomes }\end{array}$ & High risk & 'open label.' \\
\hline
\end{tabular}

Inhaled analgesia for pain management in labour (Review) 
Yeo 2007 (Continued)

\begin{tabular}{|c|c|c|}
\hline & & $\begin{array}{l}\text { withdrew before inhalation of any admin- } \\
\text { istration (requested an epidural), these } 3 \\
\text { women were not followed up because of the } \\
\text { early withdrawal (before first cross-over) } \\
5 \text { withdrew because of requested epidural } \\
\text { analgesia whilst in the Entonox phase of the } \\
\text { study, } 4 \text { in the ESE group in the last phase } \\
\text { using Entonox and } 1 \text { in the SES group, } 2 \\
\text { withdrawals because of starting the second } \\
\text { stage of labour before ending the trial }\end{array}$ \\
\hline Selective reporting (reporting bias) & Low risk & Aall prespecified outcomes reported upon. \\
\hline Other bias & Low risk & $\begin{array}{l}\text { Both groups comparable and no use of } \\
\text { other analgesia. }\end{array}$ \\
\hline Correct analyses for cross-over design used & High risk & $\begin{array}{l}\text { Overall pain relief scores of experimental } \\
\text { and comparison groups separately }\end{array}$ \\
\hline
\end{tabular}

\section{Zhang 2001}

Methods

Randomised study conducted in The Third Affiliated Hospital of Henan Medical School, China

\begin{tabular}{l|l}
\hline Participants & 110 participants, 60 in the experimental group and 50 in the control group \\
\hline Interventions & $\begin{array}{l}\text { Experiment group received } 30 \% \text { to } 50 \% \text { nitrous oxide and oxygen } 5 \mathrm{~L} / \mathrm{min} \text { while controls } \\
\text { received only oxygen } 5 \mathrm{~L} / \mathrm{min}\end{array}$ \\
\hline
\end{tabular}

Outcomes Labour pain, mode of delivery, Apgar score, postpartum haemorrhage, vomiting and neonatal asphyxia

Notes Concurrent or prior use of other analgesia not reported.

\section{Risk of bias}

\begin{tabular}{l|ll}
\hline Bias & Authors' judgement & Support for judgement \\
\hline $\begin{array}{l}\text { Random sequence generation (selection } \\
\text { bias) }\end{array}$ & Unclear risk & Randomly chosen. \\
\hline Allocation concealment (selection bias) & Unclear risk & Not reported.
\end{tabular}

Blinding of participants and personnel Unclear risk (performance bias)

All outcomes 
Zhang 2001 (Continued)

\begin{tabular}{|c|c|c|}
\hline $\begin{array}{l}\text { Blinding of outcome assessment (detection } \\
\text { bias) } \\
\text { All outcomes }\end{array}$ & Unclear risk & Not reported. \\
\hline $\begin{array}{l}\text { Incomplete outcome data (attrition bias) } \\
\text { All outcomes }\end{array}$ & Low risk & No loss. \\
\hline Selective reporting (reporting bias) & High risk & $\begin{array}{l}\text { Apgar score mentioned in abstract of study, } \\
\text { but no results were reported within the re- } \\
\text { sults section of the paper }\end{array}$ \\
\hline Other bias & Unclear risk & Not clear. \\
\hline Correct analyses for cross-over design used & Low risk & Not cross-over trial. \\
\hline
\end{tabular}

ASA: American Society of Anaesthesiologists

NACS: neurologic and adaptive capacity score

NICU: neonatal intensive care unit

OMV: Oxford Miniature. Vaporizer

SD: standard deviation

VAS: visual analogue scale

Characteristics of excluded studies [ordered by study ID]

\begin{tabular}{|c|c|}
\hline Study & Reason for exclusion \\
\hline Arozenius 1980 & Not randomised. \\
\hline Arthurs 1981 & Quasi-randomised trial. \\
\hline Chessor 2005 & Not randomised. \\
\hline Clark 1979 & Comparison with opioids which are higher than inhalation in the pain management hierarchy \\
\hline Cosmi 1969 & Spinal block compared to general anaesthesia study. Not randomised \\
\hline Crawford 1975 & Participants not women in labour. Study on general anaesthesia and it's side effects in caesarean section \\
\hline Creasser 1974 & $\begin{array}{l}\text { Complex intervention -all women had a pudendal block. } 1 \text { group received methoxyflurane and the other group } \\
\text { received intramuscular analgesia + nitrous oxide. Does not fit in with our hierarchy }\end{array}$ \\
\hline Davies 1974 & Quasi-randomised trial. Study mainly concerned with resistance of the delivery system \\
\hline Davies 1975 & Not randomised. \\
\hline
\end{tabular}


(Continued)

\begin{tabular}{|c|c|}
\hline Howell 2001 & $\begin{array}{l}\text { Intervention investigated was epidural and both groups received Entonox. Fits in with epidural review according } \\
\text { to pain management hierarchy }\end{array}$ \\
\hline Krantz 1974 & General anaesthesia trial and participants were not women in labour \\
\hline Major 1966 & Controls treatment (Trichloroethylene) not used any more since 1975. Quasi-randomised trial \\
\hline Major 1967 & Quasi-randomised trial. \\
\hline McAneny 1963 & Participants were distributed between groups and not randomised \\
\hline Phillips 1971 & Controls treatment (Trichloroethylene) not used any more since 1975 and all groups got pethidine \\
\hline Roberts 1957 & Not randomised. Comparison of nitrous oxide to opioids which are higher in the pain management hierarchy \\
\hline Robinson 1980 & $\begin{array}{l}\text { Epidural is higher than inhalation in the pain management hierarchy } \\
\text { The main comparison is between opioids and inhaled analgesic versus epidural analgesia }\end{array}$ \\
\hline Rosen 1969 & Quasi-randomised trial. \\
\hline Rosen 1972 & Quasi-randomised trial. Controls were not pregnant. \\
\hline Shnider 1963 & Cyclopropane no longer used in practice. Study conducted during episiotomy repair after delivery \\
\hline Volmanen 2005 & Comparison of nitrous oxide to opioids which are higher in the pain management hierarchy \\
\hline
\end{tabular}

\section{Characteristics of studies awaiting assessment [ordered by study ID]}

\section{Su 2002}

\begin{tabular}{ll}
\hline Methods & $\begin{array}{l}\text { Unclear - article in Chinese, awaiting translation. In English abstract just states "women in labour were divided into } \\
\text { two groups" }\end{array}$ \\
\hline Participants & 1300 cases of term primiparous women in labour. \\
\hline Interventions & $\begin{array}{l}\text { Study group }(\mathrm{n}=658) 50 \% \text { nitrous oxide in oxygen. } \\
\text { Control group }(\mathrm{n}=642) \text { intermittent inhalation of } 50 \% \text { oxygen }\end{array}$ \\
\hline Outcomes & $\begin{array}{l}\text { Duration of labour; delivery mode; meconium-stained amniotic fluid; postpartum bleeding volume; neonatal Apgar } \\
\text { score; blood gas analysis }\end{array}$ \\
\hline Notes & Awaiting translation June 2012. \\
\hline
\end{tabular}


DATA ANDANALYSES

Comparison 1. Nitrous oxide versus flurane derivatives

\begin{tabular}{|c|c|c|c|c|}
\hline Outcome or subgroup title & $\begin{array}{l}\text { No. of } \\
\text { studies }\end{array}$ & $\begin{array}{c}\text { No. of } \\
\text { participants }\end{array}$ & Statistical method & Effect size \\
\hline $\begin{array}{l}1 \text { Pain intensity (VAS 0-100 first } \\
\text { stage) }\end{array}$ & 3 & 70 & Mean Difference (IV, Random, 95\% CI) & $14.39[4.41,24.37]$ \\
\hline $\begin{array}{l}2 \text { Pain relief (VAS } 0-100 \text { as } 100 \text { is } \\
\text { the most pain relief, first stage) }\end{array}$ & 2 & 70 & Mean Difference (IV, Random, 95\% CI) & $\begin{array}{l}-16.32[-26.85,-5 . \\
79]\end{array}$ \\
\hline $\begin{array}{l}3 \text { Satisfaction with pain relief (first } \\
\text { and second stage, considerable } \\
\text { to complete) }\end{array}$ & 2 & 98 & Risk Ratio (M-H, Fixed, 95\% CI) & $0.98[0.80,1.18]$ \\
\hline $\begin{array}{l}4 \text { Satisfaction with pain relief } \\
\text { (second stage, good to } \\
\text { excellent) }\end{array}$ & 4 & 323 & Risk Ratio (M-H, Fixed, 95\% CI) & $0.89[0.78,1.01]$ \\
\hline 5 Assisted vaginal birth & 5 & 371 & Risk Ratio (M-H, Random, 95\% CI) & $0.71[0.44,1.15]$ \\
\hline 6 Caesarean section & 1 & 98 & Risk Ratio (M-H, Fixed, 95\% CI) & $0.0[0.0,0.0]$ \\
\hline 7 Amnesia & 3 & 245 & Risk Ratio (M-H, Random, 95\% CI) & $0.26[0.03,2.38]$ \\
\hline 8 Drowsiness (VAS 0-100 mm) & 1 & 18 & Mean Difference (IV, Fixed, 95\% CI) & $\begin{array}{l}11.64[-16.04,39 . \\
32]\end{array}$ \\
\hline 9 Nausea & 2 & 98 & Risk Ratio (M-H, Fixed, 95\% CI) & $6.6[1.85,23.52]$ \\
\hline 10 Vomiting & 3 & 203 & Risk Ratio (M-H, Fixed, 95\% CI) & $2.02[0.75,5.46]$ \\
\hline 11 Blood loss in $\mathrm{mL}$ & 2 & 185 & Mean Difference (IV, Fixed, 95\% CI) & $6.0[-32.91,44.91]$ \\
\hline $\begin{array}{l}12 \text { Apgar score less than seven at } \\
\text { five minutes }\end{array}$ & 5 & 373 & Risk Ratio (M-H, Fixed, 95\% CI) & $0.22[0.01,4.47]$ \\
\hline $\begin{array}{l}13 \text { NACS }<35 \text { at } 2 \text { hours after } \\
\text { delivery }\end{array}$ & 3 & 170 & Risk Ratio (M-H, Fixed, 95\% CI) & $1.45[0.91,2.33]$ \\
\hline
\end{tabular}

Comparison 2. Inhaled analgesia of one strength versus inhaled analgesia of different strength

\begin{tabular}{|c|c|c|c|c|}
\hline Outcome or subgroup title & $\begin{array}{l}\text { No. of } \\
\text { studies }\end{array}$ & $\begin{array}{c}\text { No. of } \\
\text { participants }\end{array}$ & Statistical method & Effect size \\
\hline $\begin{array}{l}1 \text { Satisfaction with pain relief (first } \\
\text { stage, good to complete) }\end{array}$ & 1 & 501 & Risk Ratio (M-H, Fixed, 95\% CI) & $1.05[0.94,1.17]$ \\
\hline $\begin{array}{l}2 \text { Satisfaction with pain relief } \\
\text { (second stage, good to } \\
\text { complete) }\end{array}$ & 1 & 501 & Risk Ratio (M-H, Fixed, 95\% CI) & $0.97[0.87,1.08]$ \\
\hline 3 Caesarean section & 1 & 501 & Risk Ratio (M-H, Fixed, 95\% CI) & $0.31[0.06,1.53]$ \\
\hline 4 Assisted vaginal birth & 1 & 501 & Risk Ratio (M-H, Fixed, 95\% CI) & $0.83[0.61,1.14]$ \\
\hline 5 Vomiting & 1 & 501 & Risk Ratio (M-H, Fixed, 95\% CI) & $1.29[0.86,1.94]$ \\
\hline 6 Postpartum haemorrhage & 1 & 501 & Risk Ratio (M-H, Fixed, 95\% CI) & $0.80[0.38,1.70]$ \\
\hline 7 Hypoxaemia mother & 1 & 24 & Risk Ratio (M-H, Fixed, 95\% CI) & $1.0[0.07,14.21]$ \\
\hline
\end{tabular}




\begin{tabular}{|c|c|c|c|c|}
\hline Outcome or subgroup title & $\begin{array}{l}\text { No. of } \\
\text { studies }\end{array}$ & $\begin{array}{c}\text { No. of } \\
\text { participants }\end{array}$ & Statistical method & Effect size \\
\hline $\begin{array}{l}1 \text { Satisfaction with pain relief } \\
\text { (first stage, considerable to } \\
\text { complete) }\end{array}$ & 1 & 42 & Risk Ratio (M-H, Fixed, 95\% CI) & $1.18[0.94,1.48]$ \\
\hline 2 Caesarean section & 1 & 26 & Risk Ratio (M-H, Fixed, 95\% CI) & $2.6[0.12,58.48]$ \\
\hline 3 Vomiting (N2O + nasal) & 1 & 49 & Risk Ratio (M-H, Fixed, 95\% CI) & $1.76[0.77,4.00]$ \\
\hline $\begin{array}{l}4 \text { Vomiting dichotomous } \\
\text { Penthr./Cypr. }\end{array}$ & 1 & 26 & Risk Ratio (M-H, Fixed, 95\% CI) & $0.0[0.0,0.0]$ \\
\hline 5 Postpartum haemorrhage & 1 & 26 & Risk Ratio (M-H, Fixed, 95\% CI) & $0.29[0.01,6.50]$ \\
\hline 6 Mild pre-eclampsia & 1 & 26 & Risk Ratio (M-H, Fixed, 95\% CI) & $0.86[0.06,12.28]$ \\
\hline $\begin{array}{l}7 \text { Apgar score (continuous, at } 5 \\
\text { min.Penthr/Cypr) }\end{array}$ & 1 & 24 & Mean Difference (IV, Fixed, 95\% CI) & $0.0[-0.37,0.37]$ \\
\hline $\begin{array}{l}8 \text { Apgar score (continuous } \\
\mathrm{N} 2 \mathrm{O} / \mathrm{N} 2 \mathrm{O} \text { with nasal suppl.) }\end{array}$ & 1 & 49 & Mean Difference (IV, Fixed, 95\% CI) & $-0.30[-0.81,0.21]$ \\
\hline
\end{tabular}

Comparison 4. Inhaled analgesia versus placebo control/no treatment

\begin{tabular}{lccll} 
Outcome or subgroup title & $\begin{array}{c}\text { No. of } \\
\text { studies }\end{array}$ & $\begin{array}{c}\text { No. of } \\
\text { participants }\end{array}$ & \multicolumn{1}{c}{ Statistical method } & Effect size \\
\hline $\begin{array}{l}\text { 1 Pain intensity (first stage, } \\
\quad \text { clear/severe to intense/extreme) }\end{array}$ & 2 & 310 & Risk Ratio (M-H, Random, 95\% CI) & $0.06[0.01,0.34]$ \\
$\begin{array}{l}\text { 2 Pain intensity (first stage, VAS } \\
\quad \text { 0-10 after 1 hour) }\end{array}$ & 1 & 509 & Mean Difference (IV, Fixed, 95\% CI) & $-3.50[-3.75,-3.25]$ \\
3 Assisted vaginal birth & 1 & 200 & Risk Ratio (M-H, Fixed, 95\% CI) & $1.5[0.44,5.15]$ \\
4 Caesarean section & 3 & 465 & Risk Ratio (M-H, Fixed, 95\% CI) & $1.20[0.75,1.91]$ \\
5 Vomiting & 2 & 619 & Risk Ratio (M-H, Fixed, 95\% CI) & $9.05[1.18,69.32]$ \\
6 Nausea & 1 & 509 & Risk Ratio (M-H, Fixed, 95\% CI) & $43.10[2.63,706.74]$ \\
7 Dizziness & 1 & 509 & Risk Ratio (M-H, Fixed, 95\% CI) & $113.98[7.09,1833$. \\
& & & & $69]$ \\
8 Drowsiness & 1 & 509 & Risk Ratio (M-H, Fixed, 95\% CI) & $77.59[4.80,1254$. \\
& 1 & 110 & Risk Ratio (M-H, Fixed, 95\% CI) & $96]$ \\
9 Neonatal asphyxia & 1 & 200 & Risk Ratio (M-H, Fixed, 95\% CI) & $1.11[0.26,4.73]$ \\
10 Apgar score 5 min. \& 7 dich. & 1 & 509 & Mean Difference (IV, Fixed, 95\% CI) & $9.0[0.49,165.00]$ \\
11 Apgar score 5 min.cont. & & & & $0.0[-0.13,0.13]$ \\
\hline
\end{tabular}




\begin{tabular}{lcccc} 
Outcome or subgroup title & $\begin{array}{c}\text { No. of } \\
\text { studies }\end{array}$ & $\begin{array}{c}\text { No. of } \\
\text { participants }\end{array}$ & Statistical method & Effect size \\
\hline $\begin{array}{l}1 \text { Satisfaction pain relief first } \\
\text { period ordinal partial to } \\
\text { complete }\end{array}$ & 1 & 20 & Risk Ratio (M-H, Fixed, 95\% CI) & $0.56[0.29,1.07]$ \\
$\begin{array}{l}2 \text { Pain intensity first period ordinal } \\
\text { moderate to severe }\end{array}$ & 1 & 19 & Risk Ratio (M-H, Fixed, 95\% CI) & $1.1[0.84,1.45]$ \\
\hline
\end{tabular}

\section{Analysis I.I. Comparison I Nitrous oxide versus flurane derivatives, Outcome I Pain intensity (VAS 0-I00} first stage).

Review: Inhaled analgesia for pain management in labour

Comparison: I Nitrous oxide versus flurane derivatives

Outcome: I Pain intensity (VAS 0-100 first stage)

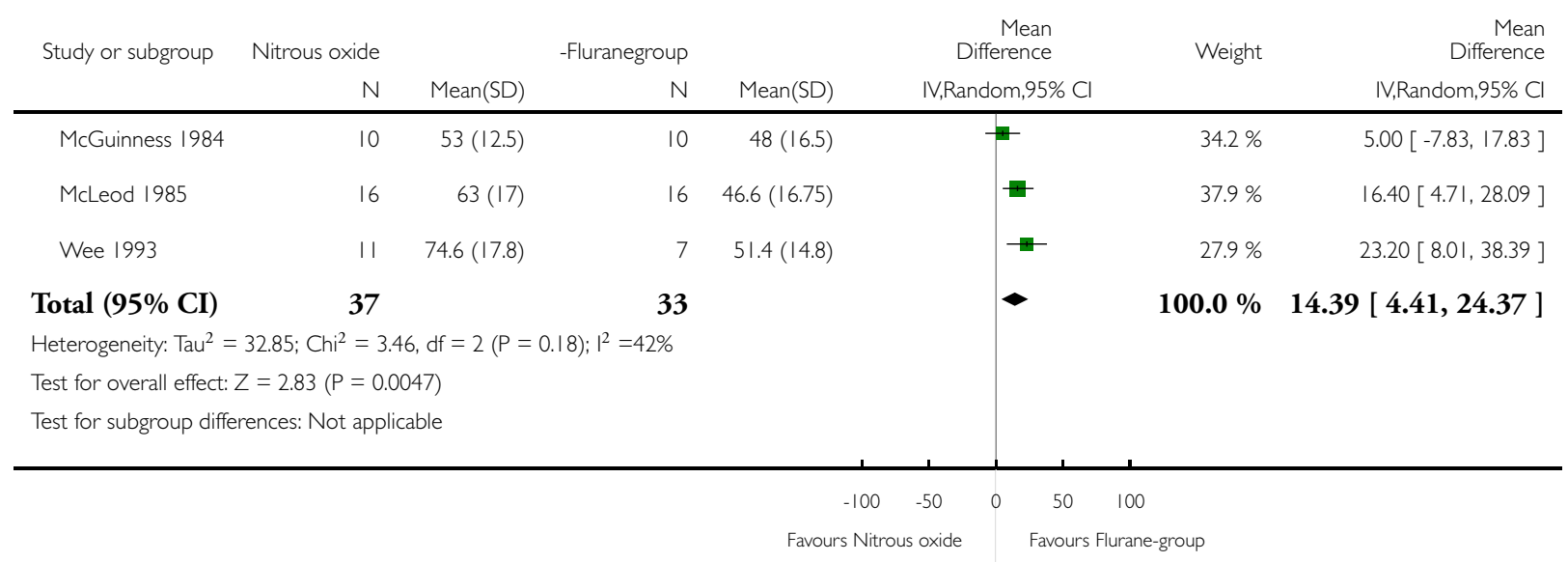


Analysis I.2. Comparison I Nitrous oxide versus flurane derivatives, Outcome 2 Pain relief (VAS 0-I00 as 100 is the most pain relief, first stage).

Review: Inhaled analgesia for pain management in labour

Comparison: I Nitrous oxide versus flurane derivatives

Outcome: 2 Pain relief (VAS 0-100 as 100 is the most pain relief, first stage)

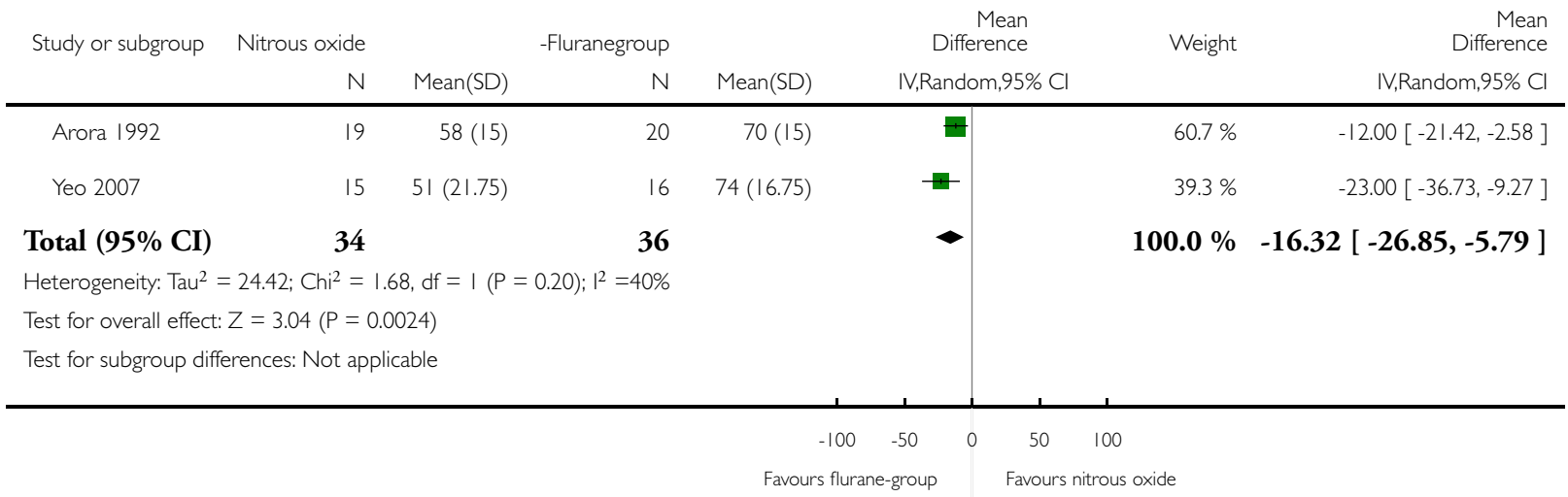

Analysis I.3. Comparison I Nitrous oxide versus flurane derivatives, Outcome 3 Satisfaction with pain relief (first and second stage, considerable to complete).

Review: Inhaled analgesia for pain management in labour

Comparison: I Nitrous oxide versus flurane derivatives

Outcome: 3 Satisfaction with pain relief (first and second stage, considerable to complete)

\begin{tabular}{|c|c|c|c|c|c|}
\hline \multirow[t]{2}{*}{ Study or subgroup } & Nitrous oxide & -Fluranegroup & Risk Ratio & Weight & Risk Ratio \\
\hline & $n / N$ & $\mathrm{n} / \mathrm{N}$ & M-H,Fixed,95\% Cl & & M-H,Fixed,95\% Cl \\
\hline Jones 1969 & $19 / 24$ & $19 / 24$ & & $47.5 \%$ & $1.00[0.75,1.34]$ \\
\hline Jones 1969a & $20 / 25$ & $21 / 25$ & P & $52.5 \%$ & $0.95[0.73,1.24]$ \\
\hline
\end{tabular}

Total (95\% CI)

49

49

Total events: 39 (Nitrous oxide), 40 (-Fluranegroup)

Heterogeneity: $\mathrm{Chi}^{2}=0.06, \mathrm{df}=\mathrm{I}(\mathrm{P}=0.8 \mathrm{I}) ; \mathrm{I}^{2}=0.0 \%$

Test for overall effect: $Z=0.26(P=0.80)$

Test for subgroup differences: Not applicable

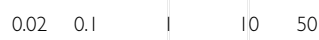

Favours Flurane-group Favours Nitrous oxide

Inhaled analgesia for pain management in labour (Review)

Copyright @ 2012 The Cochrane Collaboration. Published by John Wiley \& Sons, Ltd. 
Analysis I.4. Comparison I Nitrous oxide versus flurane derivatives, Outcome 4 Satisfaction with pain relief (second stage, good to excellent).

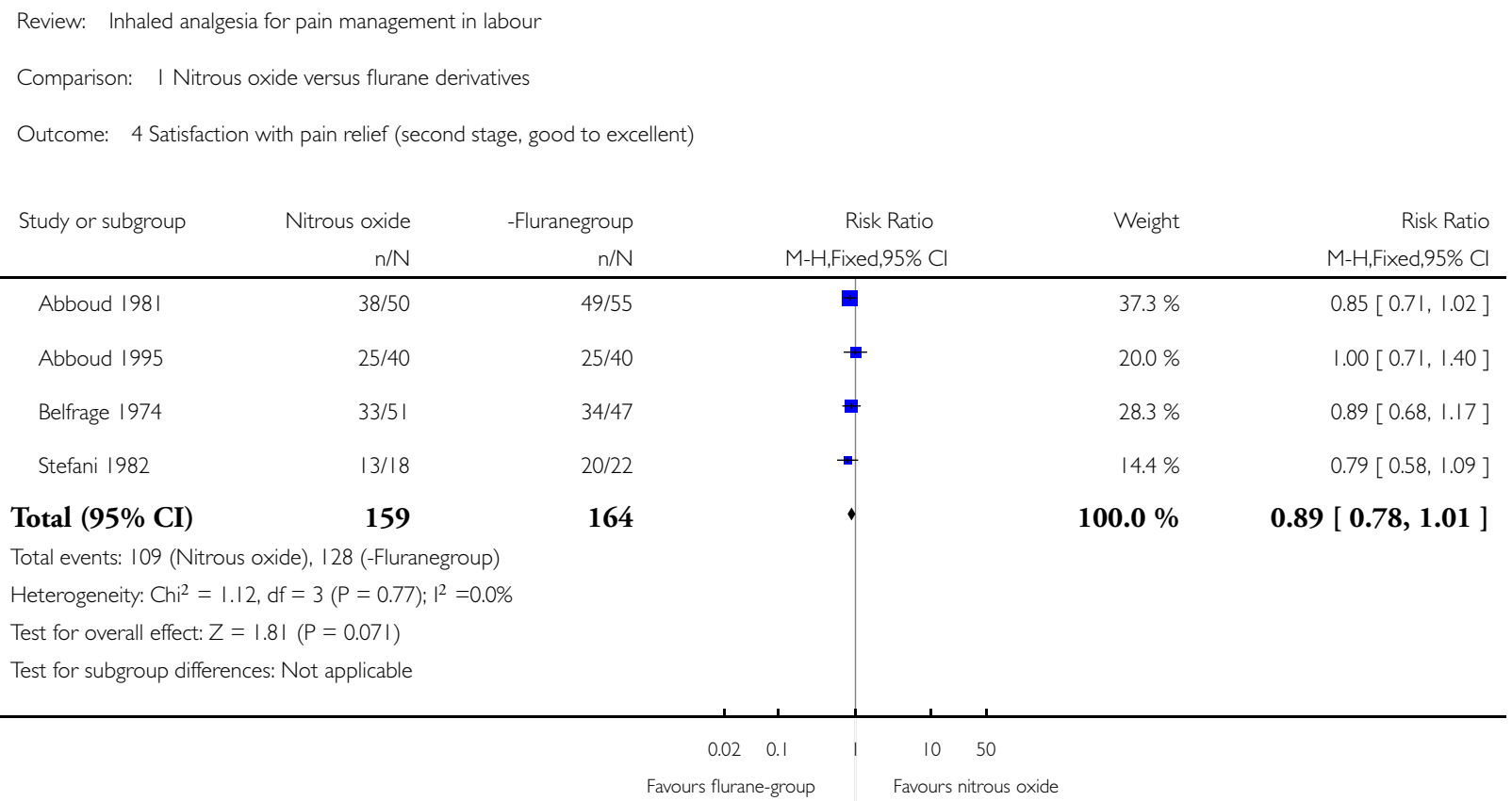




\section{Analysis I.5. Comparison I Nitrous oxide versus flurane derivatives, Outcome 5 Assisted vaginal birth.}

Review: Inhaled analgesia for pain management in labour

Comparison: I Nitrous oxide versus flurane derivatives

Outcome: 5 Assisted vaginal birth

\begin{tabular}{|c|c|c|c|c|c|}
\hline Study or subgroup & $\begin{array}{r}\text { Nitrous oxide } \\
n / N\end{array}$ & -Fluranegroup & $\begin{array}{r}\text { Risk Ratio } \\
\text { M- } \\
\text { H,Random,95\% } \\
\text { Cl }\end{array}$ & Weight & $\begin{array}{c}\text { Risk Ratio } \\
\text { M- } \\
\text { H,Random,95\% } \\
\text { Cl }\end{array}$ \\
\hline Abboud 1981 & $18 / 50$ & $18 / 55$ & - & $35.0 \%$ & $1.10[0.65,1.87]$ \\
\hline Abboud 1995 & $5 / 40$ & $9 / 40$ & $\rightarrow$ & $17.0 \%$ & $0.56[0.20,1.51]$ \\
\hline Belfrage 1974 & $3 / 51$ & $4 / 47$ & $\longrightarrow$ & $9.6 \%$ & $0.69[0.16,2.93]$ \\
\hline Jones 1969 & $5 / 24$ & $5 / 24$ & $\longrightarrow$ & $14.7 \%$ & $1.00[0.33,3.01]$ \\
\hline Stefani 1982 & $5 / 18$ & $17 / 22$ & $\rightarrow-$ & $23.7 \%$ & $0.36[0.17,0.78]$ \\
\hline
\end{tabular}

Total (95\% CI)

183

188

$100.0 \%$

0.71 [ $0.44,1.15$ ]

Total events: 36 (Nitrous oxide), 53 (-Fluranegroup)

Heterogeneity: $\operatorname{Tau}^{2}=0.10 ; \mathrm{Chi}^{2}=6.08, \mathrm{df}=4(\mathrm{P}=0.19) ; \mathrm{I}^{2}=34 \%$

Test for overall effect: $Z=1.38(P=0.17)$

Test for subgroup differences: Not applicable

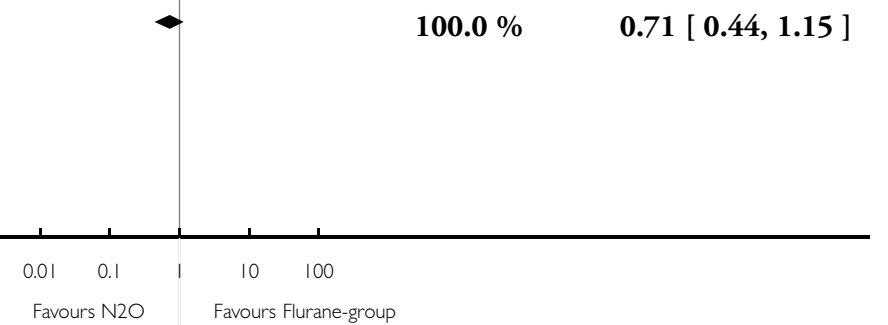


Analysis I.6. Comparison I Nitrous oxide versus flurane derivatives, Outcome 6 Caesarean section.

Review: Inhaled analgesia for pain management in labour

Comparison: I Nitrous oxide versus flurane derivatives

Outcome: 6 Caesarean section

$\begin{array}{llll}\text { Study or subgroup } & \text { Nitrous oxide } & \text {-Fluranegroup } & \text { Risk Ratio Ratio }\end{array}$

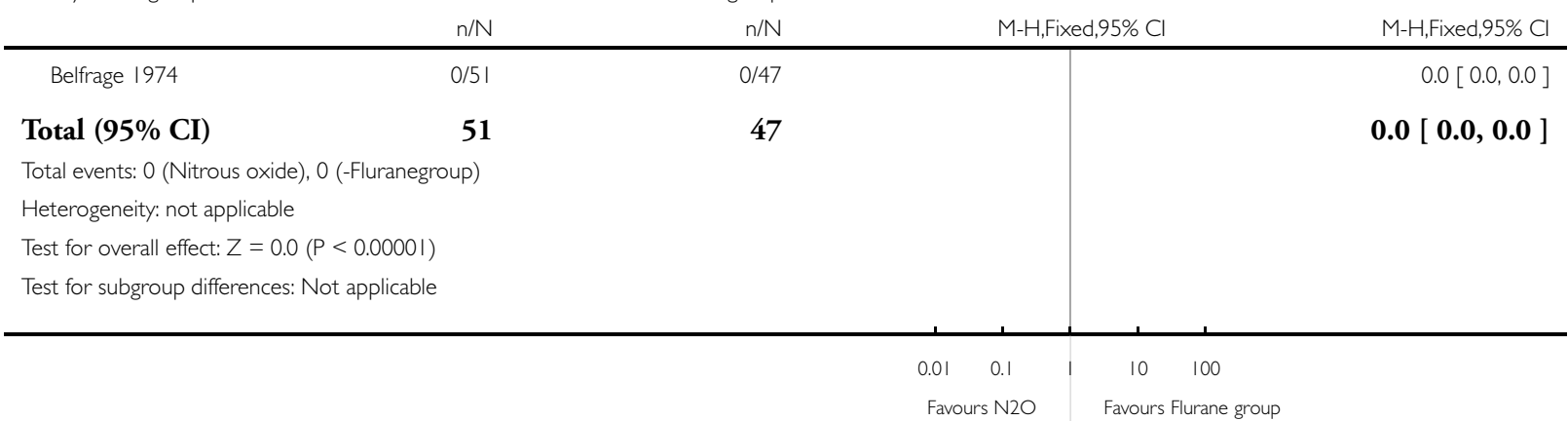

Analysis I.7. Comparison I Nitrous oxide versus flurane derivatives, Outcome 7 Amnesia.

Review: Inhaled analgesia for pain management in labour

Comparison: I Nitrous oxide versus flurane derivatives

Outcome: 7 Amnesia

Study or subgroup

Nitrous oxide

-Fluranegroup

Risk Ratio

$M$ -

H,Random,95\%

\begin{tabular}{lc} 
& $\mathrm{n} / \mathrm{N}$ \\
\hline Abboud 1981 & $5 / 50$ \\
Abboud 1995 & $0 / 40$ \\
Swart 1991 & $1 / 30$
\end{tabular}

Total (95\% CI)

120

$\mathrm{n} / \mathrm{N}$

C

4/55

$\longrightarrow$

$9 / 40$

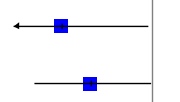

$8 / 30$

125

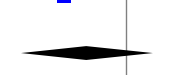

Total events: 6 (Nitrous oxide), 21 (-Fluranegroup)

Heterogeneity: $\mathrm{Tau}^{2}=2.76 ; \mathrm{Chi}^{2}=7.62, \mathrm{df}=2(\mathrm{P}=0.02) ; \mathrm{I}^{2}=74 \%$

Test for overall effect: $Z=1.19(P=0.23)$

Test for subgroup differences: Not applicable

Weight Risk Ratio H,Random, $95 \%$

$40.2 \%$

$26.5 \%$ $1.38[0.39,4.84]$

$33.4 \%$ $0.05[0.00,0.87]$ $0.13[0.02,0.94]$ $0.26[0.03,2.38$ ]

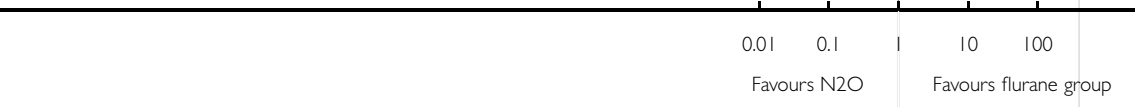

Inhaled analgesia for pain management in labour (Review)

Copyright $\odot 2012$ The Cochrane Collaboration. Published by John Wiley \& Sons, Ltd. 
Analysis I.8. Comparison I Nitrous oxide versus flurane derivatives, Outcome 8 Drowsiness (VAS 0-I00 $\mathbf{m m})$.

Review: Inhaled analgesia for pain management in labour

Comparison: I Nitrous oxide versus flurane derivatives

Outcome: 8 Drowsiness (VAS 0-100 mm)

\begin{tabular}{|c|c|c|c|c|c|c|c|c|c|c|}
\hline \multirow[t]{2}{*}{ Study or subgroup } & \multirow{2}{*}{$\begin{array}{r}\text {-Fluranegroup } \\
N\end{array}$} & \multicolumn{4}{|c|}{ Nitrous oxide } & \multicolumn{2}{|c|}{$\begin{array}{l}\text { Mean } \\
\text { Difference }\end{array}$} & \multicolumn{2}{|r|}{ Weight } & \multirow{2}{*}{$\begin{array}{r}\text { Mean } \\
\text { Difference } \\
\text { IV,Fixed,95\% Cl }\end{array}$} \\
\hline & & Mean(SD) & N & Mean(SD) & & \multicolumn{2}{|c|}{ IV,Fixed,95\% Cl } & & & \\
\hline Wee 1993 & 8 & $83.14(24.12)$ & 10 & $71.5(35.6)$ & & & , & $\longrightarrow$ & $100.0 \%$ & | $1.64[-16.04,39.32]$ \\
\hline Total (95\% CI) & 8 & & 10 & & & & & & $100.0 \%$ & $11.64[-16.04,39.32]$ \\
\hline \multicolumn{11}{|c|}{ Heterogeneity: not applicable } \\
\hline \multicolumn{11}{|c|}{ Test for overall effect: $Z=0.82(P=0.4 I)$} \\
\hline \multicolumn{11}{|c|}{ Test for subgroup differences: Not applicable } \\
\hline & & & & & -20 & -10 & 10 & 20 & & \\
\hline \multicolumn{11}{|c|}{ Favours Flurane group } \\
\hline
\end{tabular}




\section{Analysis 1.9. Comparison I Nitrous oxide versus flurane derivatives, Outcome 9 Nausea.}

\begin{tabular}{|c|c|c|c|c|c|}
\hline \multicolumn{6}{|c|}{ Comparison: I Nitrous oxide versus flurane derivatives } \\
\hline \multicolumn{6}{|c|}{ Outcome: 9 Nausea } \\
\hline \multirow[t]{2}{*}{ Study or subgroup } & Nitrous oxide & -Fluranegroup & Risk Ratio & Weight & Risk Ratio \\
\hline & $n / N$ & $n / N$ & M-H,Fixed,95\% Cl & & M-H,Fixed,95\% Cl \\
\hline Jones 1969 & $8 / 24$ & 2/24 & 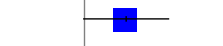 & $80.0 \%$ & $4.00[0.95,16.92]$ \\
\hline Jones 1969a & $8 / 25$ & $0 / 25$ & $\longrightarrow$ & $20.0 \%$ & $17.00[1.03,279.53]$ \\
\hline Total $(95 \% \mathrm{CI})$ & 49 & 49 & $\longrightarrow$ & $100.0 \%$ & $6.60[1.85,23.52]$ \\
\hline \multicolumn{6}{|c|}{ Total events: 16 (Nitrous oxide), 2 (-Fluranegroup) } \\
\hline \multicolumn{6}{|c|}{ Heterogeneity: $\mathrm{Ch}^{2}=0.90, \mathrm{df}=1(P=0.34) ;\left.\right|^{2}=0.0 \%$} \\
\hline \multicolumn{6}{|c|}{ Test for overall effect: $Z=2.91(P=0.0036)$} \\
\hline Test for subgroup dif & : Not applicable & & & & \\
\hline
\end{tabular}

$\begin{array}{llcc}0.01 \quad 0.1 & 1 & 10 \quad 100 \\ \text { Favours N2O } & \text { Favours Flurane-group }\end{array}$

Analysis I.10. Comparison I Nitrous oxide versus flurane derivatives, Outcome 10 Vomiting.

Review: Inhaled analgesia for pain management in labour

Comparison: I Nitrous oxide versus flurane derivatives

Outcome: 10 Vomiting

\begin{tabular}{|c|c|c|c|c|c|}
\hline \multirow[t]{2}{*}{ Study or subgroup } & Nitrous oxide & -Fluranegroup & Risk Ratio & Weight & Risk Ratio \\
\hline & $\mathrm{n} / \mathrm{N}$ & $\mathrm{n} / \mathrm{N}$ & M-H,Fixed,95\% Cl & & M-H,Fixed,95\% Cl \\
\hline Abboud |98| & $1 / 50$ & 0/55 & 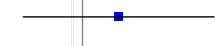 & $9.6 \%$ & $3.29[0.14,79.06]$ \\
\hline Jones 1969 & $6 / 24$ & $4 / 24$ & & $80.4 \%$ & $1.50[0.48,4.65]$ \\
\hline Jones 1969a & $2 / 25$ & $0 / 25$ & & $10.0 \%$ & $5.00[0.25,99.16]$ \\
\hline Total (95\% CI) & 99 & 104 & & $0.0 \%$ & $2[0.75,5.46$ \\
\hline
\end{tabular}

Total events: 9 (Nitrous oxide), 4 (-Fluranegroup)

Heterogeneity: $\mathrm{Chi}^{2}=0.7 \mathrm{I}, \mathrm{df}=2(\mathrm{P}=0.70) ; \mathrm{I}^{2}=0.0 \%$

Test for overall effect: $Z=1.39(P=0.16)$

Test for subgroup differences: Not applicable 
Analysis I.I I. Comparison I Nitrous oxide versus flurane derivatives, Outcome I I Blood loss in $\mathrm{mL}$.

Review: Inhaled analgesia for pain management in labour

Comparison: I Nitrous oxide versus flurane derivatives

Outcome: I I Blood loss in $\mathrm{mL}$

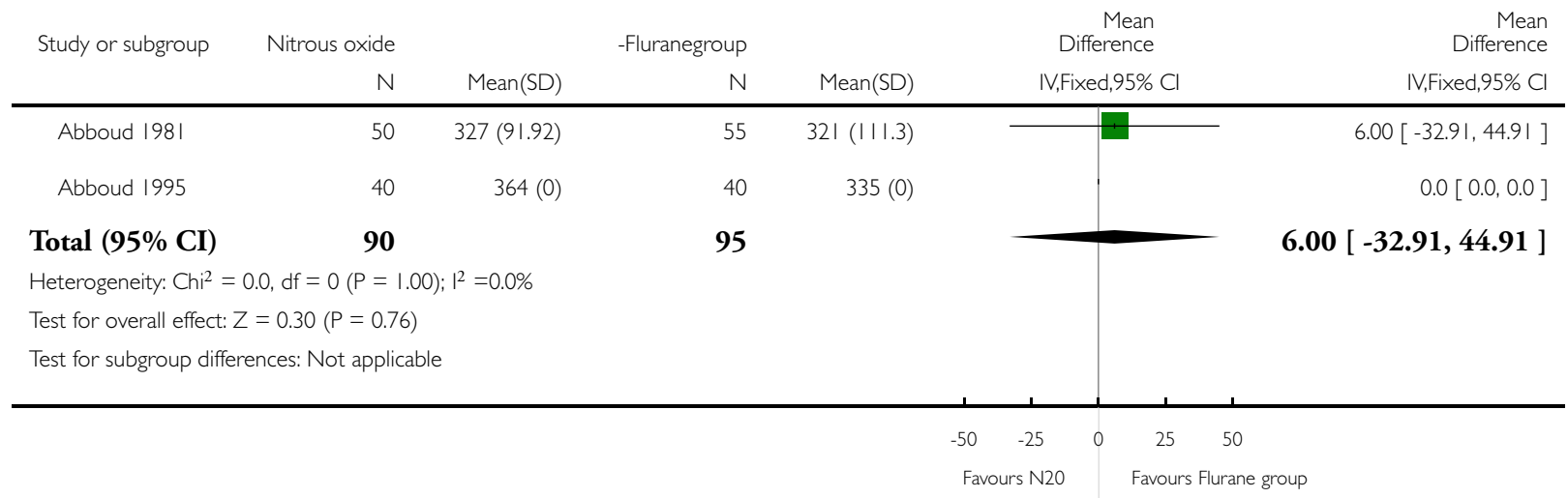


Analysis I.I2. Comparison I Nitrous oxide versus flurane derivatives, Outcome I 2 Apgar score less than seven at five minutes.

Review: Inhaled analgesia for pain management in labour

Comparison: I Nitrous oxide versus flurane derivatives

Outcome: 12 Apgar score less than seven at five minutes

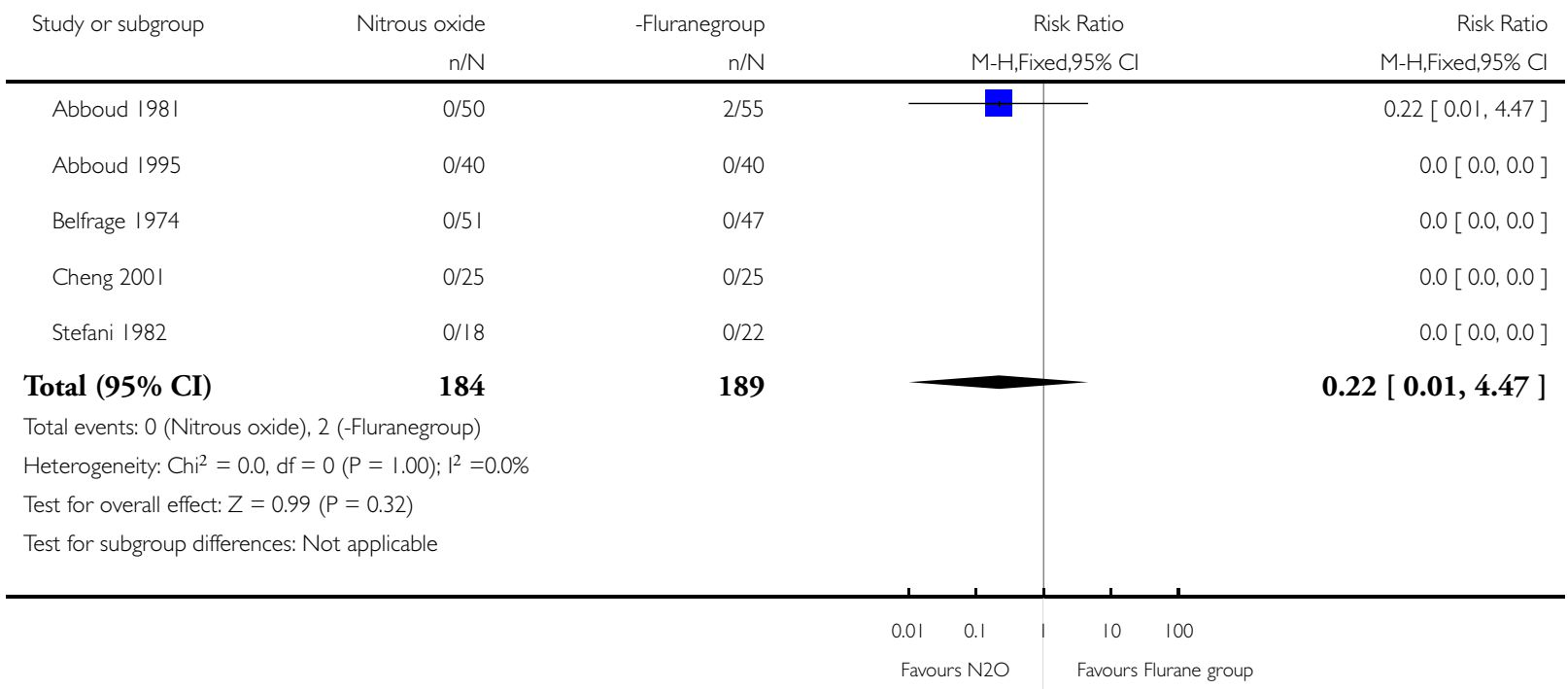


Analysis I.13. Comparison I Nitrous oxide versus flurane derivatives, Outcome I 3 NACS $<35$ at 2 hours after delivery.

Review: Inhaled analgesia for pain management in labour

Comparison: I Nitrous oxide versus flurane derivatives

Outcome: 13 NACS $<35$ at 2 hours after delivery

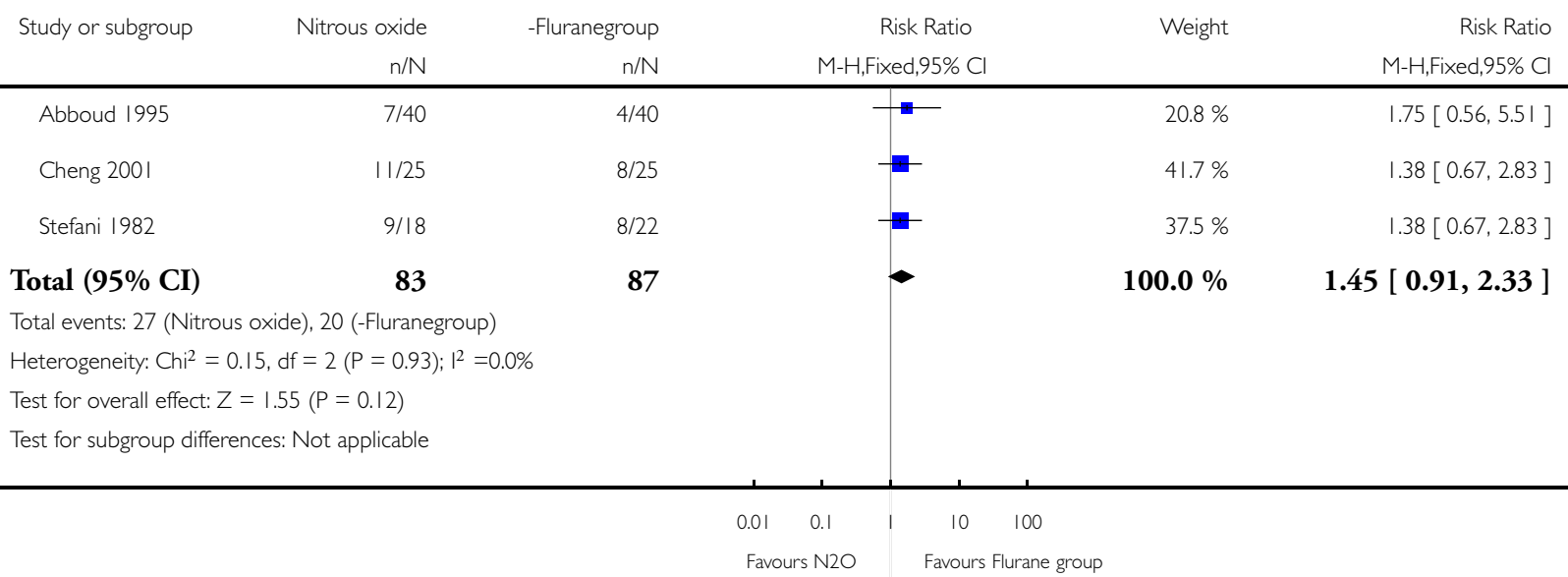

Analysis 2.I. Comparison 2 Inhaled analgesia of one strength versus inhaled analgesia of different strength, Outcome I Satisfaction with pain relief (first stage, good to complete).

Review: Inhaled analgesia for pain management in labour

Comparison: 2 Inhaled analgesia of one strength versus inhaled analgesia of different strength

Outcome: I Satisfaction with pain relief (first stage, good to complete)

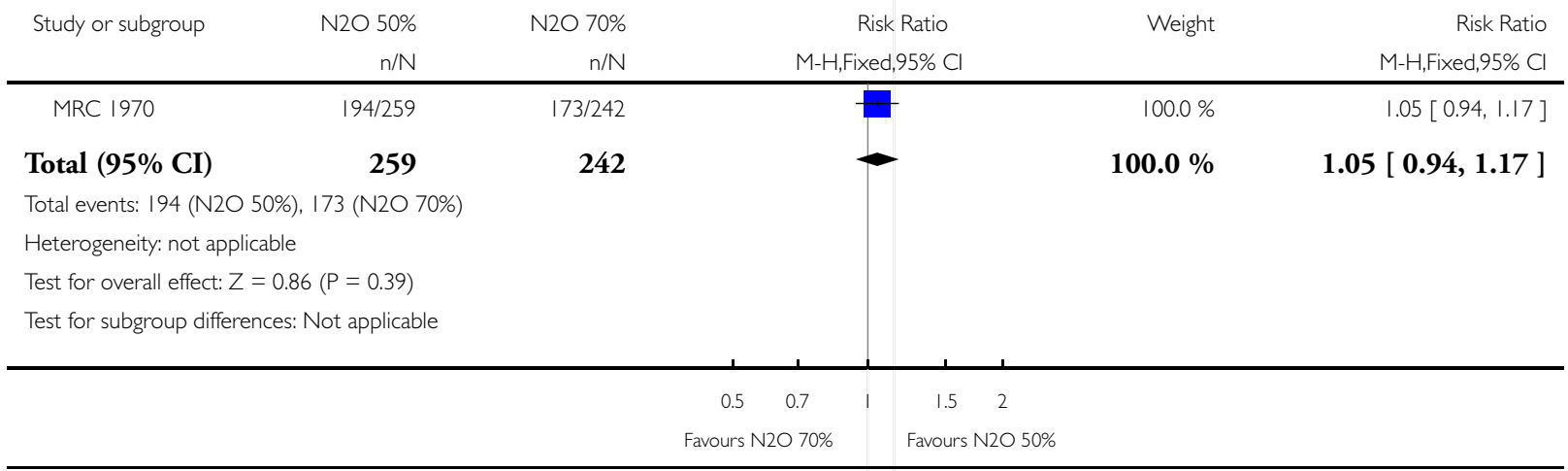

Inhaled analgesia for pain management in labour (Review)

Copyright $\odot 2012$ The Cochrane Collaboration. Published by John Wiley \& Sons, Ltd. 


\section{Analysis 2.2. Comparison 2 Inhaled analgesia of one strength versus inhaled analgesia of different strength,}

Outcome 2 Satisfaction with pain relief (second stage, good to complete).

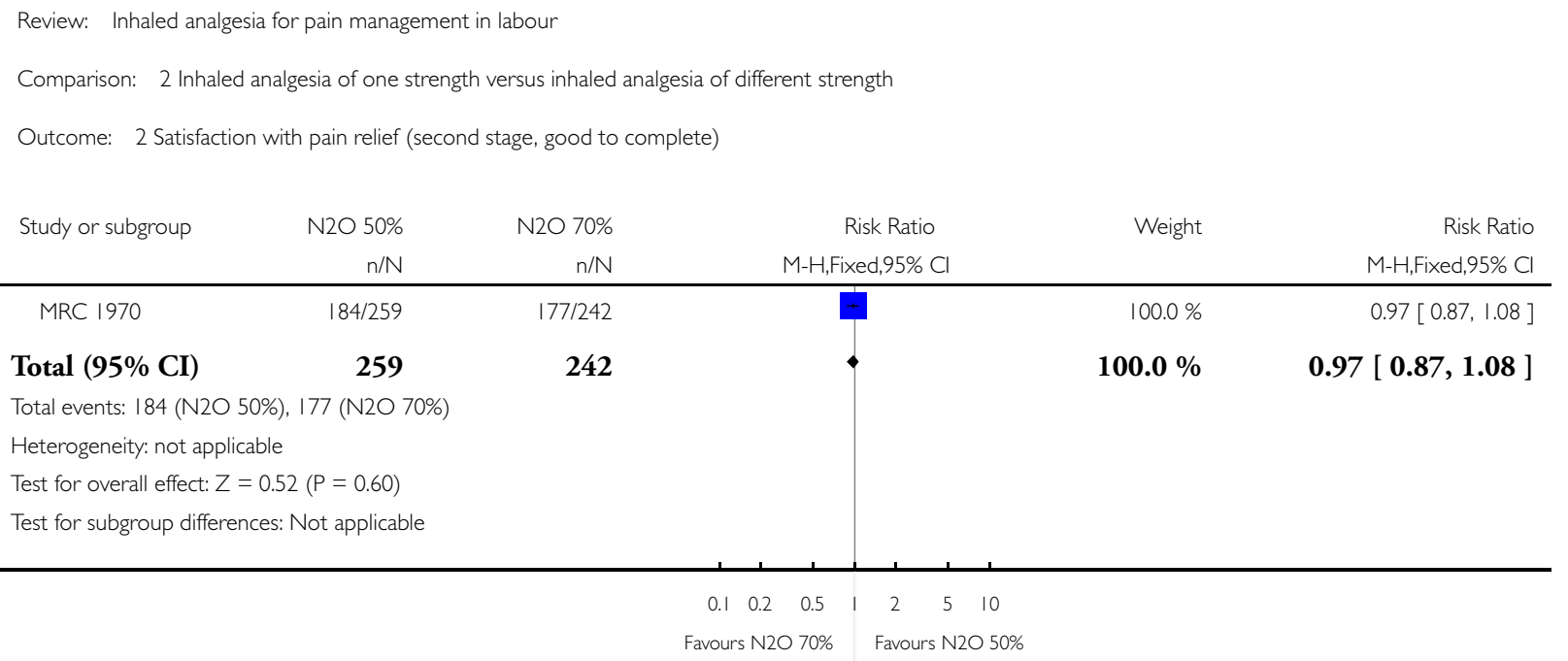


Analysis 2.3. Comparison 2 Inhaled analgesia of one strength versus inhaled analgesia of different strength, Outcome 3 Caesarean section.

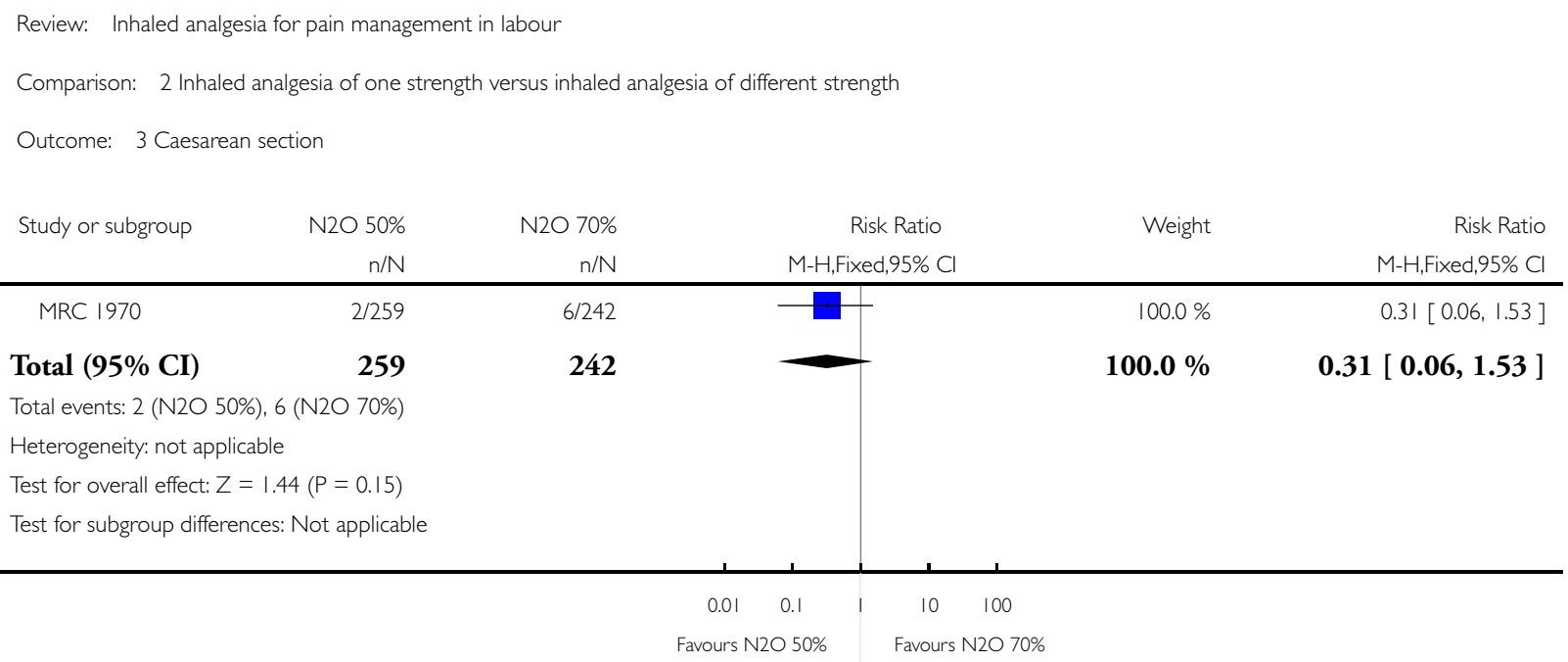

Analysis 2.4. Comparison 2 Inhaled analgesia of one strength versus inhaled analgesia of different strength, Outcome 4 Assisted vaginal birth.

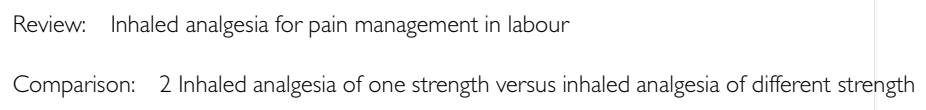

\begin{tabular}{|c|c|c|c|c|c|c|}
\hline \multirow[t]{2}{*}{ Study or subgroup } & $\mathrm{N} 2 \mathrm{O} 50 \%$ & $\mathrm{~N} 2 \mathrm{O} 70 \%$ & \multirow{2}{*}{\multicolumn{2}{|c|}{$\begin{array}{c}\text { Risk Ratio } \\
\text { M-H,Fixed,95\% Cl }\end{array}$}} & \multirow[t]{2}{*}{ Weight } & Risk Ratio \\
\hline & $n / N$ & $n / N$ & & & & M-H,Fixed,95\% Cl \\
\hline MRC 1970 & $57 / 259$ & $64 / 242$ & & $E$ & $100.0 \%$ & $0.83[0.61,1.14]$ \\
\hline Total $(95 \% \mathrm{CI})$ & 259 & 242 & & $\bullet$ & $100.0 \%$ & $0.83[0.61,1.14]$ \\
\hline \multicolumn{7}{|c|}{ Total events: 57 (N2O 50\%), 64 (N2O 70\%) } \\
\hline \multicolumn{7}{|c|}{ Heterogeneity: not applicable } \\
\hline \multicolumn{7}{|c|}{ Test for overall effect: $Z=1.16(P=0.25)$} \\
\hline Test for subgroup diff & Vot applicable & & & & & \\
\hline
\end{tabular}


Analysis 2.5. Comparison 2 Inhaled analgesia of one strength versus inhaled analgesia of different strength, Outcome 5 Vomiting.

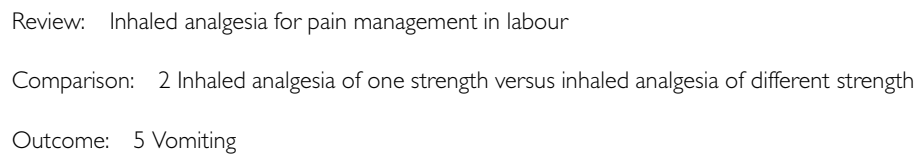

$\begin{array}{lllll}\text { Total }(95 \% \mathrm{CI}) & 259 & 242 & 100.0 \% & 1.29[0.86,1.94]\end{array}$

Total events: 47 (N2O 50\%), 34 (N2O 70\%)

Heterogeneity: not applicable

Test for overall effect: $Z=1.24(P=0.22)$

Test for subgroup differences: Not applicable

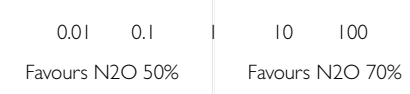

Analysis 2.6. Comparison 2 Inhaled analgesia of one strength versus inhaled analgesia of different strength, Outcome 6 Postpartum haemorrhage.

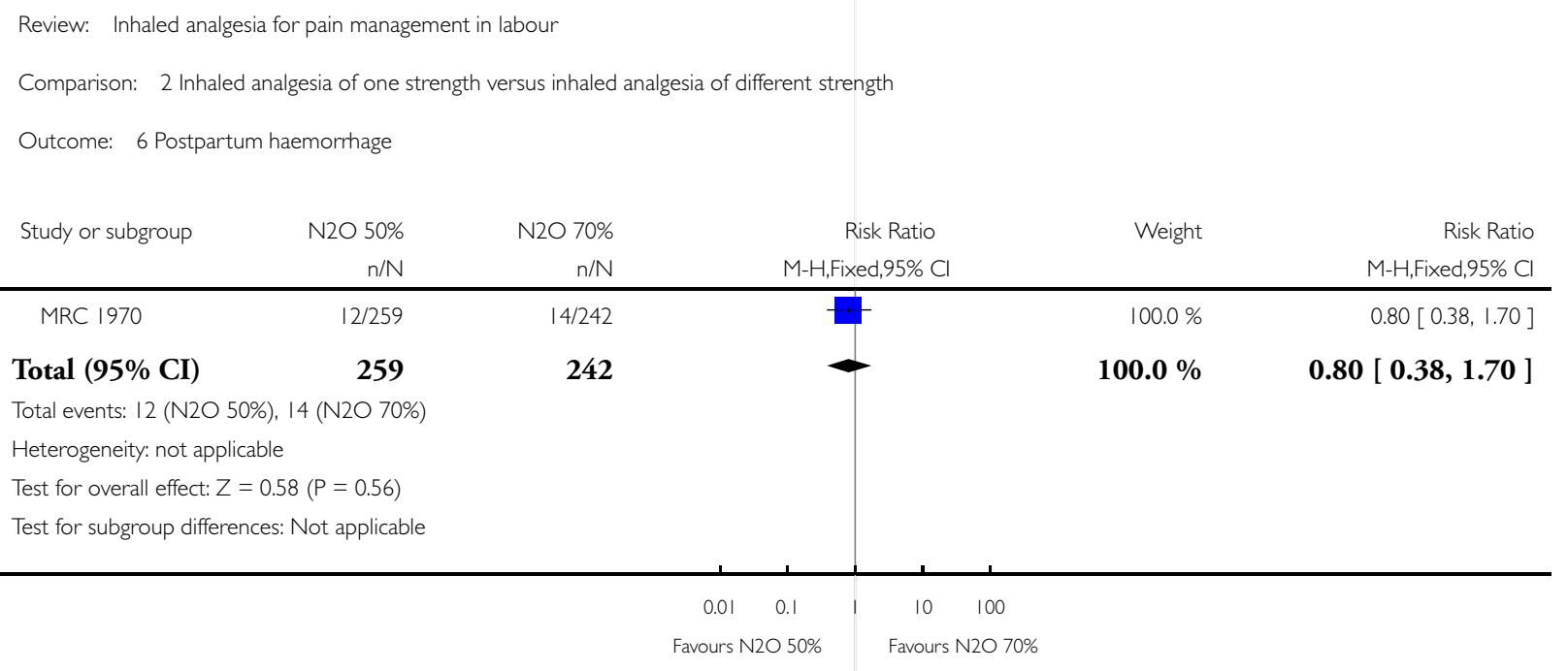


Analysis 2.7. Comparison 2 Inhaled analgesia of one strength versus inhaled analgesia of different strength, Outcome 7 Hypoxaemia mother.

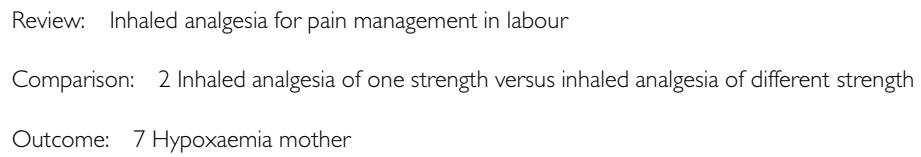

\begin{tabular}{|c|c|c|c|c|c|}
\hline \multirow[t]{2}{*}{ Study or subgroup } & $\mathrm{N} 2 \mathrm{O} 50 \%$ & $\mathrm{~N} 2 \mathrm{O} 70 \%$ & Risk Ratio & Weight & Risk Ratio \\
\hline & $\mathrm{n} / \mathrm{N}$ & $\mathrm{n} / \mathrm{N}$ & M-H,Fixed,95\% Cl & & M-H,Fixed,95\% Cl \\
\hline Einarsson 1996 & $1 / 12$ & $1 / 12$ & & $100.0 \%$ & $1.00[0.07,14.21]$ \\
\hline Total (95\% CI) & 12 & 12 & & $100.0 \%$ & $1.00[0.07,14.21]$ \\
\hline \multicolumn{6}{|c|}{ Total events: I (N2O 50\%), I (N2O 70\%) } \\
\hline \multicolumn{6}{|c|}{ Heterogeneity: not applicable } \\
\hline \multicolumn{6}{|c|}{ Test for overall effect: $Z=0.0(P=1.0)$} \\
\hline Test for subgroup diffe & Not applicable & & & & \\
\hline
\end{tabular}

Analysis 3.1. Comparison 3 Inhaled analgesia using one type of delivery system versus a different delivery system, Outcome I Satisfaction with pain relief (first stage, considerable to complete).

Review: Inhaled analgesia for pain management in labour

Comparison: 3 Inhaled analgesia using one type of delivery system versus a different delivery system

Outcome: I Satisfaction with pain relief (first stage, considerable to complete)

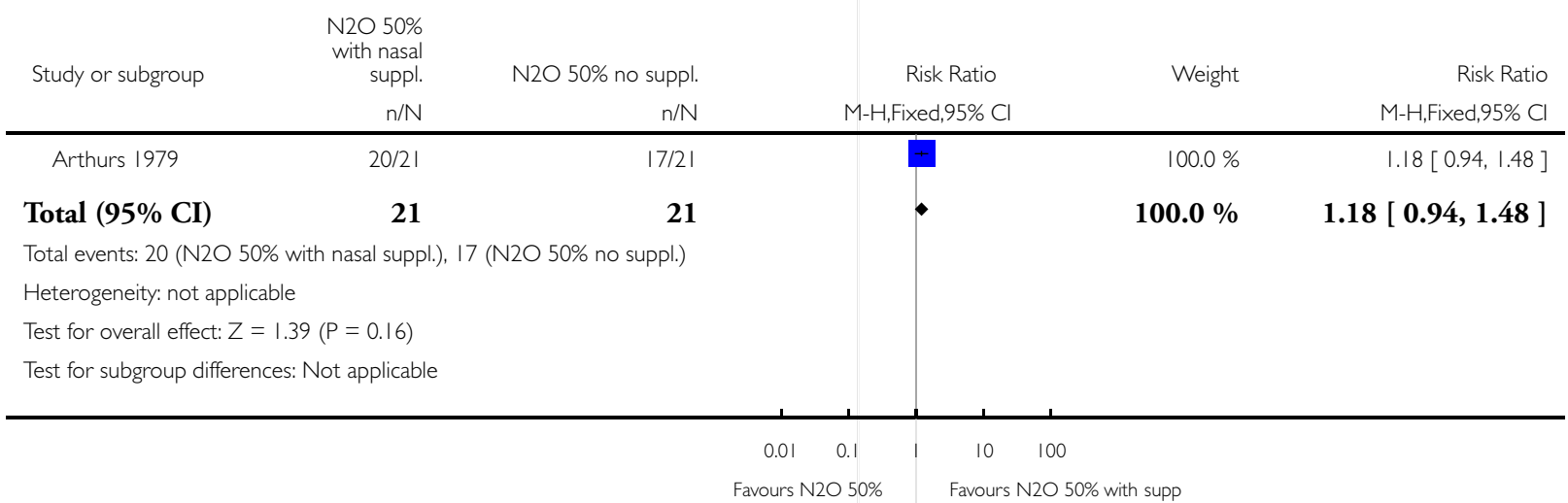


Analysis 3.2. Comparison 3 Inhaled analgesia using one type of delivery system versus a different delivery system, Outcome 2 Caesarean section.

Review: Inhaled analgesia for pain management in labour

Comparison: 3 Inhaled analgesia using one type of delivery system versus a different delivery system

Outcome: 2 Caesarean section

\begin{tabular}{|c|c|c|c|c|c|c|}
\hline \multirow[t]{2}{*}{ Study or subgroup } & $\begin{array}{r}\text { Meth. } \\
\text { Penthrane } \\
\text { Analg. }\end{array}$ & $\begin{array}{c}\text { Meth.Cyprane } \\
\text { inhaler }\end{array}$ & & \multirow{2}{*}{$\begin{array}{c}\text { Risk Ratio } \\
\text { M-H,Fixed,95\% Cl }\end{array}$} & \multirow[t]{2}{*}{ Weight } & \multirow{2}{*}{$\begin{array}{r}\text { Risk Ratio } \\
\text { M-H,Fixed,95\% Cl }\end{array}$} \\
\hline & $\mathrm{n} / \mathrm{N}$ & $\mathrm{n} / \mathrm{N}$ & & & & \\
\hline Enrile 1973 & $1 / 14$ & $0 / 12$ & & - & $100.0 \%$ & $2.60[0.12,58.48]$ \\
\hline Total (95\% CI) & 14 & 12 & & & $100.0 \%$ & $2.60[0.12,58.48]$ \\
\hline \multicolumn{7}{|c|}{ Total events: I (Meth. Penthrane Analg.), 0 (Meth.Cyprane inhaler) } \\
\hline \multicolumn{7}{|c|}{ Heterogeneity: not applicable } \\
\hline \multicolumn{7}{|c|}{ Test for overall effect: $Z=0.60(P=0.55)$} \\
\hline \multicolumn{7}{|c|}{ Test for subgroup differences: Not applicable } \\
\hline & & & 0.01 & 0.1 & 100 & \\
\hline
\end{tabular}

Analysis 3.3. Comparison 3 Inhaled analgesia using one type of delivery system versus a different delivery system, Outcome 3 Vomiting (N2O + nasal).

Review: Inhaled analgesia for pain management in labour

Comparison: 3 Inhaled analgesia using one type of delivery system versus a different delivery system

Outcome: 3 Vomiting $(\mathrm{N} 2 \mathrm{O}+$ nasal)

\begin{tabular}{|c|c|c|c|c|c|}
\hline \multirow[t]{2}{*}{ Study or subgroup } & $\mathrm{N} 2 \mathrm{O} 50 \%$ & with nasal suppl. & Risk Ratio & Weight & Risk Ratio \\
\hline & $\mathrm{n} / \mathrm{N}$ & $\mathrm{n} / \mathrm{N}$ & M-H,Fixed,95\% Cl & & M-H,Fixed,95\% Cl \\
\hline Arthurs 1979 & $11 / 25$ & $6 / 24$ & & $100.0 \%$ & $1.76[0.77,4.00]$ \\
\hline Total (95\% CI) & 25 & 24 & & $100.0 \%$ & $1.76[0.77,4.00$ \\
\hline
\end{tabular}

Total events: II (N2O 50\%), 6 (with nasal suppl.)

Heterogeneity: not applicable

Test for overall effect: $Z=1.35(P=0.18)$

Test for subgroup differences: Not applicable

$\begin{array}{ccccc}0.01 & 0.1 & 1 & 10 & 100 \\ \text { Favours N2O 50\% } & & \text { Favours N2O nasal suppl. }\end{array}$


Analysis 3.4. Comparison 3 Inhaled analgesia using one type of delivery system versus a different delivery system, Outcome 4 Vomiting dichotomous Penthr./Cypr..

Review: Inhaled analgesia for pain management in labour

Comparison: 3 Inhaled analgesia using one type of delivery system versus a different delivery system

Outcome: 4 Vomiting dichotomous Penthr./Cypr.

\begin{tabular}{cccc} 
Study or subgroup & $\begin{array}{r}\text { Penthrane analgizer } \\
\mathrm{n} / \mathrm{N}\end{array}$ & $\begin{array}{c}\text { Ryprane inhaler } \\
\mathrm{n} / \mathrm{N}\end{array}$ & $\mathrm{M}-\mathrm{H}, \mathrm{Fixed}, 95 \% \mathrm{Cl}$ \\
\hline Enrile 1973 & $0 / 14$ & $0 / 12$ & $\mathrm{M}-\mathrm{H}, \mathrm{Fixed}, 95 \% \mathrm{Cl}$ \\
\hline
\end{tabular}

Total (95\% CI)

14

12

$0.0[0.0,0.0$ ]

Total events: 0 (Penthrane analgizer), 0 (Cyprane inhaler)

Heterogeneity: not applicable

Test for overall effect: $Z=0.0(P<0.00001)$

Test for subgroup differences: Not applicable

$\begin{array}{ccccc}0.01 & 0.1 & 1 & 10 & 100 \\ \text { Favours penthrane analgiz } & & \text { Favours cyprane inhaler }\end{array}$

Analysis 3.5. Comparison 3 Inhaled analgesia using one type of delivery system versus a different delivery system, Outcome 5 Postpartum haemorrhage.

Review: Inhaled analgesia for pain management in labour

Comparison: 3 Inhaled analgesia using one type of delivery system versus a different delivery system

Outcome: 5 Postpartum haemorrhage

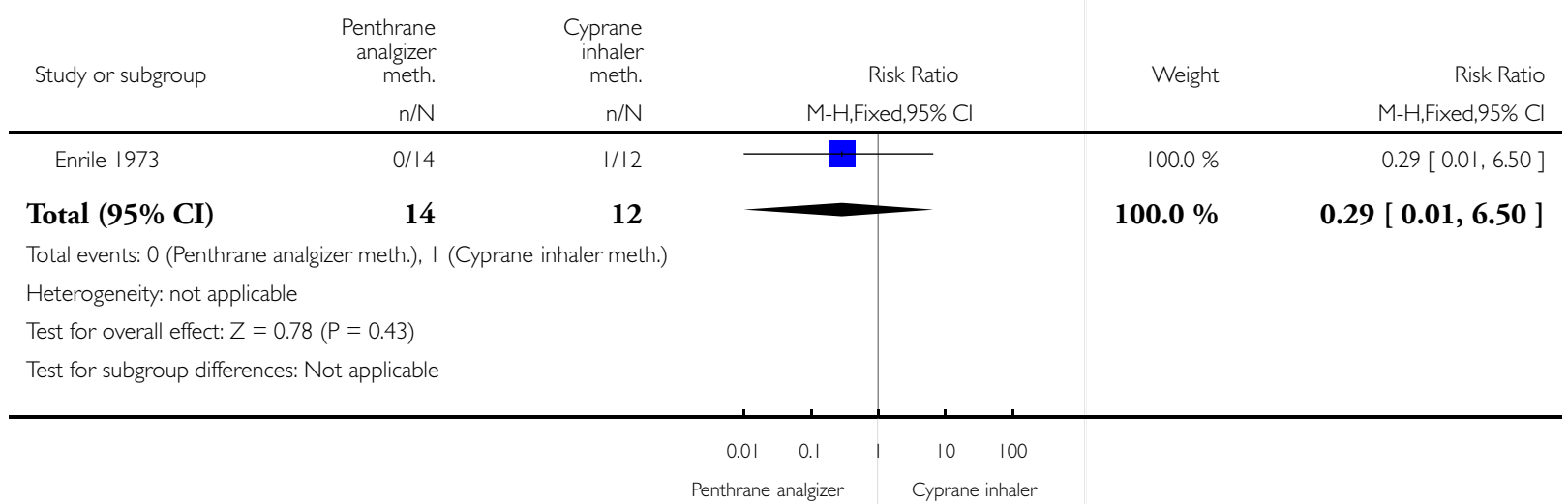

Inhaled analgesia for pain management in labour (Review)

Copyright @ 2012 The Cochrane Collaboration. Published by John Wiley \& Sons, Ltd. 
Analysis 3.6. Comparison 3 Inhaled analgesia using one type of delivery system versus a different delivery system, Outcome 6 Mild pre-eclampsia.

Review: Inhaled analgesia for pain management in labour

Comparison: 3 Inhaled analgesia using one type of delivery system versus a different delivery system

Outcome: 6 Mild pre-eclampsia

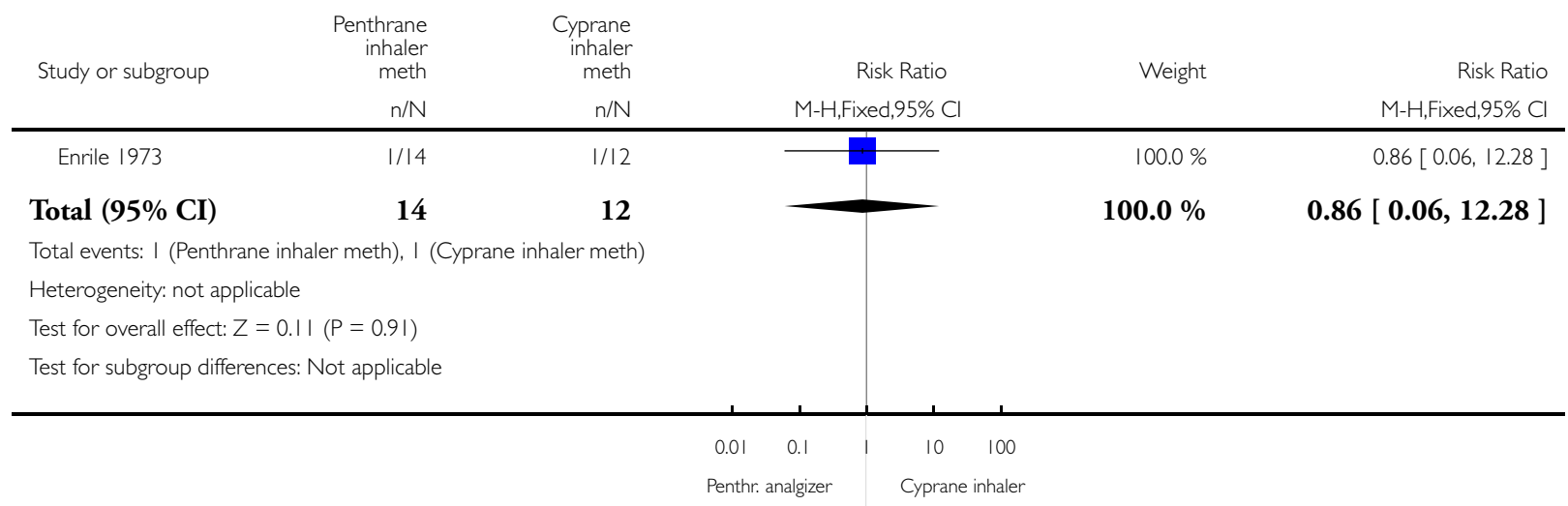

Analysis 3.7. Comparison 3 Inhaled analgesia using one type of delivery system versus a different delivery system, Outcome 7 Apgar score (continuous, at 5 min.Penthr/Cypr).

Review: Inhaled analgesia for pain management in labour

Comparison: 3 Inhaled analgesia using one type of delivery system versus a different delivery system

Outcome: 7 Apgar score (continuous, at 5 min.Penthr/Cypr)

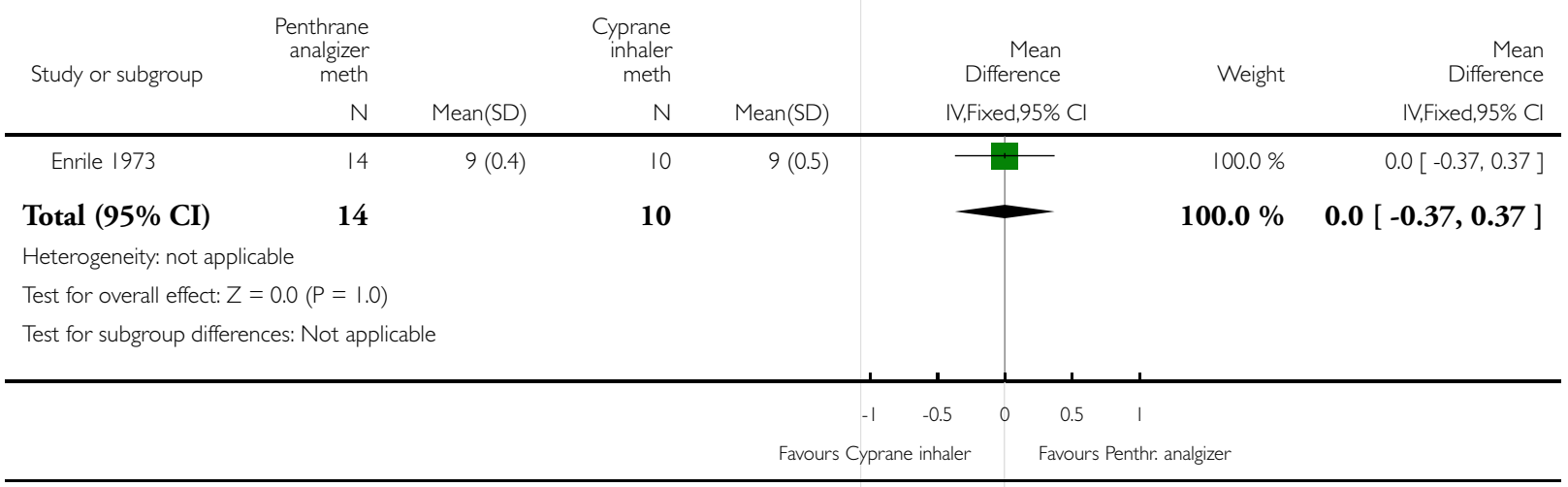

Inhaled analgesia for pain management in labour (Review)

Copyright $\odot 2012$ The Cochrane Collaboration. Published by John Wiley \& Sons, Ltd. 
Analysis 3.8. Comparison 3 Inhaled analgesia using one type of delivery system versus a different delivery system, Outcome 8 Apgar score (continuous N2O/N2O with nasal suppl.).

Review: Inhaled analgesia for pain management in labour

Comparison: 3 Inhaled analgesia using one type of delivery system versus a different delivery system

Outcome: 8 Apgar score (continuous N2O/N2O with nasal suppl.)

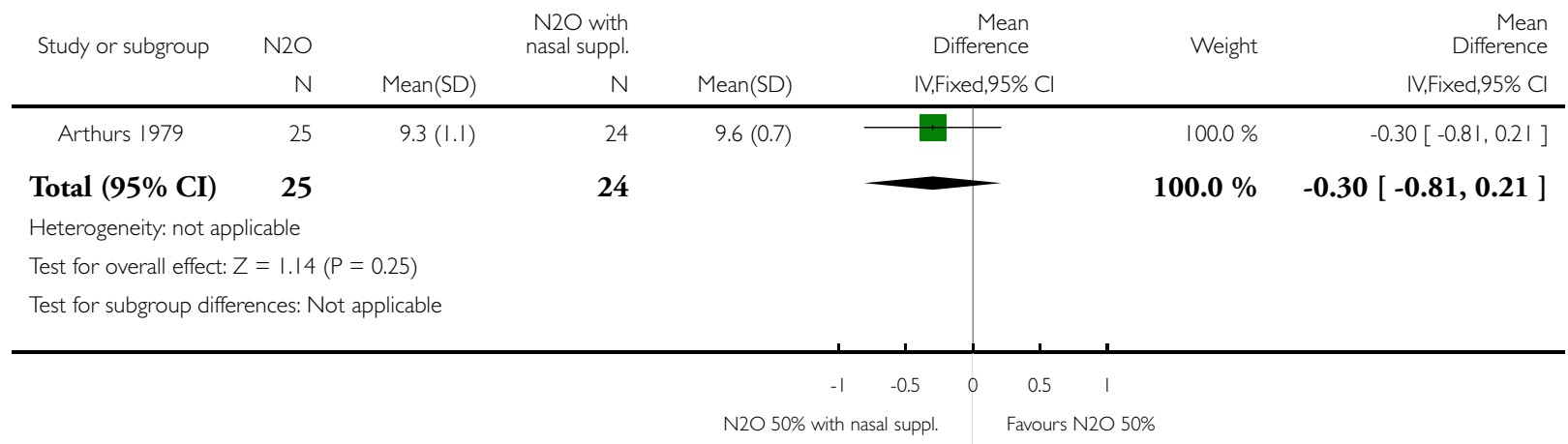


Analysis 4.I. Comparison 4 Inhaled analgesia versus placebo control/no treatment, Outcome I Pain intensity (first stage, clear/severe to intense/extreme).

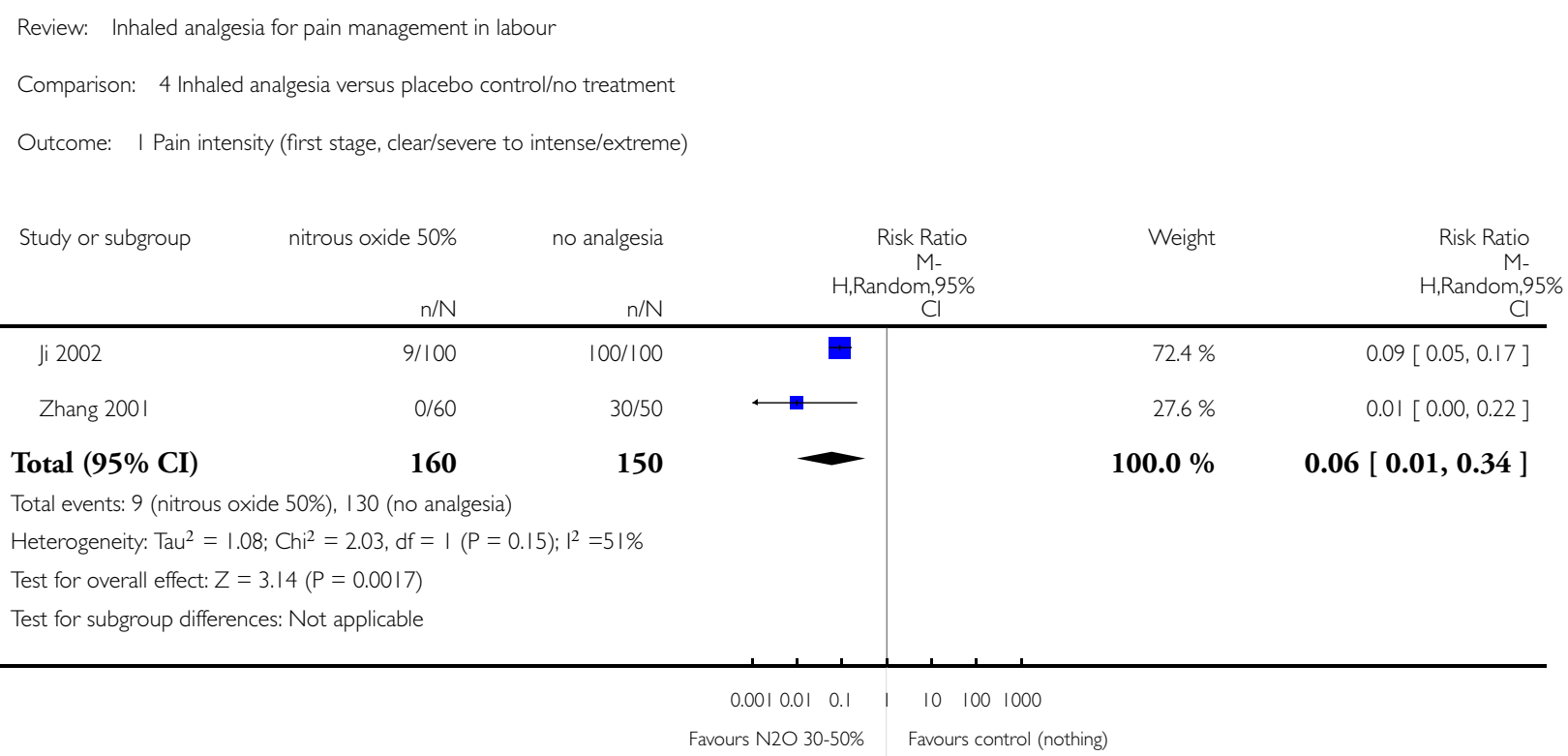

Analysis 4.2. Comparison 4 Inhaled analgesia versus placebo control/no treatment, Outcome 2 Pain intensity (first stage, VAS 0-10 after I hour).

Review: Inhaled analgesia for pain management in labour

Comparison: 4 Inhaled analgesia versus placebo control/no treatment

Outcome: 2 Pain intensity (first stage, VAS 0-10 after I hour)

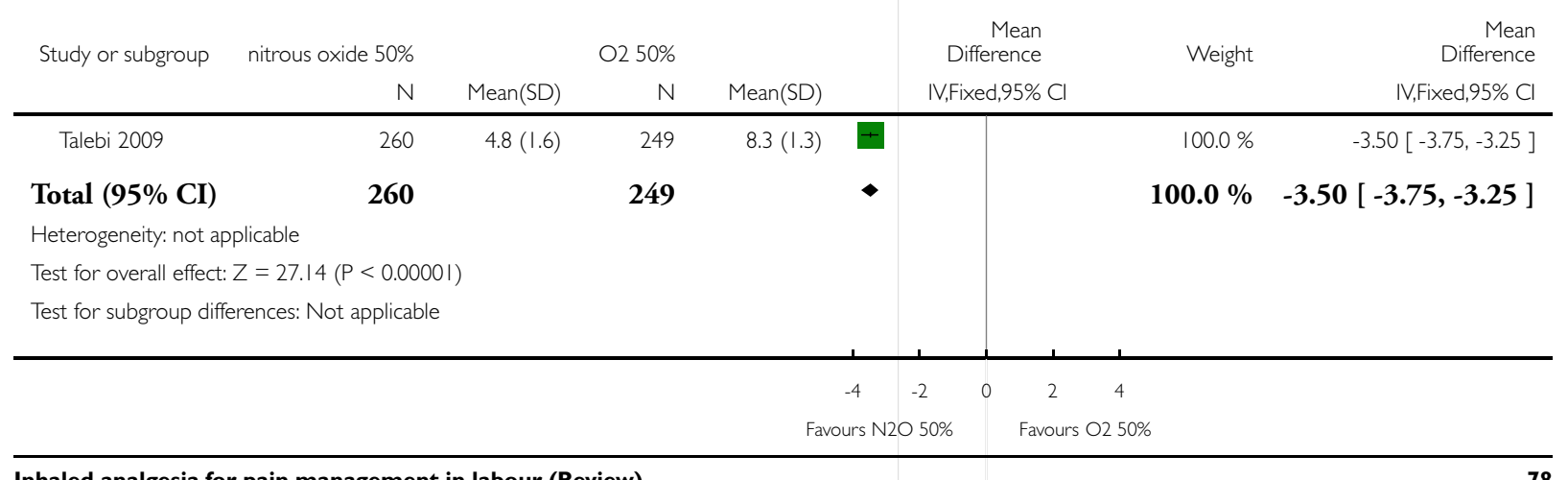

Inhaled analgesia for pain management in labour (Review)

Copyright $\odot 2012$ The Cochrane Collaboration. Published by John Wiley \& Sons, Ltd. 
Analysis 4.3. Comparison 4 Inhaled analgesia versus placebo control/no treatment, Outcome 3 Assisted vaginal birth.

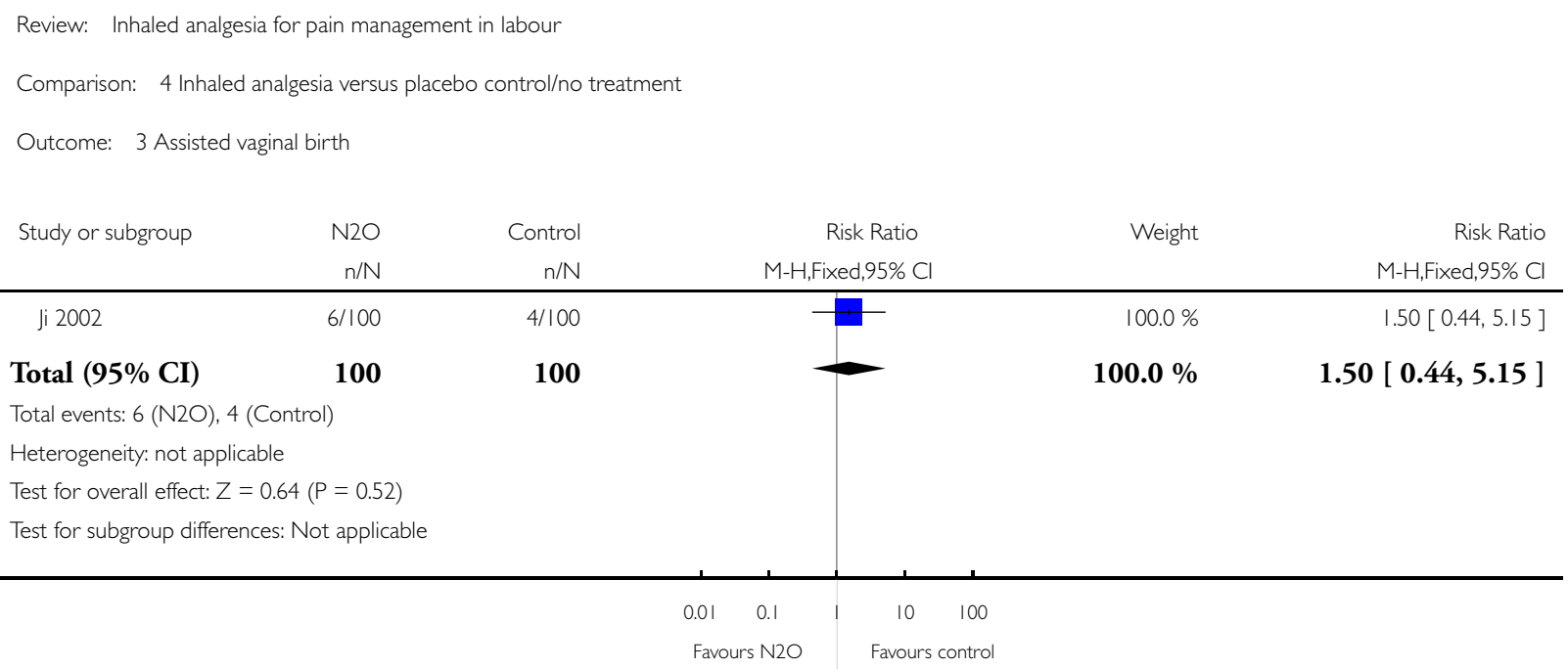




\section{Analysis 4.4. Comparison 4 Inhaled analgesia versus placebo control/no treatment, Outcome 4 Caesarean}

section.

Review: Inhaled analgesia for pain management in labour

Comparison: 4 Inhaled analgesia versus placebo control/no treatment

Outcome: 4 Caesarean section

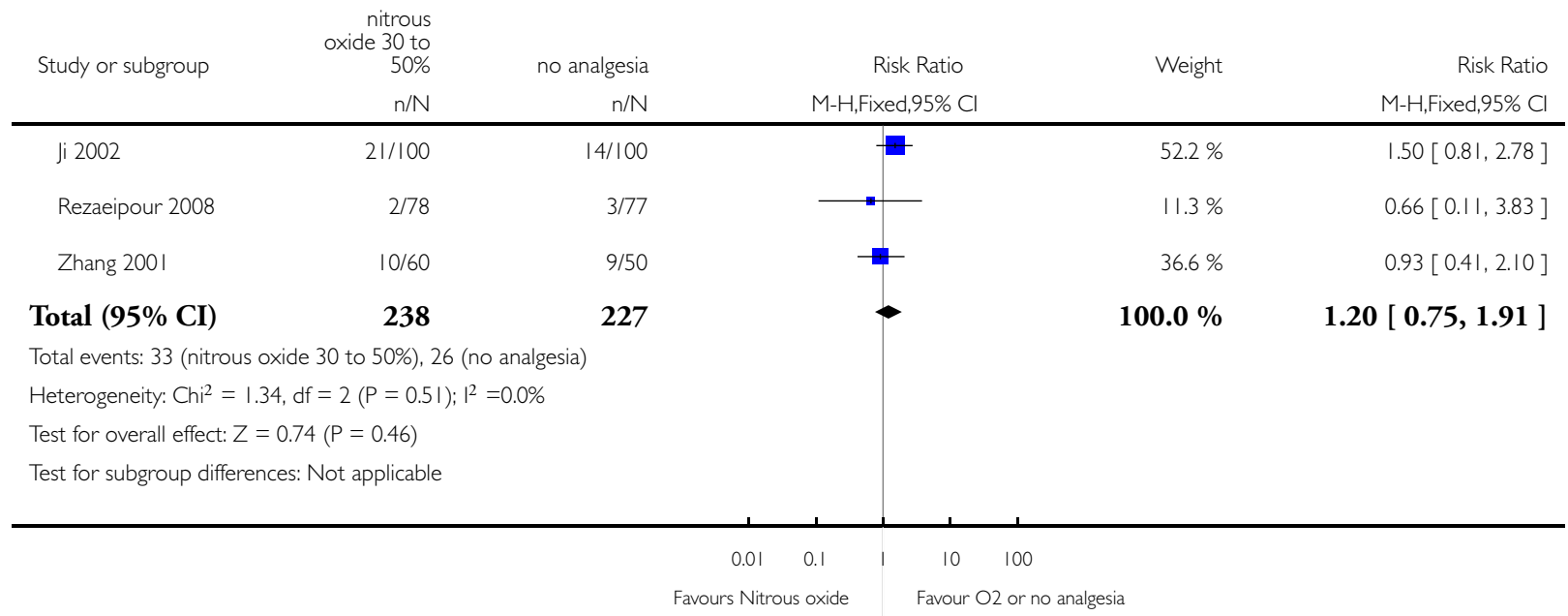

Analysis 4.5. Comparison 4 Inhaled analgesia versus placebo control/no treatment, Outcome 5 Vomiting.

Review: Inhaled analgesia for pain management in labour

Comparison: 4 Inhaled analgesia versus placebo control/no treatment

Outcome: 5 Vomiting

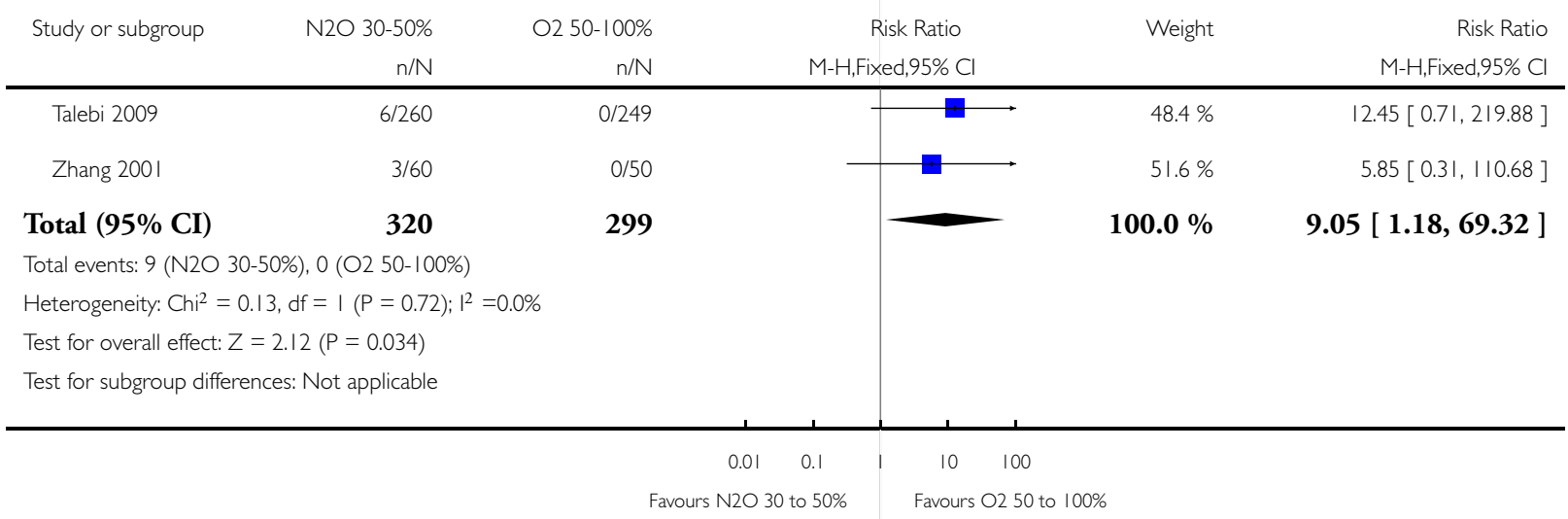

Inhaled analgesia for pain management in labour (Review)

Copyright $\odot 2012$ The Cochrane Collaboration. Published by John Wiley \& Sons, Ltd. 


\section{Analysis 4.6. Comparison 4 Inhaled analgesia versus placebo control/no treatment, Outcome 6 Nausea.}

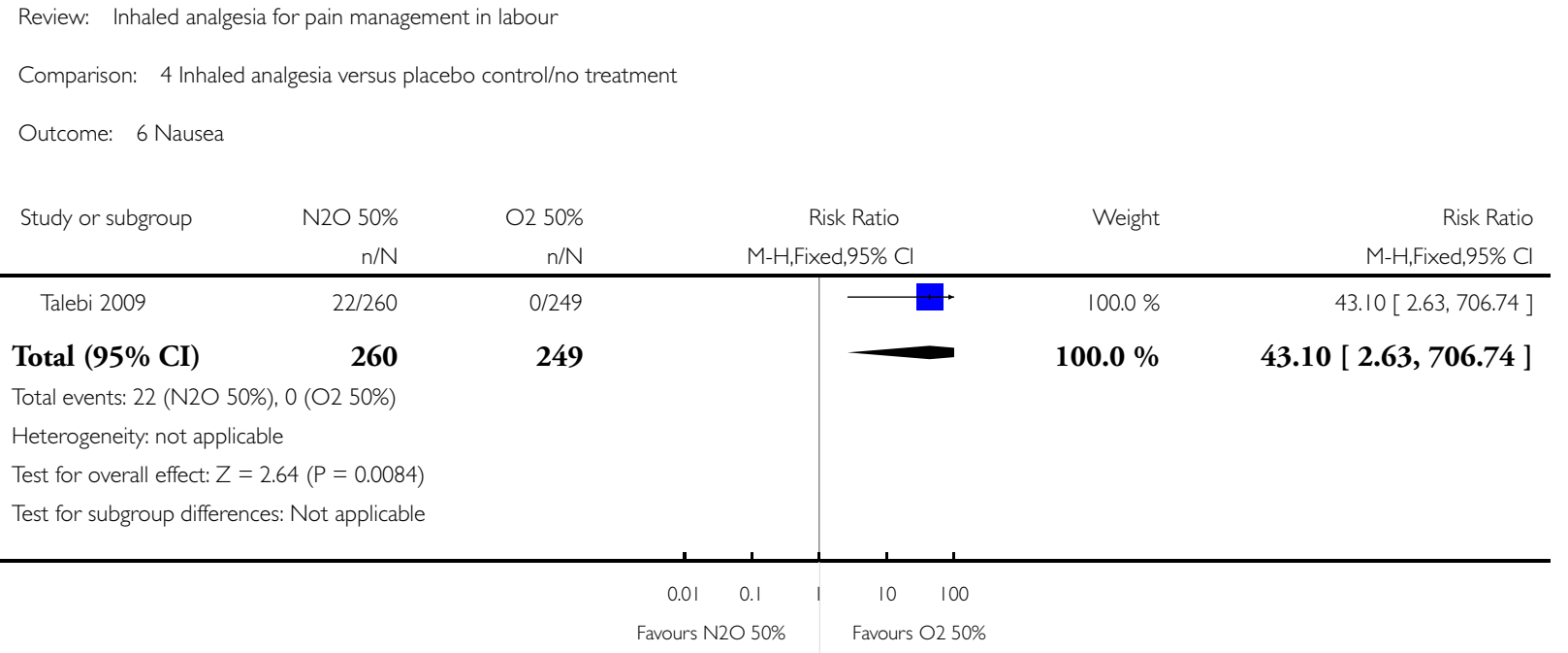


Analysis 4.7. Comparison 4 Inhaled analgesia versus placebo control/no treatment, Outcome 7 Dizziness.

Review: Inhaled analgesia for pain management in labour

Comparison: 4 Inhaled analgesia versus placebo control/no treatment

Outcome: 7 Dizziness

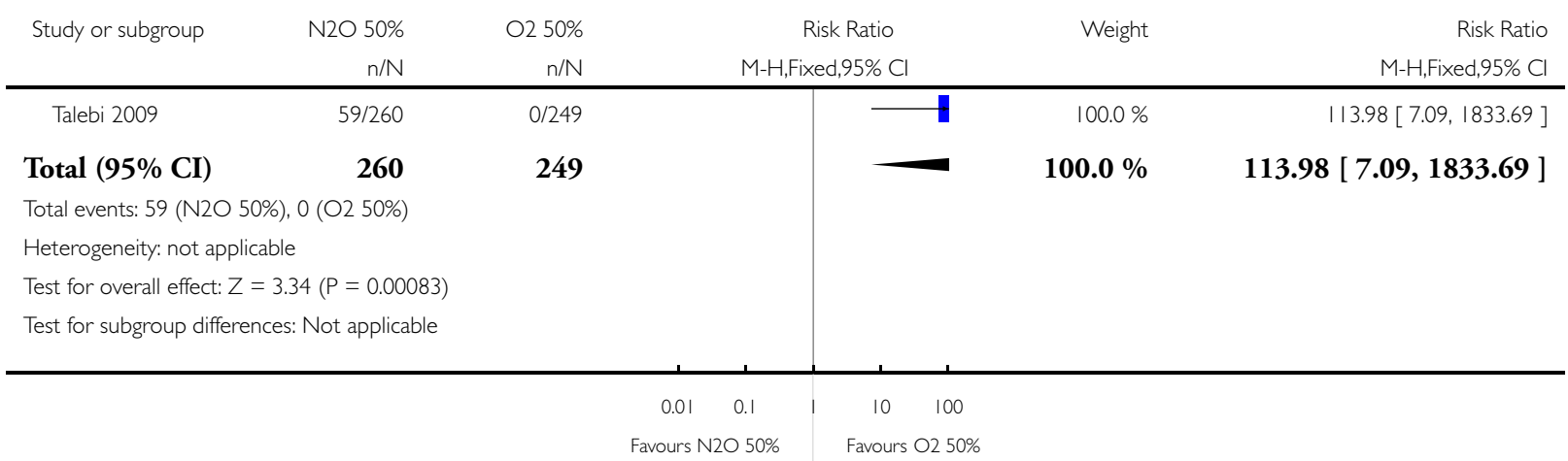

Analysis 4.8. Comparison 4 Inhaled analgesia versus placebo control/no treatment, Outcome 8 Drowsiness.

Review: Inhaled analgesia for pain management in labour

Comparison: 4 Inhaled analgesia versus placebo control/no treatment

Outcome: 8 Drowsiness

\begin{tabular}{|c|c|c|c|c|c|}
\hline \multirow[t]{2}{*}{ Study or subgroup } & $\mathrm{N} 2 \mathrm{O} 50 \%$ & O2 50\% & Risk Ratio & Weight & Risk Ratio \\
\hline & $n / N$ & $\mathrm{n} / \mathrm{N}$ & M-H,Fixed,95\% Cl & & M-H,Fixed,95\% Cl \\
\hline Talebi 2009 & $40 / 260$ & $0 / 249$ & & $100.0 \%$ & $77.59[4.80,1254.96]$ \\
\hline Total $(95 \% \mathrm{CI})$ & 260 & 249 & & $100.0 \%$ & $77.59[4.80,1254.96]$ \\
\hline
\end{tabular}

Total events: 40 (N2O 50\%), 0 (O2 50\%)

Heterogeneity: not applicable

Test for overall effect: $Z=3.06(P=0.0022)$

Test for subgroup differences: Not applicable 
Analysis 4.9. Comparison 4 Inhaled analgesia versus placebo control/no treatment, Outcome 9 Neonatal asphyxia.

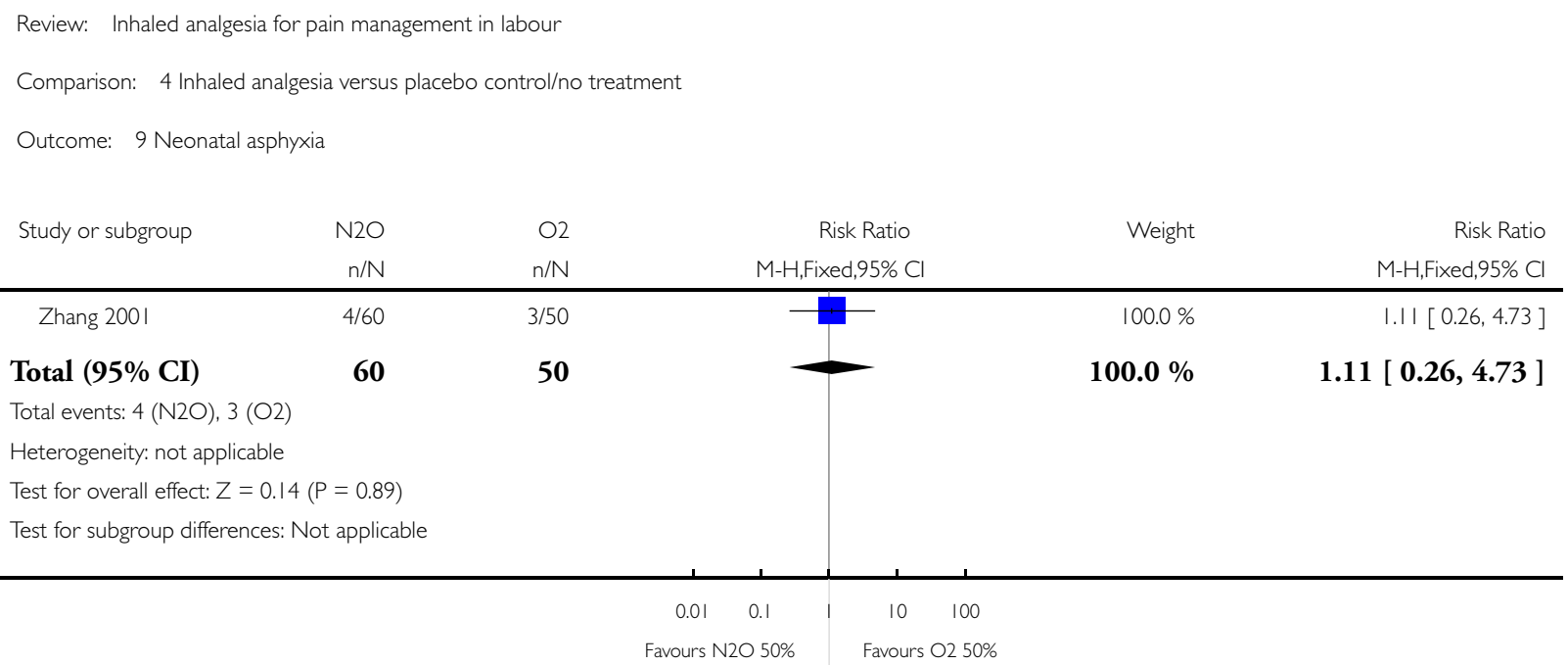

02570 155] images/nCD009351-CMP.eps 7 dich.. 